\title{
Passive Control of VOC's Using Valved Well Heads: FY1994 Report
}

by

\author{
J. Rossabi
}

Westinghouse Savannah River Company

Savannah River Site

Aiken, South Carolina 29808

B. D. Riha

\section{DISCLAIMER}

\begin{abstract}
This report was prepared as an account of work sponsored by an agency of the United States Government. Neither the United States Government nor any agency thereof, nor any of their employees, makes any warranty, express or implied, or assumes any legal liability or responsibility for the accuracy, completeness, or usefulness of any information, apparatus, product, or process disclosed, or represents that its use would not infringe privately owned rights. Reference herein to any specific commercial product, process, or service by trade name, trademark, manufacturer, or otherwise does not necessarily constitute or imply its endorsement, recommendation, or favoring by the United States Government or any agency thereof. The views and opinions of authors expressed herein do not necessarily state or reflect those of the United States Government or any agency thereof.
\end{abstract}

\section{DOE Contract No. DE-AC09-89SR18035}

This paper was prepared in connection with work done under the above contract number with the U.S.

Department of Energy. By acceptance of this paper, the publisher and/or recipient acknowledges the U.S. Government's right to retain a nonexclusive, royalty-free license in and to any copyright covering this paper, along with the right to reproduce and to authorize others to reproduce all or part of the copyrighted paper. 


\section{DISCLAIMER}

This report was prepared as an account of work sponsored by an agency of the United States Government. Neither the United States Government nor any agency thereof, nor any of their employees, makes any warranty, express or implied, or assumes any legal liability or responsibility for the accuracy, completeness, or usefulness of any information, apparatus, product, or process disclosed, or represents that its use would not infringe privately owned rights. Reference herein to any specific commercial product, process, or service by trade name, trademark, manufacturer, or otherwise does not necessarily constitute or imply its endorsement, recommendation, or favoring by the United States Government or any agency thereof. The views and opinions of authors expressed herein do not necessarily state or reflect those of the United States Government or any agency thereof.

This report has been reproduced directly from the best available copy.

Available to DOE and DOE contractors from the Office of Scientific and Technical Information, P.O. Box 62, Oak Ridge, TN 37831; prices available from (615) 576-8401.

Available to the public from the National Technical Information Service, U.S. Department of Commerce, 5285 Port Royal Road, Springfield, VA 22161. 


\section{DISCLAIMER}

\section{Portions of this document may be illegible in electronic image products. Images are produced from the best available original document.}


WSRC-TR-94-0524

October 27, 1994

\section{PASSIVE CONTROL OF VOC'S USING VALVED WELL HEADS: FY 1994 REPORT (U)}

Prepared by the Savannah River Technology Center - Environmental Sciences Section

J. Rossabi and B. D. Riha

Authentication: Buan R, ha

Prepared for the U.S. Department of Energy under contract no. DE-AC09-89SR18035 


\section{TABLE OF CONTENTS}

ABSTRACT

1.0 OBJECTVE

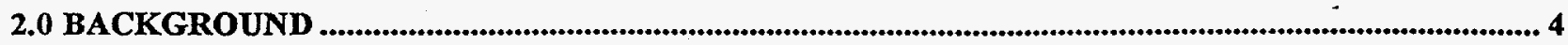

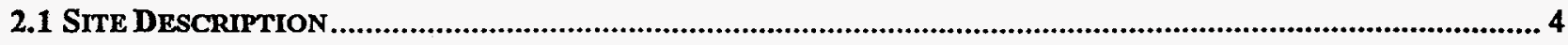

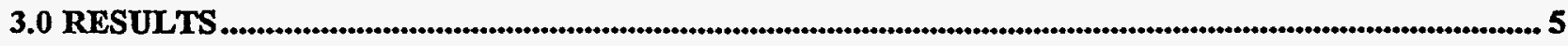

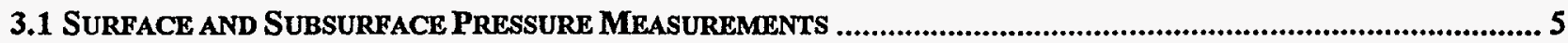

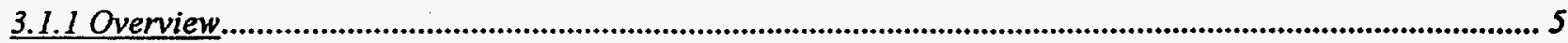

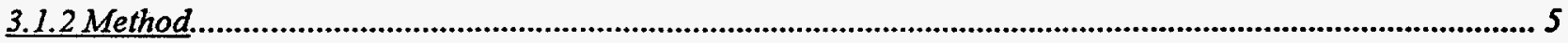

3.1.3 Development of Computer Models for Pressure Migration through the Subsurface ....................................... 6

3.1 .4 Lag Time Response .....................................................................................................................................................

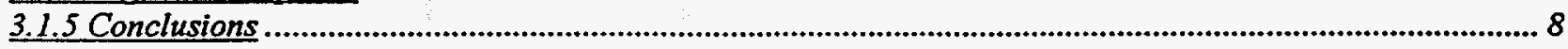

3.2 Barometrically Pumped Flow, Concentration, and Removal Rates........................................... 8

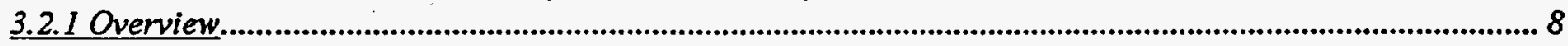

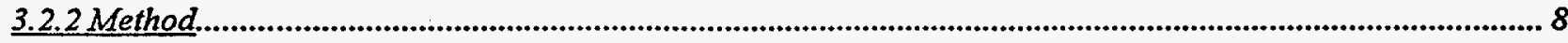

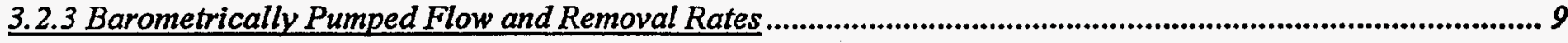

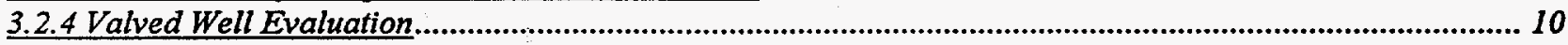

3.2.5 Conclusions ….................................................................................................................................................... 11

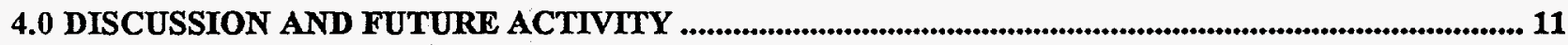

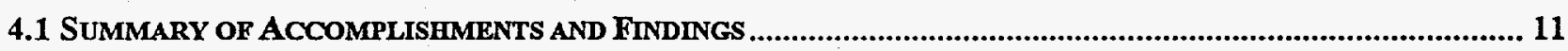

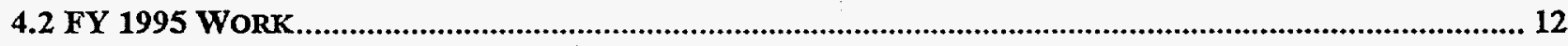

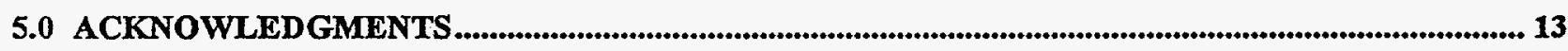

6.0 REFERENCES 


\title{
Passive Control of VOCs Using Valved Well Heads: FY1994 Report
}

TTP No: SR1-4-10-02

\begin{abstract}
The data described in this report were collected as part of a project to explore the viability of passive soil vapor extraction techniques for removal of volatile organic contaminants from the subsurface. The principal objectives of this project are to determine the mechanism and physical dynamics of the relationship between surface atmospheric pressure and subsurface flow and contaminant transport, and to use this information to design cost effective and efficient remediation systems. This work is funded under the Volatile Organic Compounds - Arid Integrated Demonstration (VOC - Arid ID). The VOC - Arid ID is one of several U.S. Department of Energy's (DOE) integrated demonstrations and programs that support the testing of emerging environmental management and restoration technologies. The purpose of the VOC Arid ID is to identify, develop, and demonstrate technologies that may be used to characterize, remediate, and/or monitor arid or semiarid sites containing VOC (e.g., carbon tetrachloride and trichloroethylene [TCE]) with or without associated metal and radionuclide contamination. The results from this project are applicable at arid, semi-arid, and non-arid sites.
\end{abstract}

This report documents the methods and findings from the Savannah River Site barometric pumping study. The results presented in this report include the following:

1) Surface and subsurface pressure measurements and analysis results from 27 subsurface ports at the Savannah River Integrated Demonstration Site (SRIDS).

2) Barometric pumping flow data measured and/or estimated from several wells.

3) Continuous concentration and flow data from one well.

4) Results from the development of two computer models that can predict either subsurface pressure or the effective cumulative permeability of the formation in the vertical direction from surface atmospheric pressure data.

5) The derivation of the analytical computer models, the executable code on disk, and written documentation for using the models including examples.

In addition, the optimization of barometric removal rates using an innovative control valve and the implications of this data for passive extraction systems are discussed.

\subsection{Objective}

This work is part of a two year project with three main purposes: (1) to determine the dynamics of subsurface pressure changes in response to surface barometric pressure fluctuations; (2) to develop an operational control model to exploit these induced pressure gradients for effective contaminant removal; and (3) to evaluate the effectiveness of a barometrically pumped VOC removal system using controlled valves on vadose zone wells to optimize removal efficiency. The information from this work will be used in future studies to develop large scale, low cost, passive soil vapor extraction systems employing barometric pumping as the driving force 


\subsection{Background}

At numerous sites across the country, wells with open intervals in the unsaturated zone have been observed to "breathe," i.e., to inhale ambient air from the surface and to exhale soil gas to the atmosphere (Rossabi et al., 1994). This process results from the difference in atmospheric pressure and the pressure in the subsurface. Barometric pressure changes, caused by diurnal fluctuations and weather events, are propagated through the subsurface with attenuation and delay induced by stratum permeability changes and depth. For example, low-permeability layers exhibit low gas flow rates and require a longer period of time to equilibrate with a change in atmospheric pressure This produces the damped and delayed pressure response. Passive soil vapor extraction (barometric pumping) enhances and harnesses this natural process as a remediation technique for removing volatile contaminants from the vadose zone.

The passive soil vapor extraction approach directly addresses three critical components of the contaminated soil problem:

1. Containment: Soil vapor extraction directly addresses the source term in most contaminated sites. Decreasing the source term decreases the potential for contaminant transport in the aqueous or non-aqueous liquid phases, which contains the plume. In addition, advective flow will move the vapor to the well and then the surface when controlling flow with one-way valves. The density driven component of flow is dominated by the advective component in these situations. Finally, by decreasing the contaminant vapor concentration near the vent well, diffusive flow will move the contaminant toward the well rather than toward the groundwater.

2. Primary Removal: In a situation where a very high removal rate is not required, interim action is required, vapor concentrations are low, or in locations away from the center of the plume, passively vented wells may be a cost-effective alternative to active soil vapor extraction (mechanical pumping).

3. Long-Term Care: After an initial large mass removal, continuing the pumping of an active extraction system at a rate faster than the contaminant's kinetic mass transfer rate into the vapor phase will result in decreased concentrations in the vented flow. At this point, passive venting is likely to be much more cost-effective than an active system per kilogram of contaminant vapor removed.

The barometric effect has been observed in many different geologic settings and is suitable for the removal of any volatile contaminant.

\subsection{Site Description}

The Savannah River Site (SRS) is underlain by a thick wedge (approximately $300 \mathrm{~m}$ ) of unconsolidated Tertiary and Cretaceous sediments which overlay the basement which consists of Precambrian and Paleozoic metamorphic rocks and consolidated Triassic sediments (siltstones and sandstones). The younger sedimentary section of interest in this study consists predominantly of sand, clayey sand, and sandy clay (Eddy et al, 1991). In the M Area, the depth to water is approximately 120 to 140 feet. The sediments in the vadose zone include interbedded sand and clay layers with varying thickness and effective permeability values.

This study was conducted at the M Area of the Savannah River Site where over two million pounds of chlorinated solvents (PCE and TCE) were released over a period of approximately 25 
years. The majority of the contamination is held in the vadose zone (Looney et al., 1992). The aqueous plume extends over an area greater than one square mile. Dense Non-Aqueous Phase Liquids (DNAPLs) have been detected in two wells on site. The site is extremely well characterized and has an established infrastructure including over 300 wells of various types, state of the art analytical equipment in field trailers, and an historical database obtained from several remediation experiments that were conducted there in the past 7 years.

\subsection{Results}

\subsection{Surface and Subsurface Pressure Measurements}

\subsubsection{Overview}

Surface and subsurface pressure data were used to qualitatively and quantitatively determine the dynamics of subsurface pressure changes in response to surface pressure changes and to evaluate the analytical models. Analysis of the data included the determination of subsurface pressure response lag times and quantification of expected times of well inflow and outflow.

Surface pressure and subsurface pressure measurements from 27 piezometers and pressure ports were logged at 15 minute intervals for the duration of the test. Appendix A contains the monthly pressure profiles, piezometer and pressure port diagrams, and a list of all computer data files included with this report. Five piezometer clusters (MHV 1-5) each consist of three piezometers (1-inch diameter) with screened intervals (5-ft screen lengths) at depths of approximately 30, 60, and $90 \mathrm{ft}$. These piezometers target the three major clay layers at the site. Wells MHV 6 and 7 (4-inch diameter) are continuously screened from $10 \mathrm{ft}$ below ground surface to the water table at approximately $140 \mathrm{ft}$. Wells MHV 8 and 9 are 4 inch wells with seven separate screened intervals. MHV 1-9 were installed using a hollow stem auger drill rig (8-10" diameter) and followed standard SRS drilling techniques as outlined WSRC Manual 3Q. The annulus of the well was tremie-filled with sand (for screened portion of well) followed by bentonite pellets and grout to the surface. The annulus around each screened section of MHV 8 and MHV 9 was filled with sand followed by bentonite pellets and grout to separate the sections. MHV11 is a SEAMIST ( Lowry and Keller, 1992) membrane system with 9 depth-discrete ports from 36.5 to $96.3 \mathrm{ft}$ below ground surface. The system is installed without packing (refer to Appendix A for well diagrams) and is designed to directly contact specific depth intervals in the formation.

\subsubsection{Method}

Subsurface and surface air pressure measurements were made using Vaisala pressure transducers. These instruments were calibrated and checked to NIST traceable standard pressure transducers available at the site. Periodic checks of the instruments were made to ensure continued accuracy and precision over the course of the experiment. The factory certified accuracy and precision of the instruments were $\pm 0.6 \mathrm{mBars}$ and $\pm 0.2 \mathrm{mBars}$ respectively.

Pressure data were taken continuously using a valved system controlled by a controller/data acquisition using a Z-80 based computer (Z-World, Inc.). For each piezometer cluster, a five port manifolded electronic solenoid valve system was mounted at the well head. A single high density polyethylene tube (diameter $=0.125$-in diameter) was attached to one of the ports of the manifold and run into the main control valve system in the field trailer. Each well head manifold system consists of three normally closed valves for each port mounted to the manifold and attached by a short tube to each piezometer port in the cluster. An additional valve on the manifold was 
normally open and vented to the atmosphere. This normally-open valve was used to maintain a zero differential pressure in the tube running to the trailer with respect to the atmosphere (vent).

When a pressure measurement was made for an individual port, the normally closed valve for that well was opened and the normally open valve (vent) was closed. The pressure in the tube was allowed to equilibrate and pressure measurements were taken and averaged over a 5 second time period. The valve for the well was then allowed to close and the vent was allowed to open for a 5 second time period. The five second measurement time period was chosen to allow an adequate stabilization period for each pressure measurement yet measure all wells as rapidly as possible. This procedure minimized the effects short term weather fluctuations on the measurement and also minimized the time that the solenoid valve was energized to prolong the life of the solenoid. Each well cluster was sampled sequentially in the same manner.

The control valve system in the field trailer also uses a manifold in which the tubes coming from the individual well clusters are attached to normally closed valves mounted on a manifold. A common tube from the manifold is run to a single pressure transducer (Vaisala). This transducer has a continuous pressure readout in millivolts. The analog voltage data from the pressure transducer was converted by the single board computer ( 12 bit accuracy) and stored at specific time intervals corresponding to the particular well sampled. Atmospheric pressure was also measured and stored. The manifold system in the field trailer cycles through the well clusters to obtain the individual pressure measurements. A full cycle of the MHV 1-5 clusters (15 ports) including atmospheric pressure takes less than 4 minutes. A full measurement cycle was taken every 15 minutes. The MHV 6-9 wells were also sampled every 15 minutes and the MHV 11 ports were sampled every 10 minutes. Higher frequency data were determined in previous scoping experiments to be unnecessary to accurately capture any pressure fluctuation significant for a full understanding of the pressure relation between the surface and subsurface at these depths and the development of the computer models.

\subsubsection{Development of Computer Models for Pressure Migration through the Subsurface}

The computer models for predicting subsurface pressure from atmospheric pressure data were developed using analytical solutions to the one-dimensional equation governing gas flow in porous media based on conservation of mass and energy, Darcy's law for fluid velocity, and the real gas law. The two models differ in boundary condition formulation. Both models successfully predicted subsurface pressure in response to surface pressure fluctuations. The models were calibrated using the subsurface pressure data obtained from the pressure monitoring system described in section 3.1.2. Soil property parameter estimates were used in the model to obtain pressure predictions. These predictions were then compared to actual data and soil property parameters were varied to optimize the predictions. Two parameters were used as a metric to optimize the models: 1) the mean squared error of the predicted pressure with respect to the actual subsurface pressure and 2) the percentage of time that the direction of flow through the piezometer was correctly predicted by the model. Using these two measures, values of the effective vertical permeability of the subsurface were determined. The values for permeability for a particular piezometer were consistent for each data period analyzed. Slight variations in the model fit (permeability) were encountered during periods with unusual precipitation or nonprecipitation events. A change in soil moisture will change the effective permeability. The details of the derivation of the model, as well as the model results, and the executable code are provided in Appendix B. 


\subsubsection{Lag Time Response}

Values for subsurface pressure time lagging in comparison to the surface barometric pressure were obtained by examining the surface and subsurface pressures in parallel using the correlation function with the correlation coefficient, $\rho_{x y}$ defined by:

$$
\rho_{x y}=\frac{\frac{1}{n} \sum_{i=1}^{n}\left(X_{i}-\mu_{x}\right)\left(Y_{i}-\mu_{y}\right)}{\sigma_{x} \sigma_{y}}
$$

where $\mathrm{n}$ is the number of data points, $\mathrm{X}_{\mathrm{i}}$ are the surface barometric pressure data through time, $\mu_{\mathrm{x}}, \sigma_{\mathrm{x}}$, and $\mu_{\mathrm{y}}, \sigma_{\mathrm{y}}$ are the mean and standard deviation of the two pressure sets respectively. For each assumed lag time, the best correlations were associated with the best estimate of lag time (highest correlation coefficient).

Lag times between the surface pressure and subsurface pressure were evaluated for the MHV 1-5 piezometer clusters for the major weather events. The small diurnal barometric pressure fluctuations did not produce a significant change in the subsurface pressure and therefore the correlation data for these events could not be obtained. The average, maximum, minimum, and standard deviation lag times for these piezometers are presented in Table 1. The large variability in the lag times is due to the variable subsurface pressure history and small formation permeability changes due to precipitation.

Table 1 - Subsurface Pressure Lag Times for MHV 1-5

\begin{tabular}{|c|c|c|c|c|}
\hline Piezometer & $\begin{array}{c}\text { Lag Time, } \\
\text { minutes } \\
\text { Average }\end{array}$ & Minimum & Maximum & Std. Dev. \\
\hline MHV1a & 800 & 360 & 1,170 & 244.1 \\
\hline MHV1b & 753 & 330 & 1,095 & 245.4 \\
\hline MHV1c & 67 & 45 & 90 & 14.8 \\
\hline MHV2a & 728 & 300 & 1,065 & 241.2 \\
\hline MHV2b & 755 & 315 & 1,110 & 249.8 \\
\hline MHV2c & 778 & 360 & 1,185 & 243.9 \\
\hline MHV3a & 655 & 270 & 1,005 & 245.0 \\
\hline MHV3b & 712 & 285 & 1,080 & 264.3 \\
\hline MHV3c & 619 & 135 & 1,020 & 286.5 \\
\hline MHV4a & 730 & 300 & 1,065 & 242.7 \\
\hline MHV4b & 743 & 300 & 1,110 & 274.3 \\
\hline MHV4c & 779 & 345 & 1,200 & 254.3 \\
\hline MHV5a- & 722 & 255 & 1,080 & 280.3 \\
\hline MHV5b & 736 & 330 & 1,140 & 265.6 \\
\hline MHV5c & 743 & 315 & 1,185 & 270.0 \\
\hline
\end{tabular}




\subsubsection{Conclusions}

Qualitative and quantitative analysis of the surface and subsurface pressure relationşhips indicate a complex mechanism for pressure wave migration through the subsurface. Several conclusions were drawn from the data:

1) Subsurface pressure responses are clearly related to the surface barometric pressure.

2) The damped and lagging response of the subsurface pressure to surface (atmospheric) pressure is a function of depth, stratum permeability, and barometric pressure history and is analogous to heat conduction in a solid.

3) The subsurface pressure is greater than the surface pressure approximately $50 \%$ of the time, implying that wells will exhale $50 \%$ of the time.

4) Pressure gradients rarely reach equilibrium in the subsurface which implies that soil gas flow in the subsurface is nearly continuous.

5) Subsurface pressure lag times are a complex function of the effective permeability of the subsurface and the historical surface pressure.

\subsection{Barometrically Pumped Flow, Concentration, and Removal Rates}

\subsubsection{Overview}

Continuous flow measurements were made on three separate piezometers. These three piezometers (CPTRAM 3, 4, and 16) were installed using a cone penetrometer truck and are made of PVC ( 1 -in diameter) with screened zones ( $5 \mathrm{ft}$ screens) set between 95 and $115 \mathrm{ft}$. Flow from several piezometers was estimated from the differential pressure in the well using a fitted equation of differential pressure and flow rate. The equation was developed using point measurements of differential pressure and flow. From these data, volumetric soil gas removal rates were calculated and contaminant removal rates were estimated from either continuous or point concentration measurements. In addition, the contaminant removal efficiency was calculated for a valved and non-valved well.

\subsubsection{Method}

Continuous flow measurements were made with calibrated mass flow meters (Omega) and logged with Cambell data loggers (Models 21X and CR10). The data were averaged over 10 minute intervals and these values were stored. Pressure transducers (Vaisala) were used to measure subsurface and surface pressure. Flow restrictions imposed by the instrumentation were minimized to provide an accurate representation of flow from the well.

Semi-continuous concentration measurements (approximately every ten minutes) of the barometrically pumped soil gas were-logged using the B\&K Model 1302 Infrared Photoacoustic gas analyzer. This instrument has been reliable and accurate in many field experiments performied at SRS. Before and after each deployment, certified standards and check standards of several concentrations of gas (trichloroethylene and tetrachloroethylene in nitrogen) were measured by 
the instrument to verify its operation. The certified standards were obtained from commercial sources. Verification of the well concentration values was obtained by analyzing well gas samples periodically using an HP 5890 series Gas Chromatograph with flame ionization and electron capture detectors. This instrument is located in an environment controlled field laboratory. The procedures for using this instrument are defined in the Savannah River Technology Center Procedures Manual L1. Calibrations of this instrument were performed using certified standard gas mixtures supplied by an outside vendor. In addition, gas standards made from certified liquid standards were also used to calibrate and verify the continued accuracy and precision of the analytical equipment. These check standards were made by direct liquid injection into a specific volume of nitrogen.

Barometrically pumped flow data were analyzed together with concentration data to determine gas volumes removed (or injected) over time and contaminant removal rates. Flow profiles were integrated over time to find the total volume of gas and then divided by the total time that the data were collected to find an average daily volume. The mass removal rates were calculated using the same method.

Barometrically pumped flow rates were estimated from a fitted curve of differential pressure and flow rate. The differential pressure was measured with a hand-held differential pressure gauge (OMEGA) with the well sealed. The flow rate was measured (both inflow and outflow) with a mass flow meter (OMEGA). The resulting curve of flow versus differential pressure was symmetrical for inflow and outflow as expected from theory and was fit with a polynomial regression routine.

The mass of contaminants removed was calculated using the ideal gas law, concentration measurements and the volume of soil gas removed.

\subsubsection{Barometrically Pumped Flow and Removal Rates}

Barometrically pumped flow rates were determined for several wells by either direct measurement of the flow rate or using differential pressure measurements and the curves relating differential pressure and flow. The flow rates were estimated for some of the wells because the pressure transducers were already installed and were less responsive to environmental changes than the mass flow meters. It was difficult to keep the mass flow meters dry in the high humidity environment. The humidity changes tended to shift the calibration of the flow meters and reduce their sensitivity. The flow profiles through time and the flow rate vs. differential pressure curves are located in Appendix A along with a listing of data files included with the report. The results from the analysis of the flow determination are shown in Table 2. The data include the following information:

1. well identification.

2. measurement dates.

3. volumetric rate of soil gas barometrically pumped from the well.

4. method of flow determination.

5. contaminant removal rates.

6. method for concentration determination.

Continuous concentration measurements on CPTRAM-16 indicate that point concentration measurements are a reliable way to estimate removal rates when surface air is not allowed to flow back into the well. This is because the concentration values measured from each well at the site remained approximately constant over all periods of outflow when using the one-way valve system. The point concentration measurements were averaged for the removal rate estimation and the individual values are located in Appendix A. The dates of measurements are included because 
it is expected that the volume of soil gas removed by barometric pumping will be dependent on the seasons (i.e. less volume during the summer months because of smaller pressure gradients).

Table 2 - Barometrically Pumped Flow and Removal Rates

\begin{tabular}{|c|c|c|c|c|c|c|c|}
\hline Well ID & Dates & $\begin{array}{l}\text { Soil Gas } \\
\text { Removed }\end{array}$ & $\begin{array}{l}\text { Flow Value } \\
\text { Method }\end{array}$ & $\begin{array}{l}\text { PCE } \\
\text { Removal }\end{array}$ & $\begin{array}{l}\text { TCE } \\
\text { Removal }\end{array}$ & $\begin{array}{l}\text { Conc. } \\
\text { Method }\end{array}$ & \\
\hline MHV 7 & $\begin{array}{l}11 / 22 / 93- \\
3 / 5 / 94\end{array}$ & $7,200 \mathrm{~V} /$ day & Estimated & $2.0 \mathrm{~g} / \mathrm{day}$ & $2.7 \mathrm{~g} /$ day & Point & Valved \\
\hline CPTRAM 1 & $\begin{array}{l}6 / 30 / 94- \\
7 / 18 / 94\end{array}$ & $2,600 \mathrm{~V} /$ day & Estimated & $10.7 \mathrm{~g} /$ day & 3.4 g/day & Point & Valved \\
\hline CPTRAM 3 & $\begin{array}{l}6 / 30 / 94- \\
7 / 18 / 94\end{array}$ & $2,600 \mathrm{y} /$ day & Estimated & $5.0 \mathrm{~g} / \mathrm{day}$ & $1.6 \mathrm{~g} / \mathrm{day}$ & Point & Valved \\
\hline CPTRAM 3 & $\begin{array}{l}9 / 11 / 94- \\
9 / 27 / 94\end{array}$ & $1,3501 /$ day & Measured & 2.7 g/day & $0.9 \mathrm{~g} /$ day & Point & Valved \\
\hline CPTRAM 4 & $\begin{array}{l}6 / 30 / 94- \\
7 / 18 / 94\end{array}$ & $2,350 \mathrm{y} / \mathrm{day}$ & Estimated & $14.8 \mathrm{~g} /$ day & $4.3 \mathrm{~g} /$ day & Point & Valved \\
\hline CPTRAM 4 & $\begin{array}{l}1 / 8 / 94- \\
2 / 7 / 94\end{array}$ & $2,700 \mathrm{~V} /$ day & Measured & $17.4 \mathrm{~g} /$ day & $4.9 \mathrm{~g} / \mathrm{day}$ & Point & Valved \\
\hline CPTRAM 16 & $\begin{array}{l}3 / 10 / 94- \\
3 / 25 / 94\end{array}$ & $5800 \mathrm{l} / \mathrm{day}$ & Measured & 150 g/day & 32 g/day & Continuous & Valved \\
\hline CPTRAM $16^{*}$ & $\begin{array}{l}3 / 25 / 94- \\
4 / 25 / 94\end{array}$ & $5800 \mathrm{l} / \mathrm{day}$ & Measured & $78 \mathrm{~g} /$ day & $18 \mathrm{~g} /$ day & Continuous & Not valved \\
\hline
\end{tabular}

* Note that the surface air flowing into CPTRAM 16 during the period 3/25/94 to 4/25/94 was approximately $4250 \mathrm{~V}$ day.

\subsubsection{Valved Well Evaluation}

A significant finding during the SRS barometric pumping study was contaminant removal efficiency using a valved well was greater than for an open well or non-valved well. The removal efficiency decreased by more than a factor of two when surface air was allowed to flow into the well. Flow, pressure, and concentration were measured on CPTRAM-16 for more than one month. A Baro-ball one-way valve developed by researchers at Savannah River Laboratory was installed on this well during the first two weeks of measurements. During this time, the concentration was approximately constant (3760 ppmv PCE, $1040 \mathrm{ppmv}$ TCE) for all periods of outflow. The Baro-ball was then removed and air was allowed to flow both into and out of the formation for the next month. During this period, concentrations measured in the outflow gas varied, increasing with longer periods of consecutive outflow. The concentrations never reached the values measured during the period when the Baro-ball was installed. This finding is significant for both remediation designs and for conventional soil gas characterization and monitoring. Remediation will be more effective with higher removal efficiencies and soil gas characterization and monitoring results will be more accurate if the formation around the sampled area is not diluted by surface air. Appendix $\mathrm{C}$ provides a complete description of the valved well evaluation and findings.

\section{$\underline{3.2 .5 \text { Conclusions }}$}

Measurements of the flow into and out of wells resulting from pressufe gradients show that significant quantities of volatile contaminants can be removed using passive extraction techniques. Specific conclusions include the following: 
1) Barometrically induced flow through wells can be deduced from differential pressure measurements alone once a calibration curve relating differential pressure to flow has been established from point measurements. The models described in section 3.1 .3 can be used to provide differential pressures based on surface atmospheric pressure alone. Therefore, flow from a well can ultimately be predicted using only atmospheric pressure data and the computer model.

2) Air flow into a well has a significant diluting effect on the average soil gas concentration in the subsurface near the well screen.

3) One-way valves on wells, (allowing air flow out of the formation only) can increase contaminant removal by at least a factor of two.

\subsection{Discussion and Future Activity}

\subsection{Summary of Accomplishments and Findings}

In addition to the conclusions outlined in sections 3.1.5 and 3.2.5, there have been several additional accomplishments resulting from this work. A summary of these accomplishments and conclusions follows:

1) Subsurface gas pressure at a particular depth is a function of the surface atmospheric pressure and inherent and variable properties of the subsurface media. These properties include the sum of the intrinsic permeabilities, the volumetric moisture content, porosity, depth to the observation point, and depth to groundwater.

2) The subsurface pressure at a point through time can be accurately predicted (average error $<2 \mathrm{mBar}$ ) using only the surface atmospheric pressure data as variable input to an analytic pressure model once the inherent properties of the media are determined.

3) The direction of gas flow between the surface and subsurface through wells can be predicted well (correct prediction of flow direction $>90 \%$ ) using the pressure models. This allows engineering control of a passive system for soil vapor extraction, bioventing, etc. with no subsurface pressure monitoring equipment.

4) Controlling gas flow through wells using valves is important for passive soil vapor extraction of contaminants. The efficiency of removal can be increased by a factor of two or greater if surface air is prevented from flowing into the formation through a well (i.e., during periods of relatively high surface atmospheric pressure). This may also help prevent further spread of contaminant plumes in the vadose zone, although this requires further research.

5) Removal rates of contaminants using passive soil vapor extraction can be high depending on the permeability of the formation and the amount of contamination in the zone of influence of the well.

6) Knowledge of the effects of surface atmospheric pressure fluctuations on subsurface gas, such as the possibility of dilution of the soil gas in a formation as a result of clean air flow in during periods of high surface pressure, is critical in the development of proper methods and interpretation of soil gas monitoring through vadose zone wells.

- 7) The transfer of monitoring system equipment and software, inexpensive, one-way valves, and two pressure modeling programs to Hanford and INEL personnel has been completed. 
8) A national task team for passive soil vapor extraction has been formed and a special session on passive soil vapor extraction with more than 15 presenters will be convened at the Fall American Geophysical Union Meeting in December 1994 in San Francisco.

9) Three patent disclosures have resulted from this work:

a) Baro-ball - A one-way, low cracking pressure mechanical valve for preventing air dilution of formations. A small environmental consulting company has requested a license for this technology.

b) Multi-level sampling port - Can be used to deploy depth discrete sampling ports in a single hole ( $>1.5^{\text {" }}$ diameter) using $1^{\text {" diameter PVC with Tri-Loc }}{ }^{\text {TM }}$ or similar joints.

c) Passive control of wells using latching electronic valves -A versatile, low power (battery/photovoltaic recharge) electronic system for controlling valves to allow air flow in or out of a well depending on the site specific requirements for remediation.

\subsection{FY 1995 Work}

Future work planned for FY 1995 includes the following:

1. Determine the zone of influence of barometrically pumped wells and analyze the factors that dictate the zones of influence of these wells in response to atmospheric pressure changes

2. Develop a process control strategy and hardware and software to optimize passive removal of contaminated soil gas.

3. Refine the analytical pressure prediction model (Barosolv) and develop an analytical flow prediction model.

4. Examine the cost effectiveness of passive soil vapor extraction for several wells and scenarios at SRS.

5. Investigate enhancements to passive soil vapor extraction to a limited degree.

6. Examine additional uses of the barometric pumping effect (e.g., characterization and monitoring, and the effectiveness of injection processes when the surface pressure is relatively high).

7. Continue communication of passive soil vapor extraction theory, results and possibilities both within the DOE and outside of it. This will be accomplished through presentations at technical meetings, journal publications, and continued participation in the "Passive Voice" electronic newsletter.

8. Develop commercialization plans for all or part of the products that have evolved from this project, (i.e., Baro-ball; valve control for injection, remediation, extraction, and monitoring of subsurface contaminants; Barosolv computer model, etc.).

\subsection{Acknowledgments}

This report was prepared for the Department of Energy Office of Technology-Development, Office of Environmental Management. 
The authors are grateful for the efforts of Terry L. Walton (Battelle Pacific Northwest Laboratory) for his support and advocacy on this project; Jennifer D. Schramm (Purdue University co-op student) for her data processing and analysis support; researchers from the Hanford site and Idaho National Engineering Laboratory for their collaboration; and the Department of Energy. Specifically we acknowledge the support from the Office of Technology Development, David Biancosino (EM-551 Headquarters Program Manager), and James A. Wright (DOE-SR cognizant Technical Program Officer).

\subsection{References}

Eddy, C.A., B.B. Looney, J.M. Dougherty, T.C. Hazen, and D.S. Kaback, 1991, Characterization of the Geology, Geochemistry, Hydrology, and Microbiology of the In-Situ Air Stripping Demonstration Site at the Savannah River Site. WSRC-RD-91-21; Westinghouse Savannah River Company, Savannah River Laboratory, Aiken, SC.

Lowry W. and C. Keller, 1992, Development of the SEAMIST Concept for Site Characterization and Monitoring. DOE/CH-9213.

Looney, B.B., 1992, Assessing DNAPL Contamination, AM-Area, Savannah River Site: Phase I Results. WSRC-RP-92-1302; Westinghouse Savannah River Company, Savannah River Laboratory, Aiken, SC.

Rossabi, J., B.B. Looney, Eddy-Dilek, C.A., Riha, B.D., and Rohay, V.J., 1994, Passive Remediation of Chlorinated Volatile Organic Compounds Using Barometric Pumping. In WEF Specialty Conference Series Proceedings: Innovative Solutions for Contaminated Site Management, March 6-9, 1994, Miami, Fl. 


\section{APPENDIX A Well, Pressure, Flow and Concentration Data}

This appendix contains a map of the site, construction diagrams of the wells used during the study, pressure, flow, and concentration plots from the data accumulated during the SRS Barometric Pumping study (TTP 141002), and point concentration measurements from the wells.

The descriptions of the files included with this report containing the pressure, flow, and concentration data are presented in Table Al. Each file is a self extracting compressed file (type the file name and it will automatically extract to a usable form). All files when extracted are in Microsoft EXCEL 5.0 and include the raw data and plots. The following table provides the file names, descriptions of the data, and the file size when extracted. Some of these files are large so make sure you have enough space on your hard drive.

Table A1 - Listing of data files included with this report

\begin{tabular}{|c|c|c|c|}
\hline Disk & File Name(s) & $\begin{array}{c}\text { Size When } \\
\text { Extracted } \\
\text { Mbytes }\end{array}$ & Description of EXCEL 5.0 Files \\
\hline 1 & $\begin{array}{l}\text { 1-5oct } 93 . \text { exe } \\
\text { 1-5nov93.exe }\end{array}$ & $\begin{array}{l}0.8 \\
2.9\end{array}$ & $\begin{array}{l}\text { Piezometers MHV 1-5 surface and subsurface pressure data and } \\
\text { plots for the indicated month. }\end{array}$ \\
\hline 2 & 1-5dec93.exe & 3.2 & $\begin{array}{l}\text { Piezometers MHV 1-5 surface and subsurface pressure data and } \\
\text { plots for the indicated month. }\end{array}$ \\
\hline 3 & 1-5jan94.exe & 3.1 & $\begin{array}{l}\text { Piezometers MHV 1-5 surface and subsurface pressure data and } \\
\text { plots for the indicated month. }\end{array}$ \\
\hline 4 & $\begin{array}{l}\text { 1-5mar94.exe } \\
1-5 \text { may94.exe }\end{array}$ & $\begin{array}{l}3.1 \\
1.7\end{array}$ & $\begin{array}{l}\text { Piezometers MHV 1-5 surface and subsurface pressure data and } \\
\text { plots for the indicated month. }\end{array}$ \\
\hline 5 & $\begin{array}{l}\text { 1-5feb94.exe } \\
\text { 1-5apr94.exe }\end{array}$ & $\begin{array}{l}2.6 \\
2.3\end{array}$ & $\begin{array}{l}\text { Piezometers MHV 1-5 surface and subsurface pressure data and } \\
\text { plots for the indicated month. }\end{array}$ \\
\hline 6 & $\begin{array}{l}\text { 6-9nov93.exe } \\
\text { 6-9dec93.exe } \\
\text { 6-9jan94.exe } \\
\text { 6-9feb94.exe }\end{array}$ & $\begin{array}{l}0.6 \\
0.8 \\
1.5 \\
1.3\end{array}$ & $\begin{array}{l}\text { Wells MHV 6-9 surface and subsurface pressure data and plots } \\
\text { for the indicated month. }\end{array}$ \\
\hline 7 & $\begin{array}{l}\text { 6-9mar94.exe } \\
\text { 6-9apr94.exe } \\
\text { 6-9may94.exe }\end{array}$ & $\begin{array}{l}1.4 \\
0.9 \\
1.2 \\
\end{array}$ & $\begin{array}{l}\text { Wells MHV 6-9 surface and subsurface pressure data and plots } \\
\text { for the indicated month. }\end{array}$ \\
\hline 8 & 1lpress.exe & 4.5 & MHV 11 surface and subsurface pressure data for $12 / 93-3 / 94$. \\
\hline 9 & cptram16.exe & 2.0 & $\begin{array}{l}\text { Concentration, flow, and pressure data for CPTRAM } 16 \text { with } \\
\text { and without the Baro-Ball control valve. }\end{array}$ \\
\hline 10 & $\begin{array}{l}\text { cptflo.exe } \\
\text { dp\&qfit.exe } \\
\text { flow134.exe } \\
\text { ram4flow.exe }\end{array}$ & $\begin{array}{l}0.5 \\
0.1 \\
1.2 \\
0.5\end{array}$ & $\begin{array}{l}\text { Measured flow into CPTRAM } 1 \text { and out of CPTRAM } 3 \text { with } \\
\text { Baro-Ball control valves. } \\
\text { Differential pressure and flow data used to fit curves to estimate } \\
\text { flow rates from pressure data. Includes plots and curve fits. } \\
\text { CPTRAM } 1,3 \text {, and } 4 \text { estimated flow data from differential flow } \\
\text { measurements. } \\
\text { Measured flow and surface pressure from CPTRAM } 4 \text { with the } \\
\text { Baro-Ball control valve. }\end{array}$ \\
\hline
\end{tabular}


APPENDIX A - Site Map 


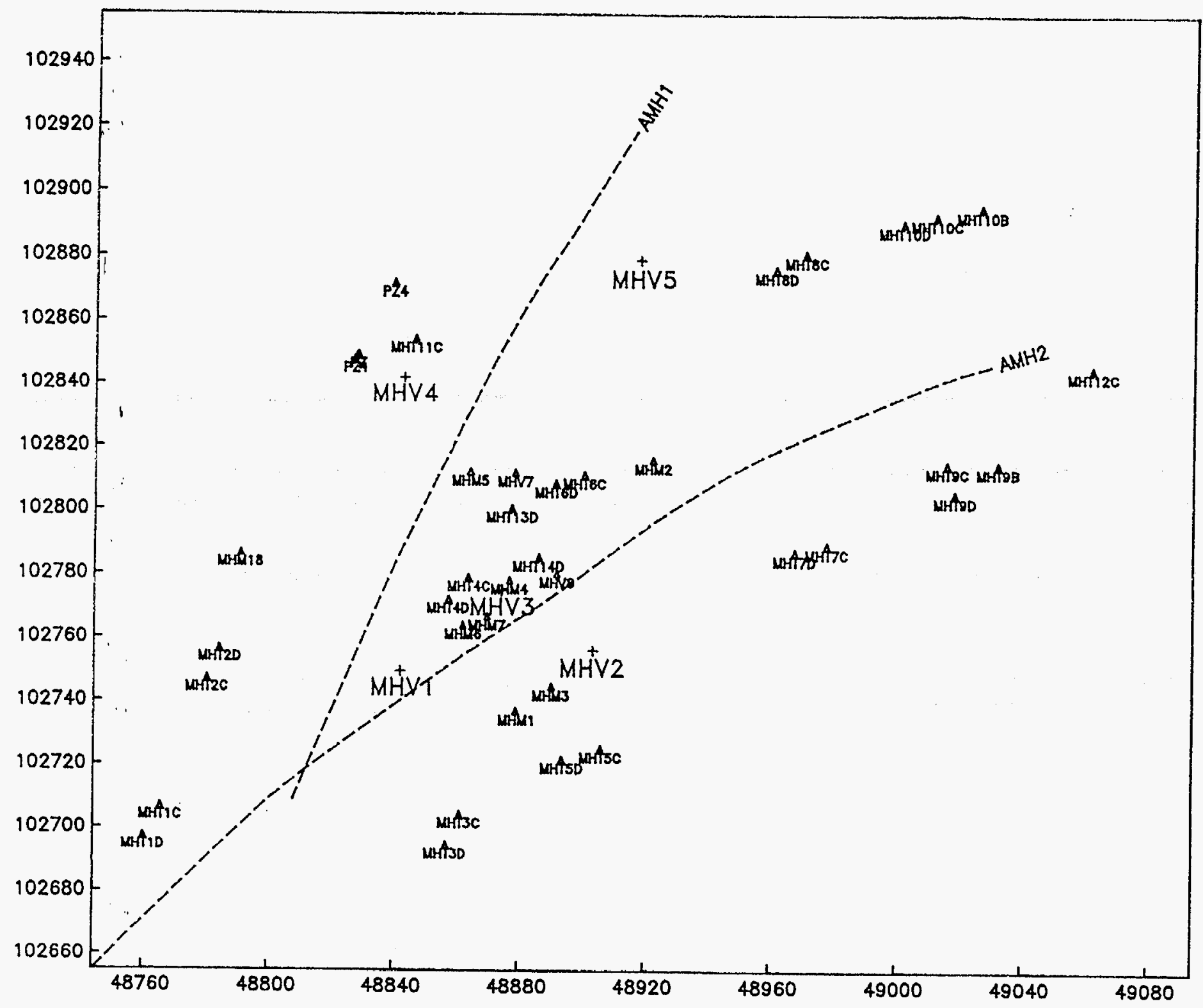




\section{APPENDIX A- Well Diagrams}




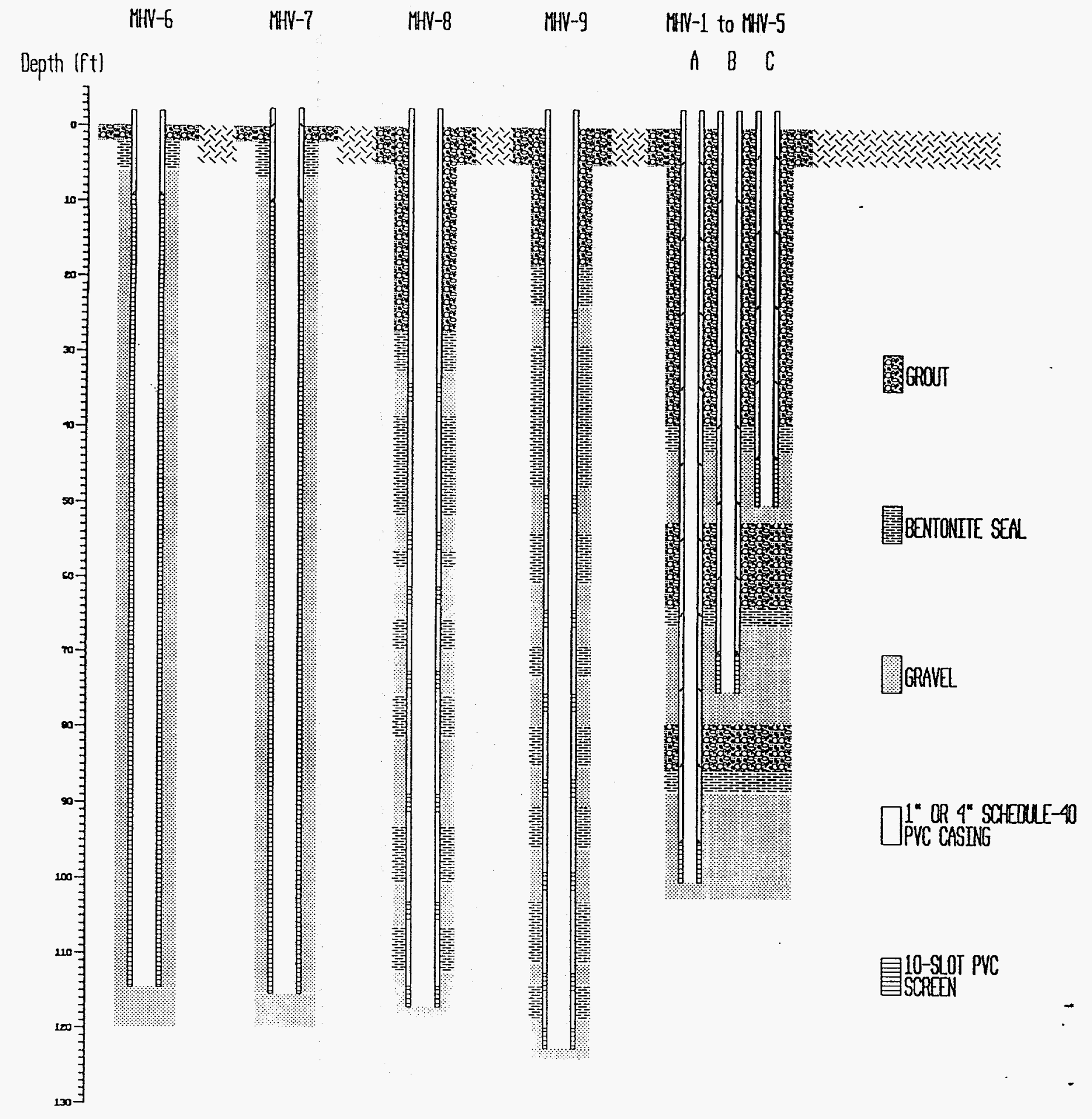

SRS Vadose-Zone Well Construction Diagrams 


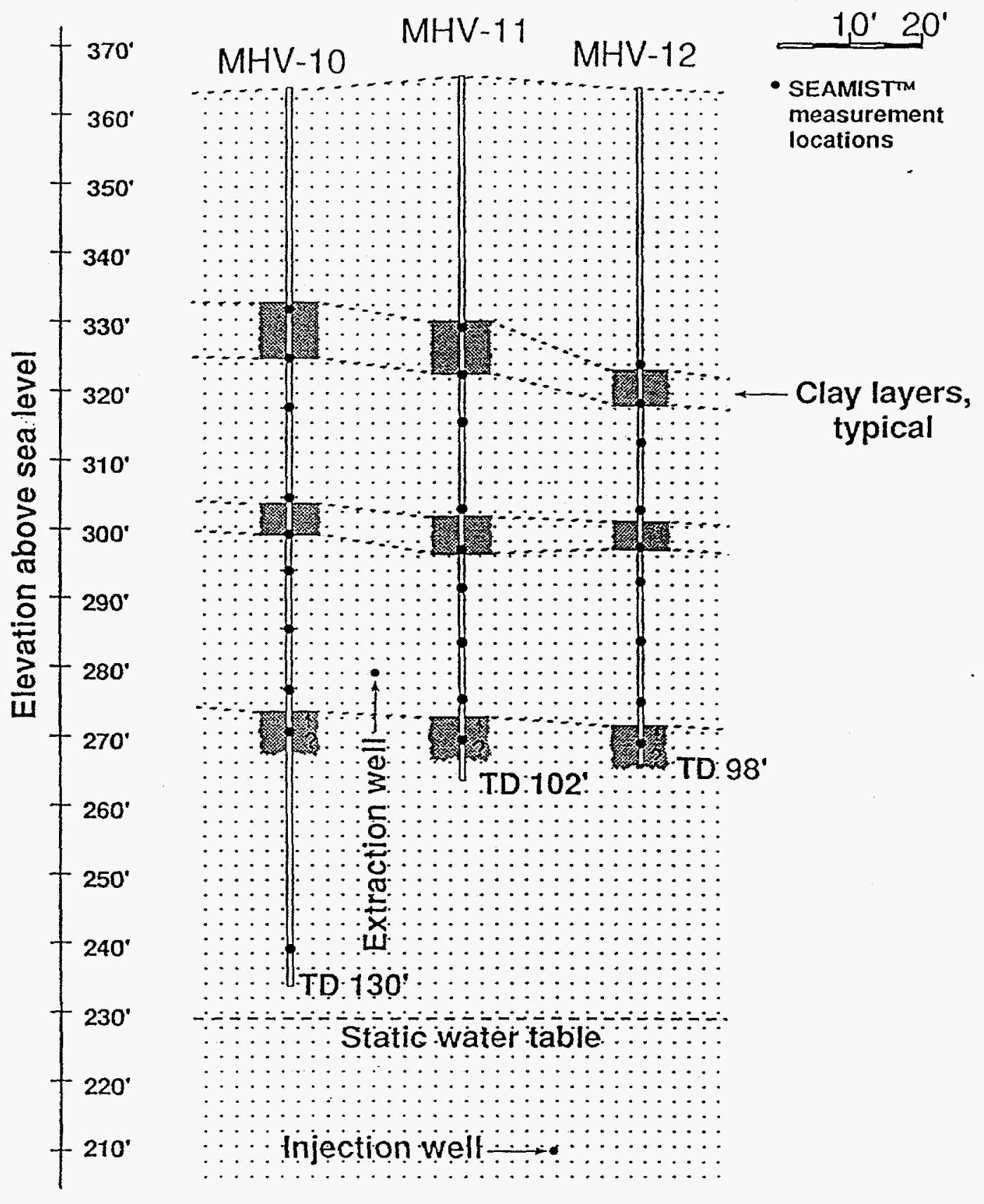

Figure 2. Cross-section of M-Area SEAMISTTM installations, showing sampling elevations. 
vertical scale $1^{\prime \prime}=10^{\prime}$

horizontal scale $1 "=10^{\prime \prime}$

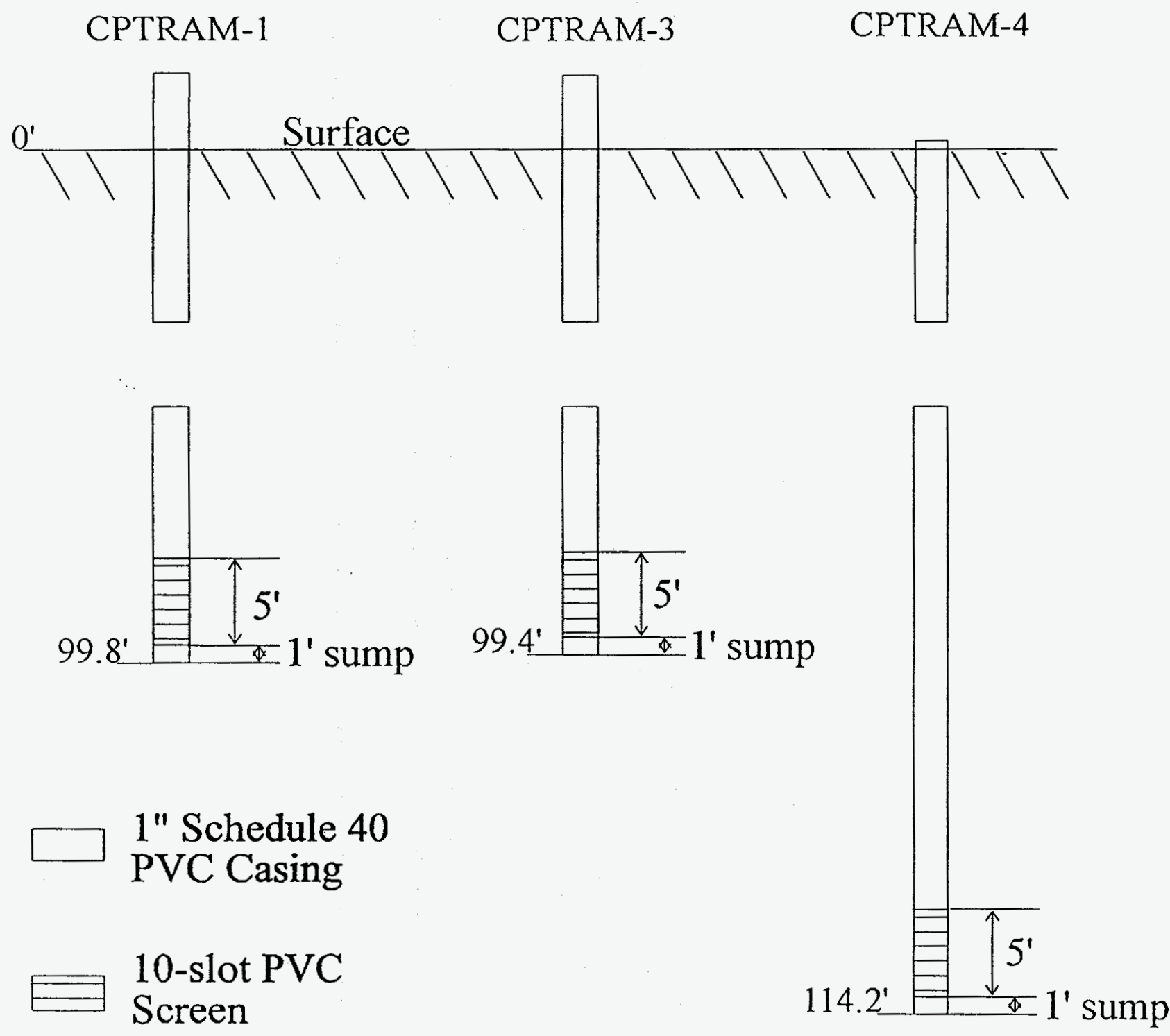

vertical scale $1 "=10^{\prime \prime}$

fence line horizontal scale $1 "=10^{\prime}$.

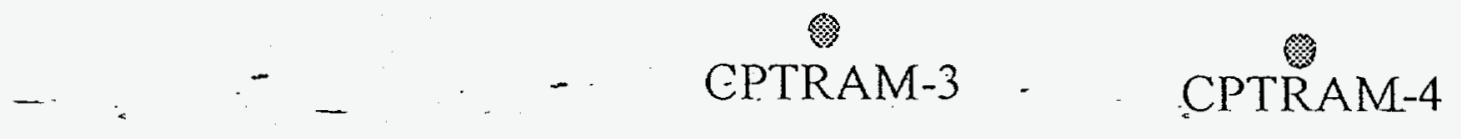

CPTRAM-1 


\section{APPENDIX A - Pressure Profiles}




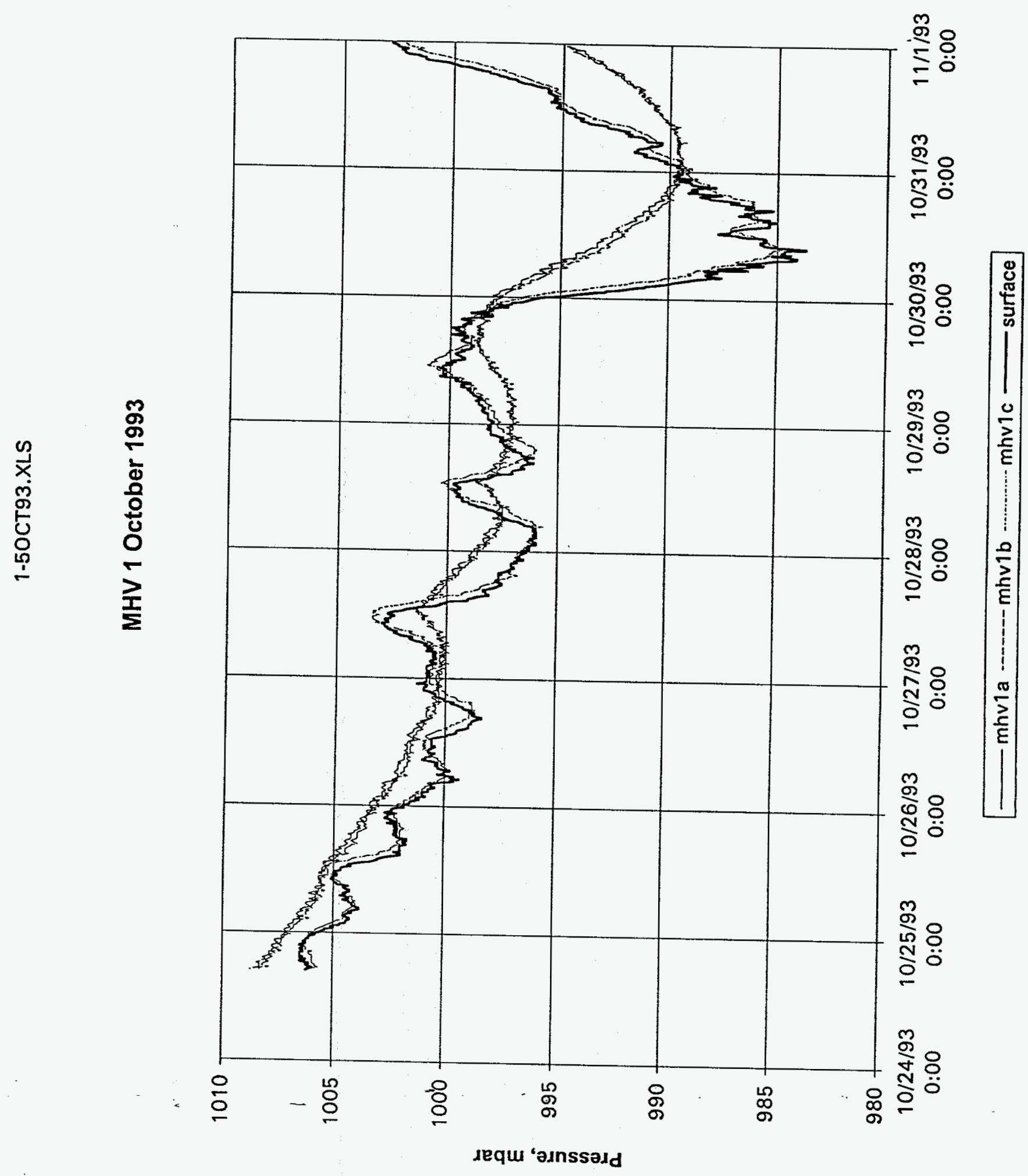




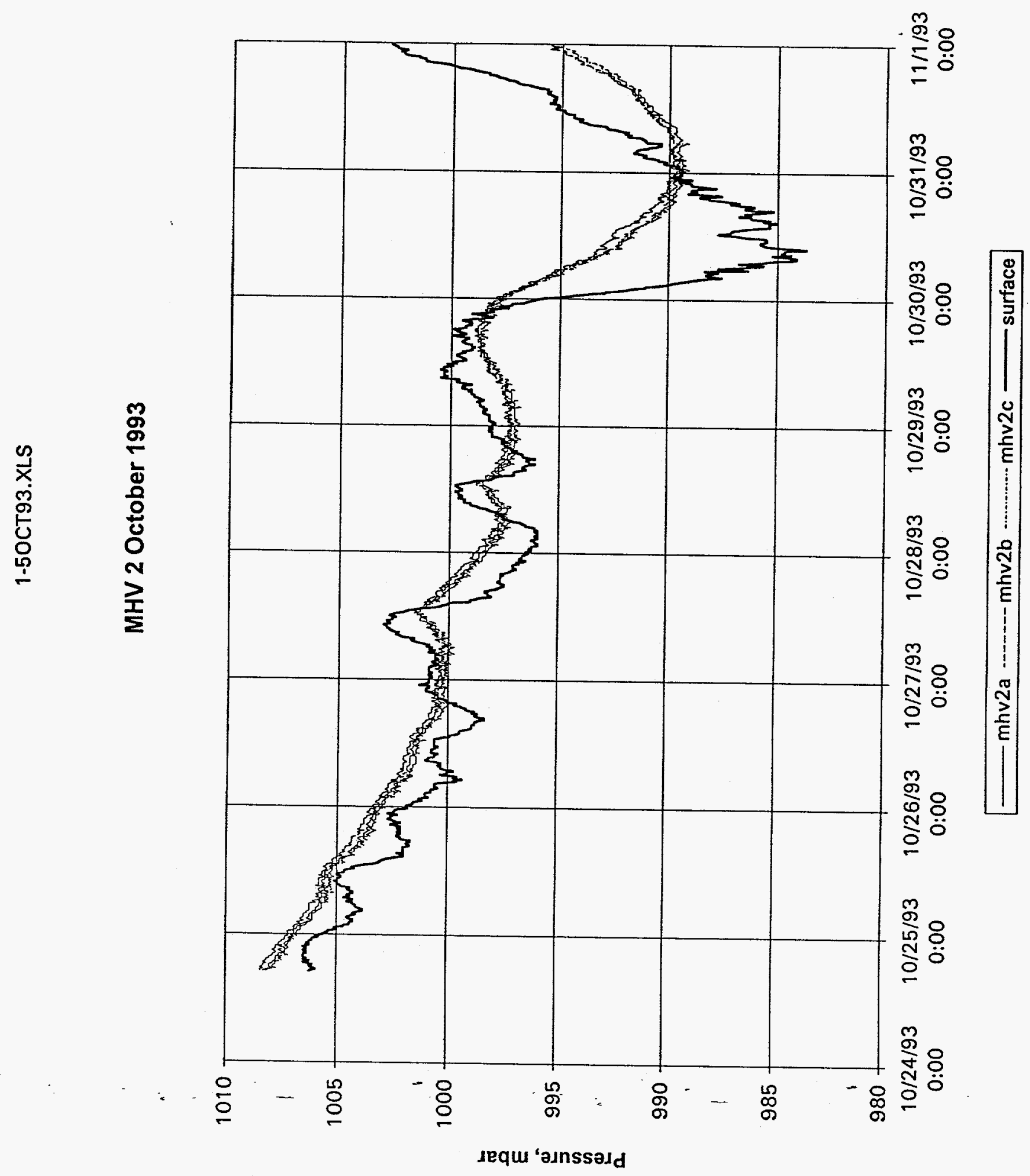




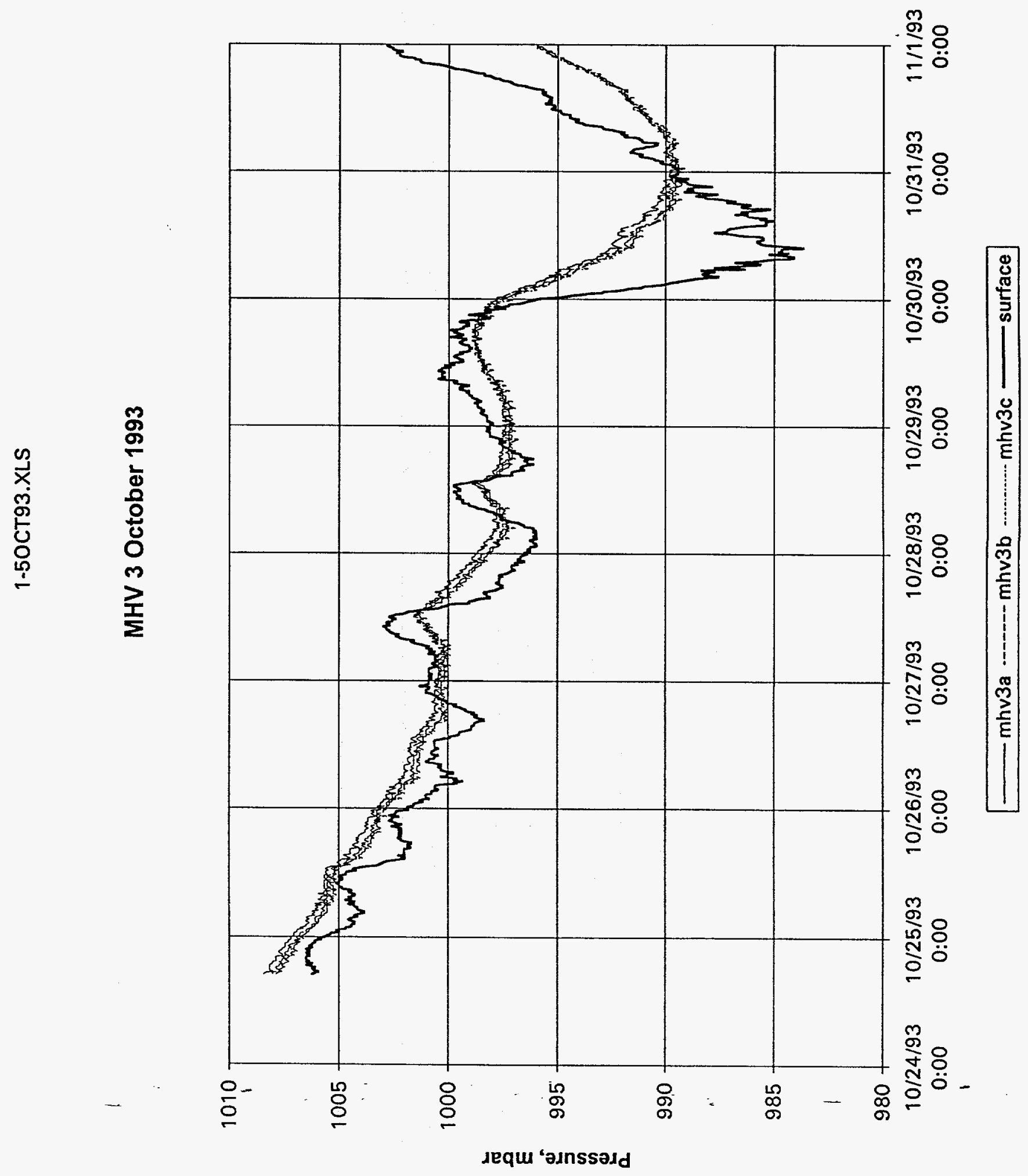




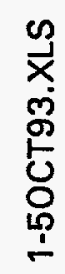

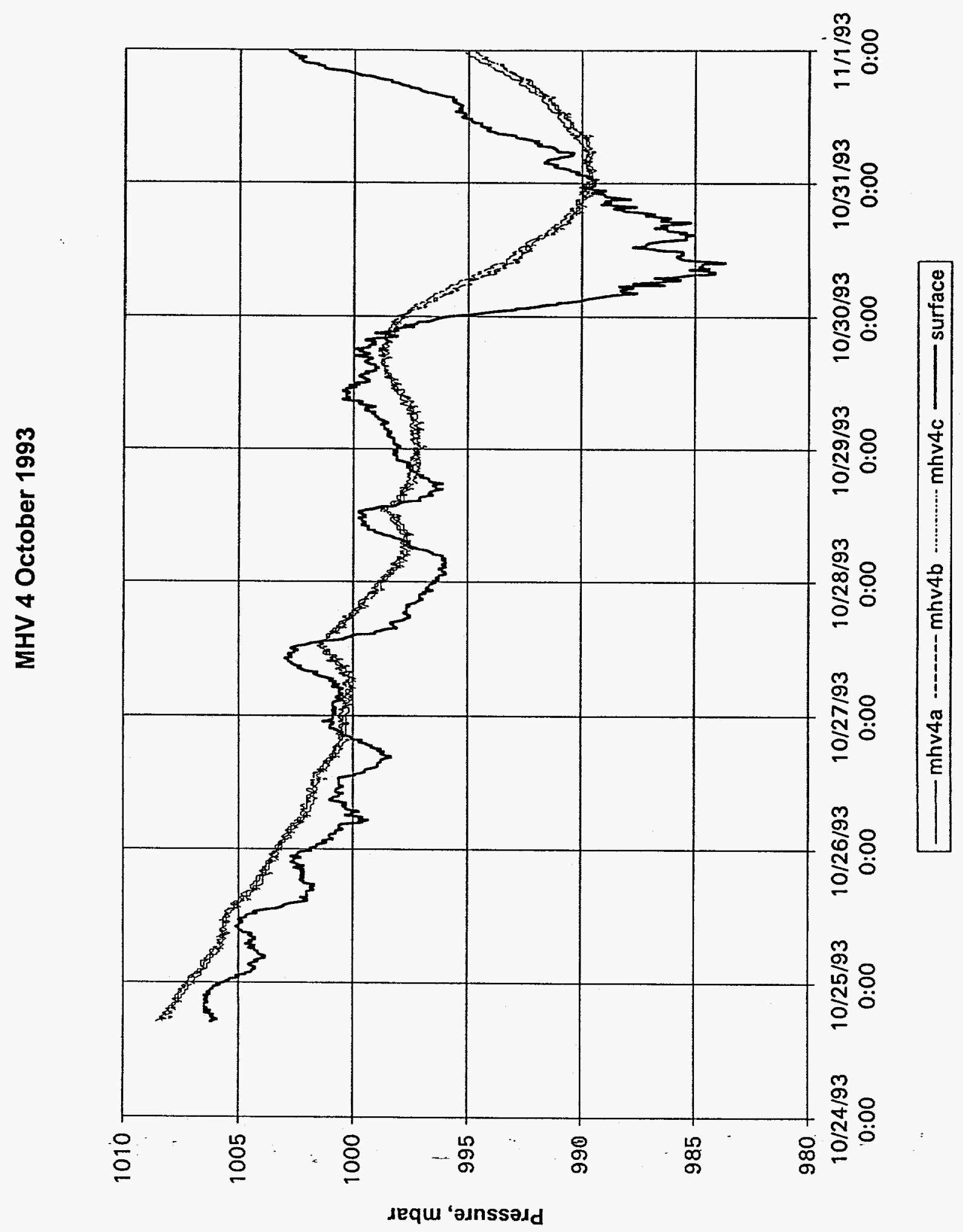




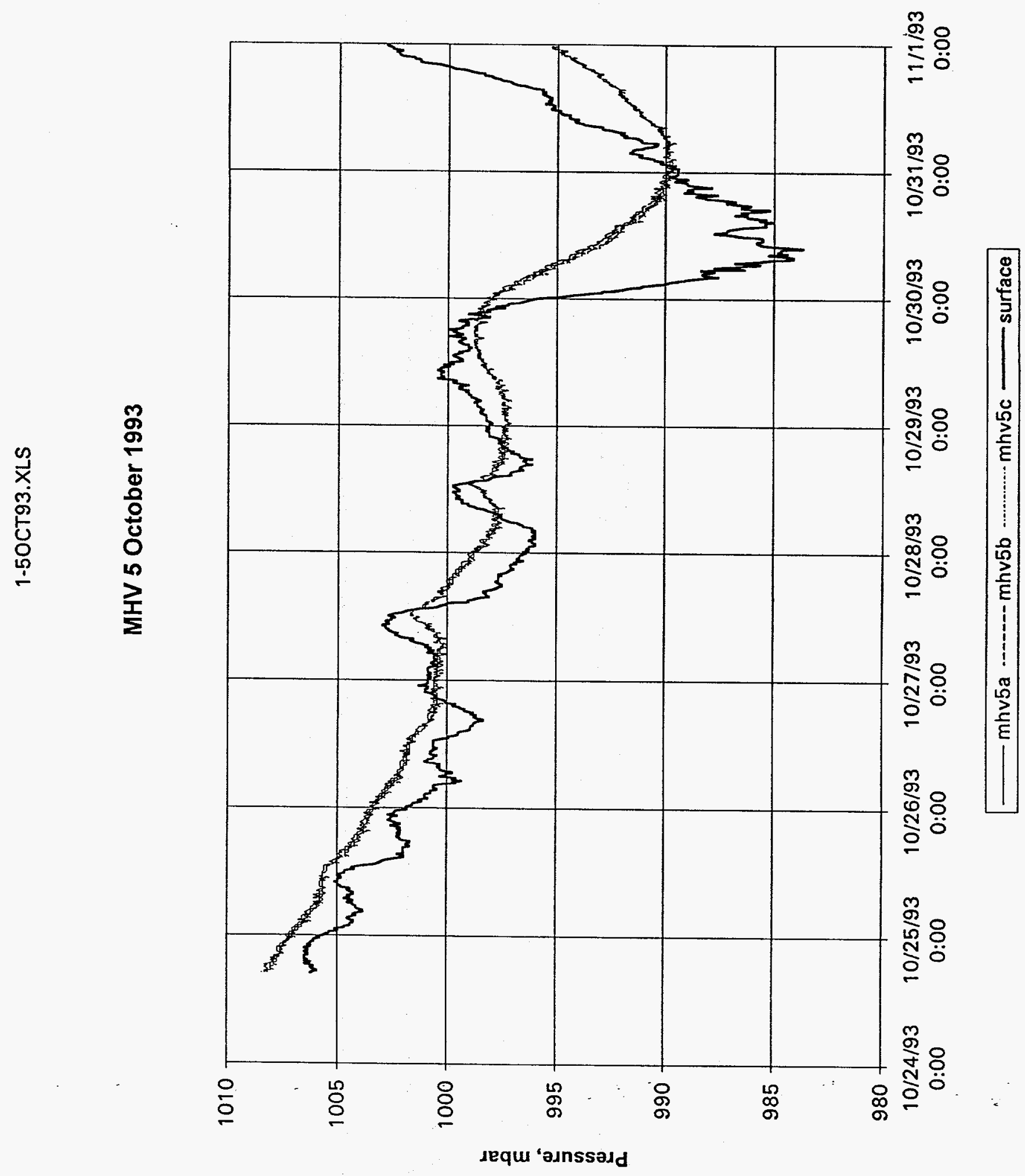




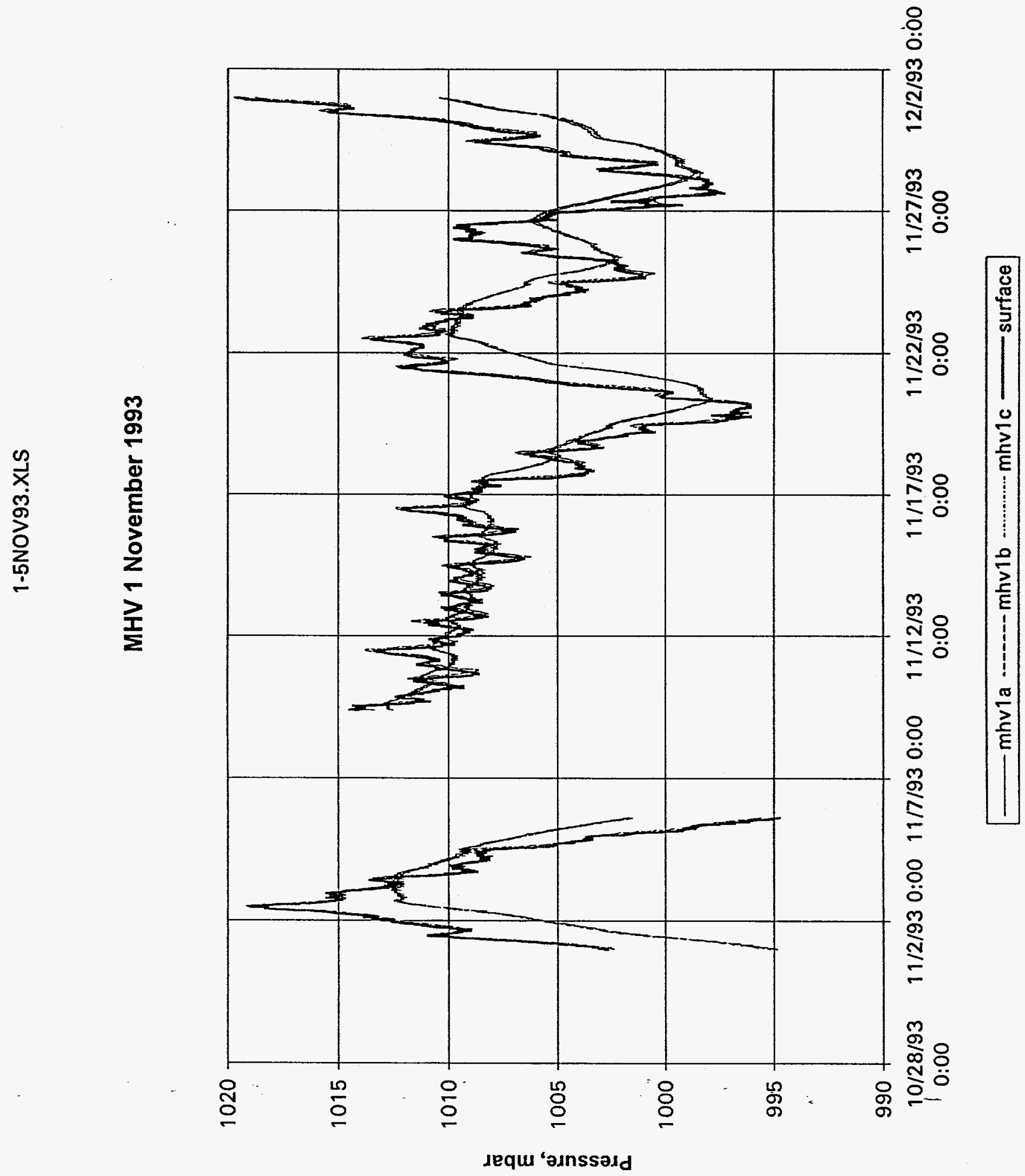




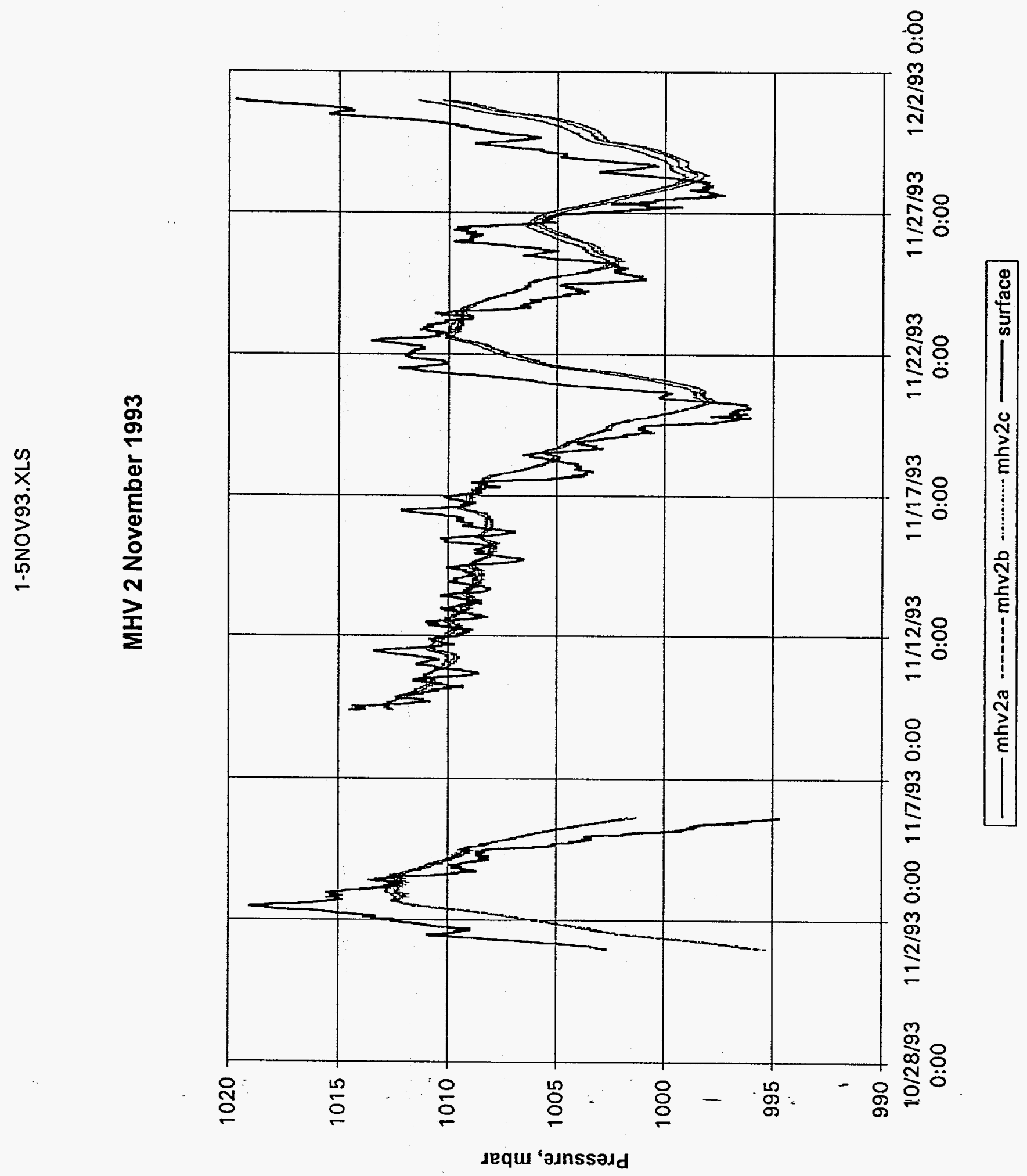




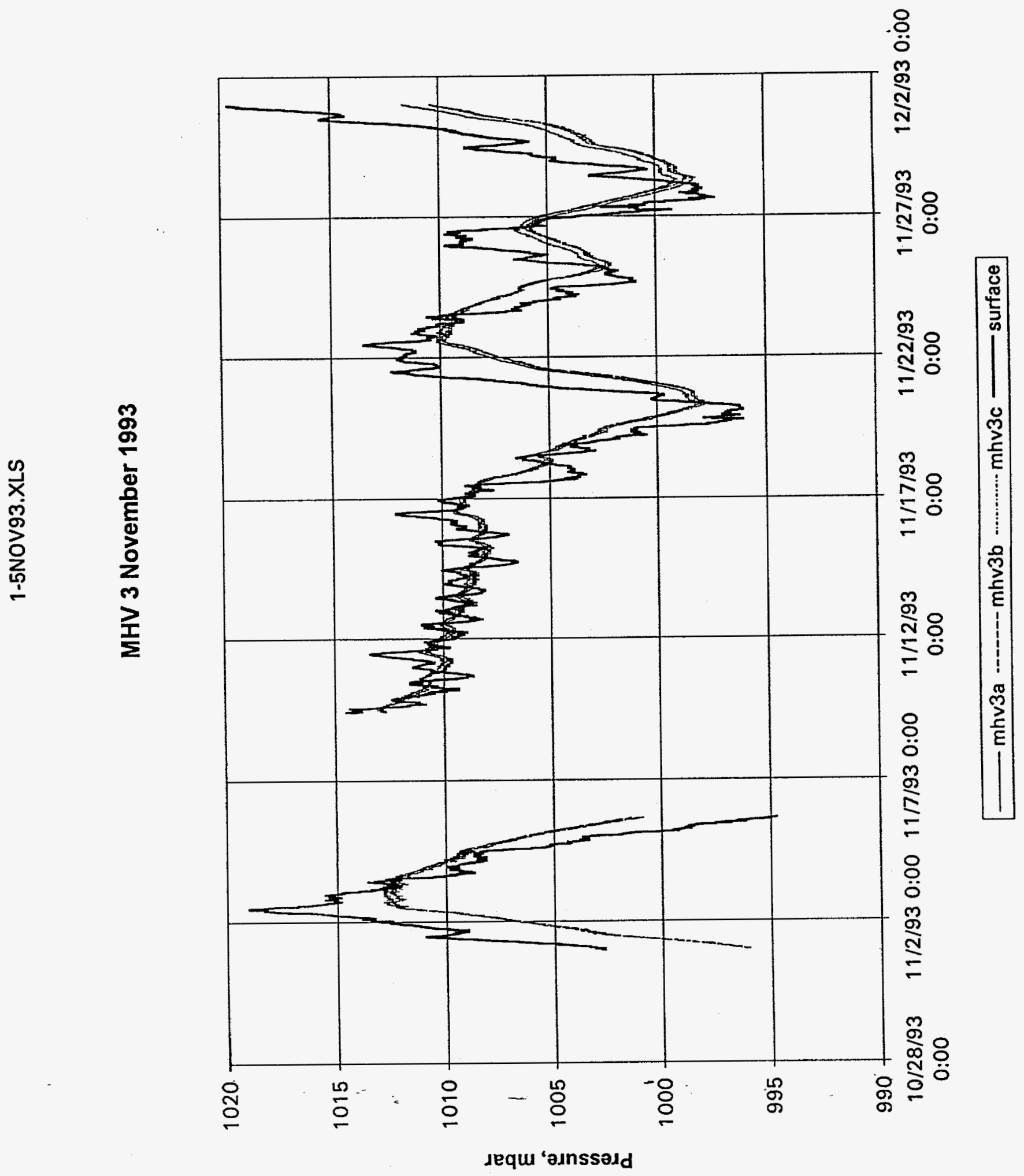


' , ' 


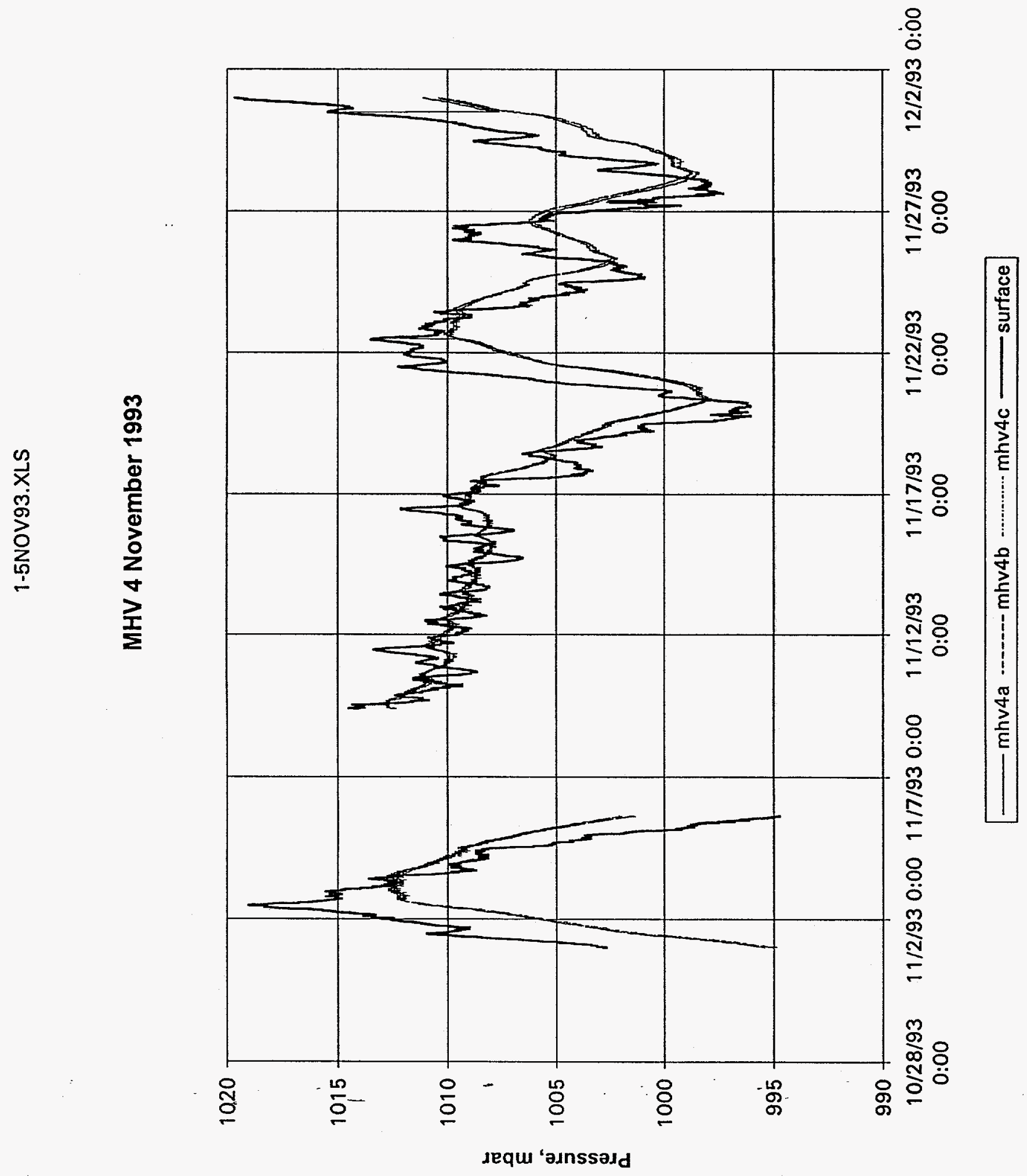




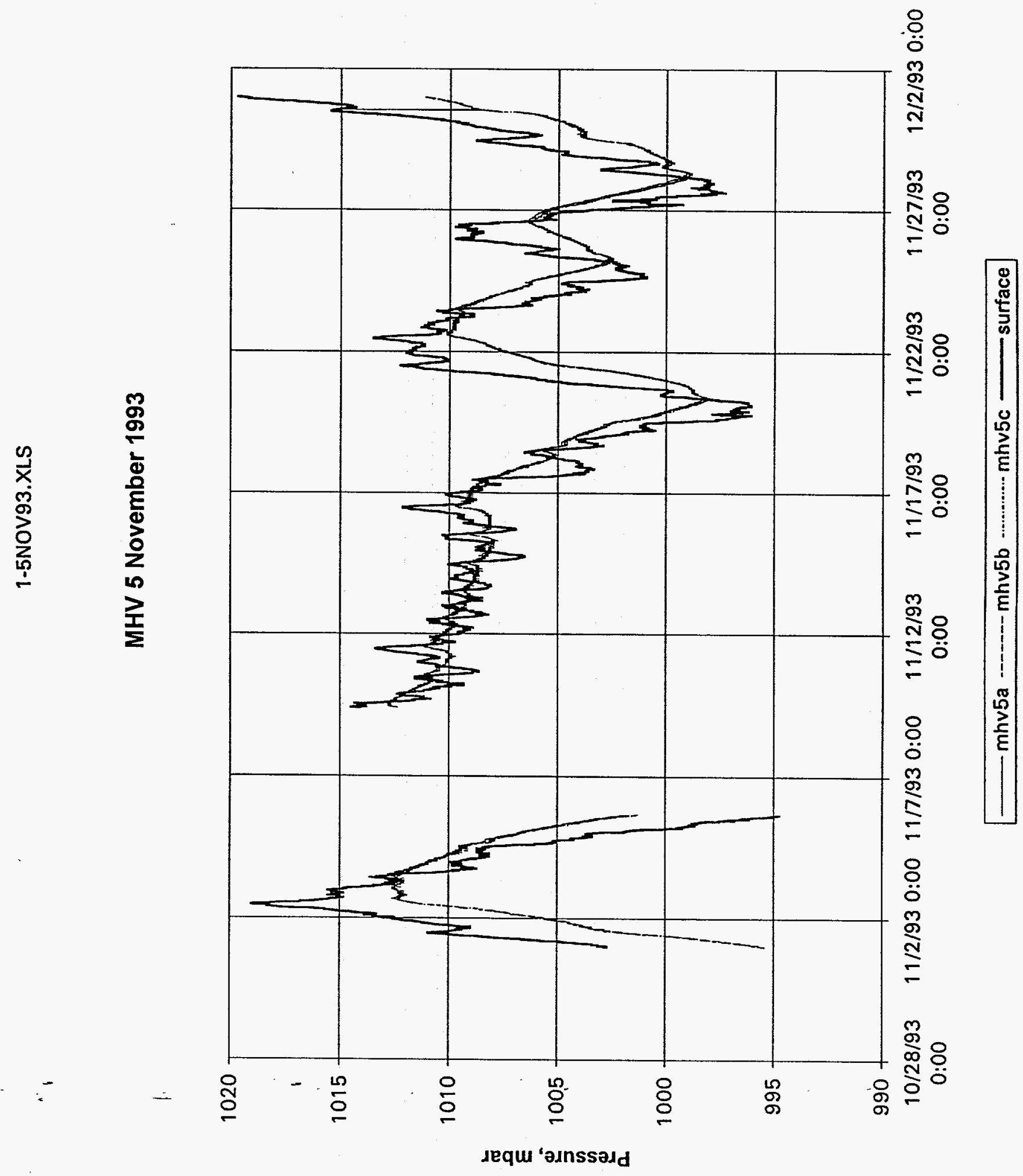




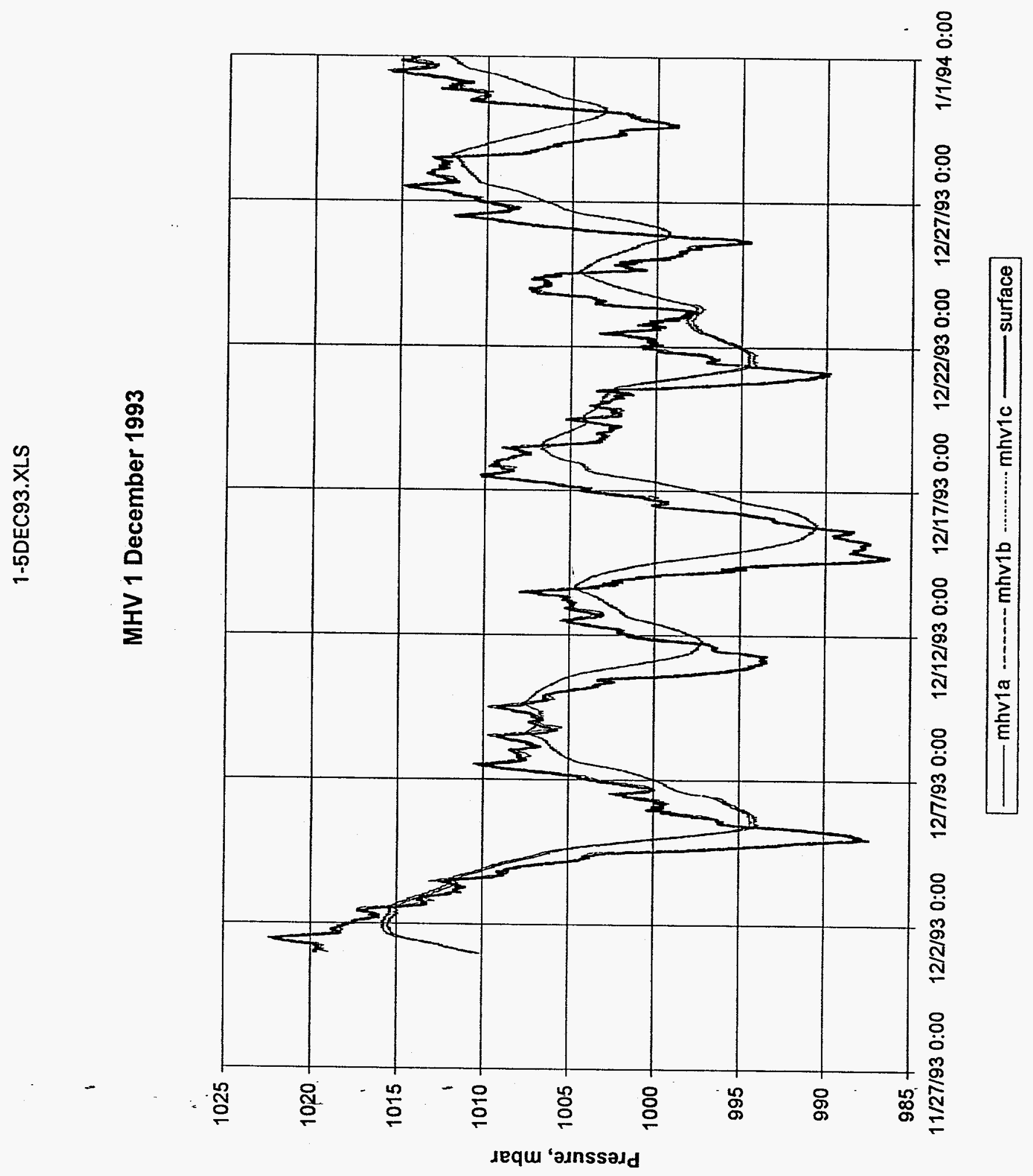




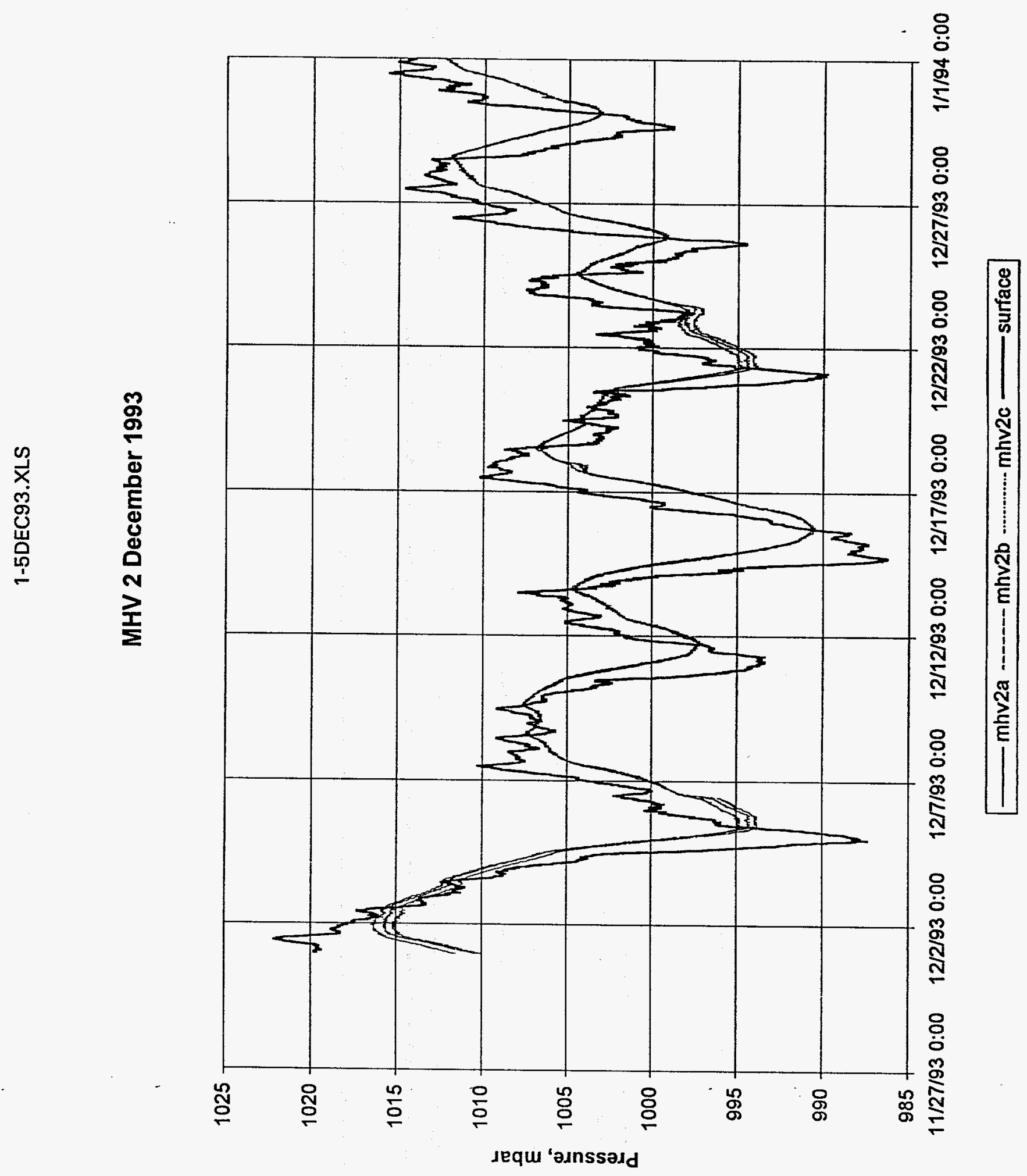




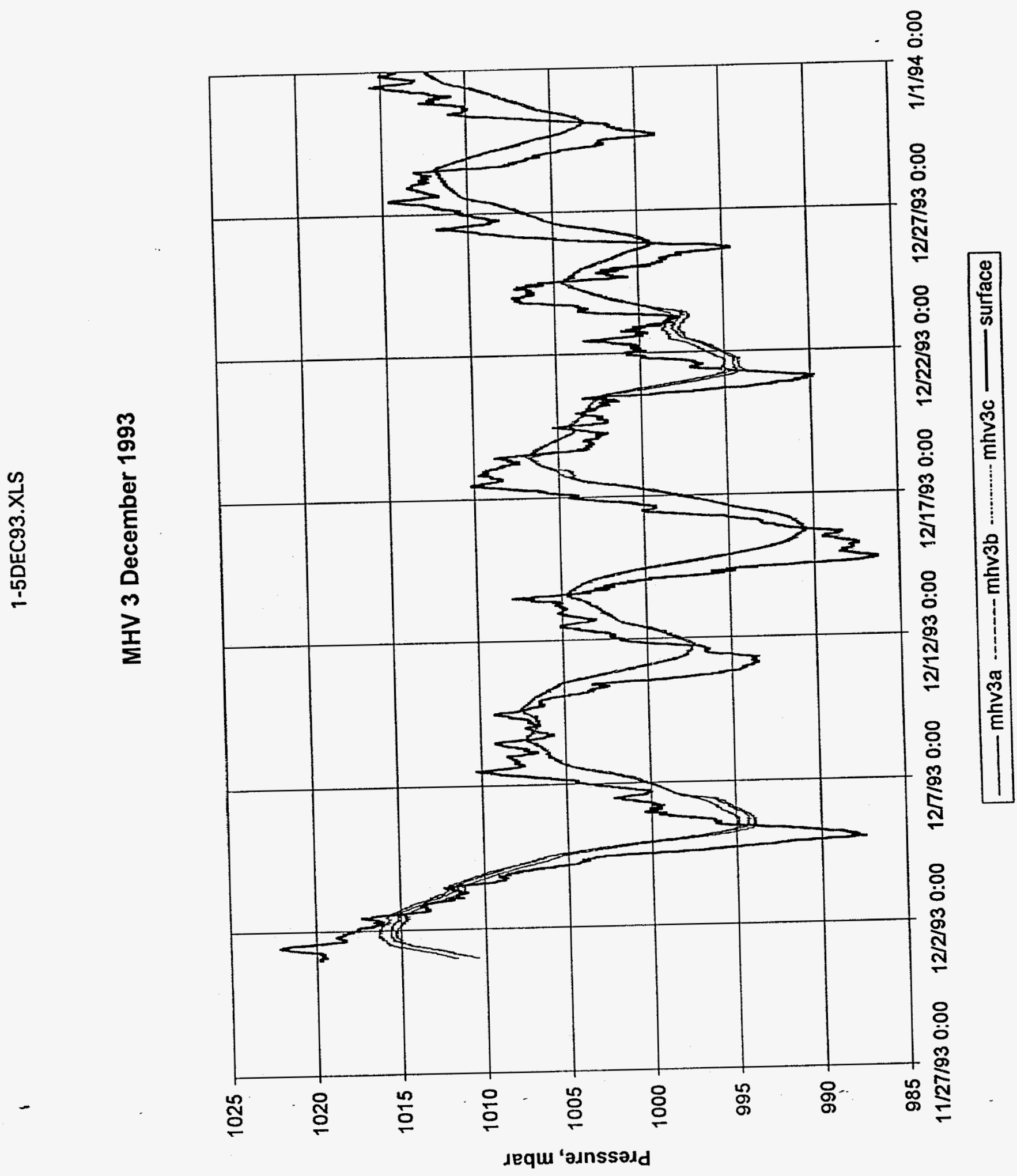




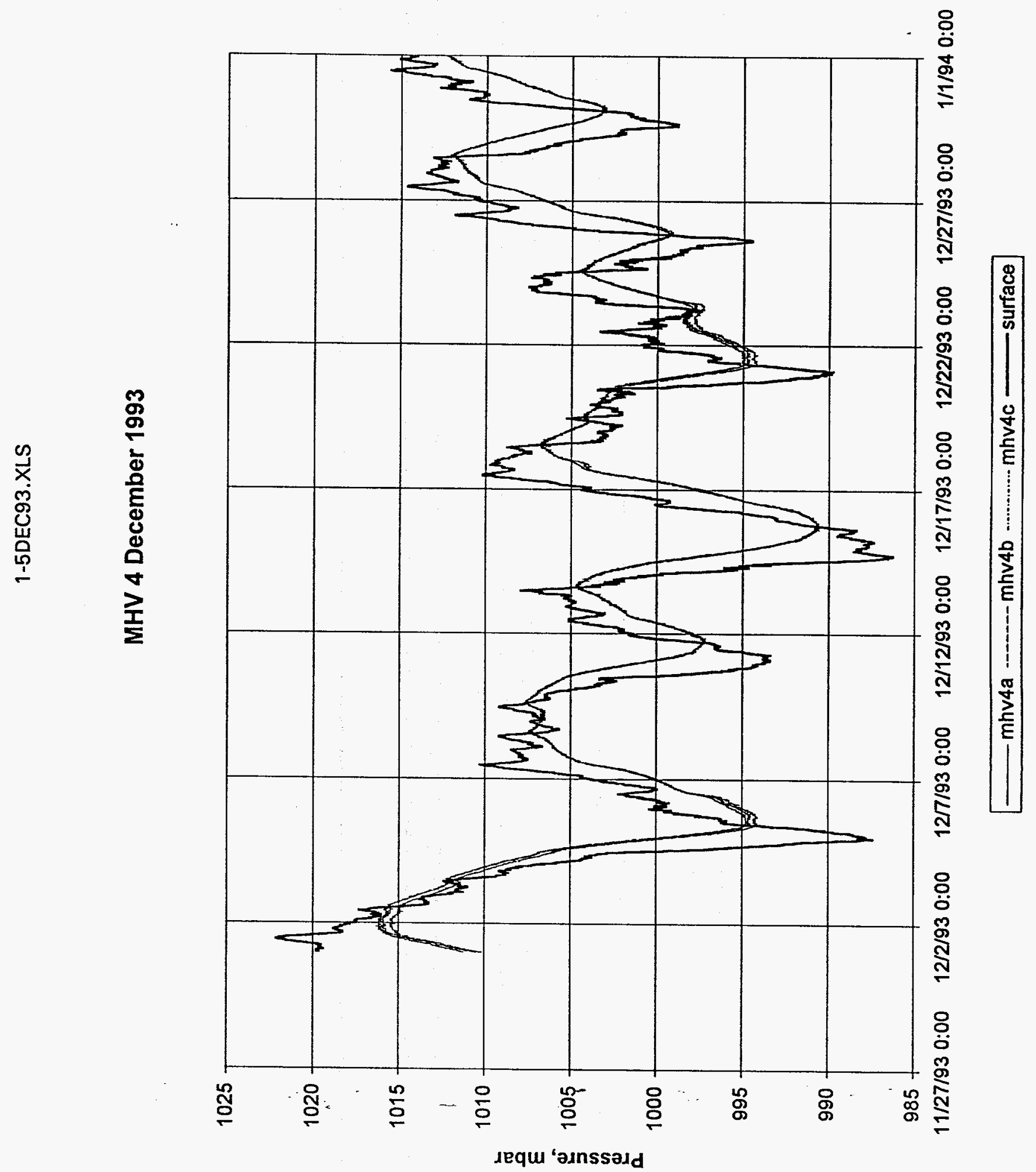




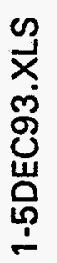

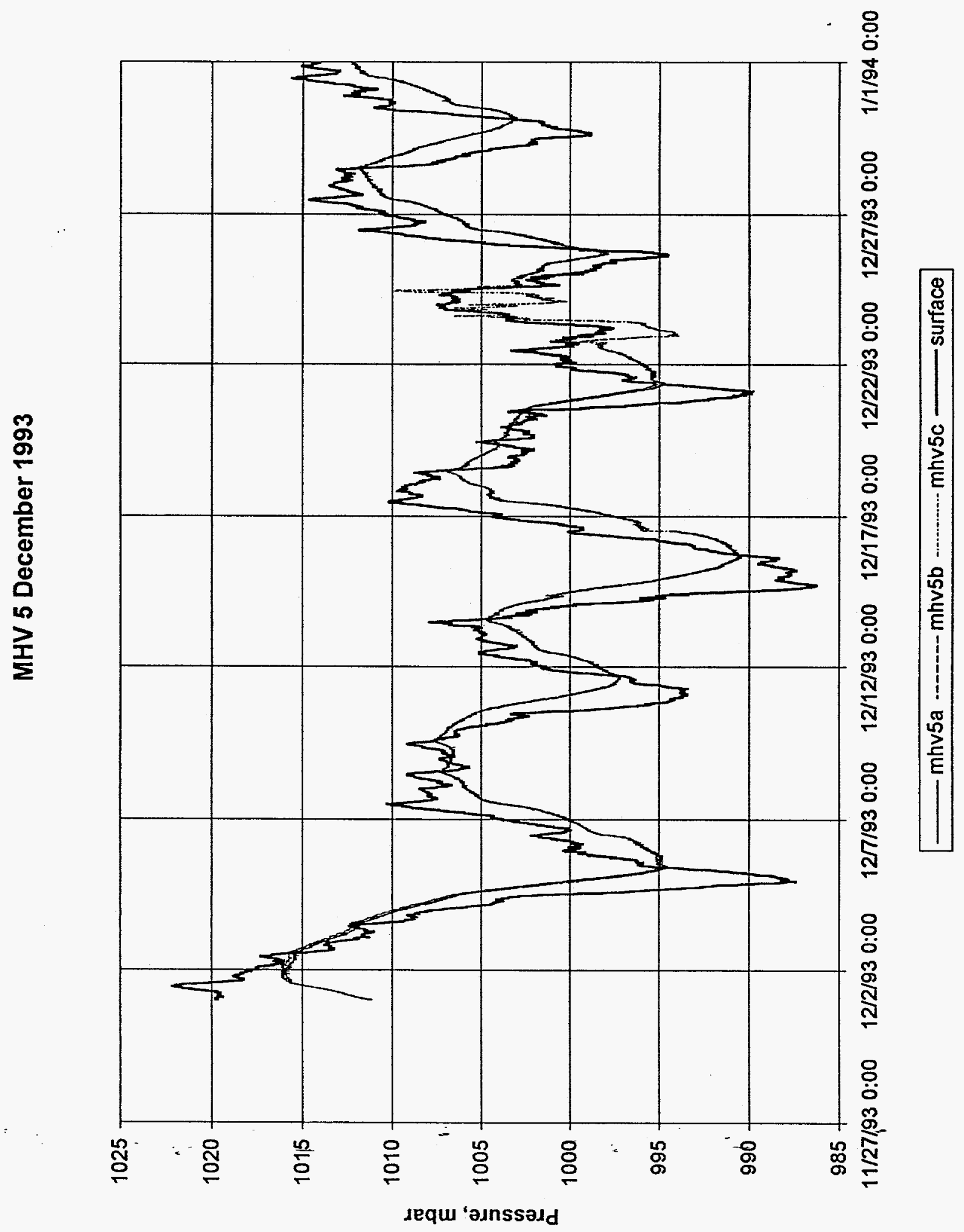




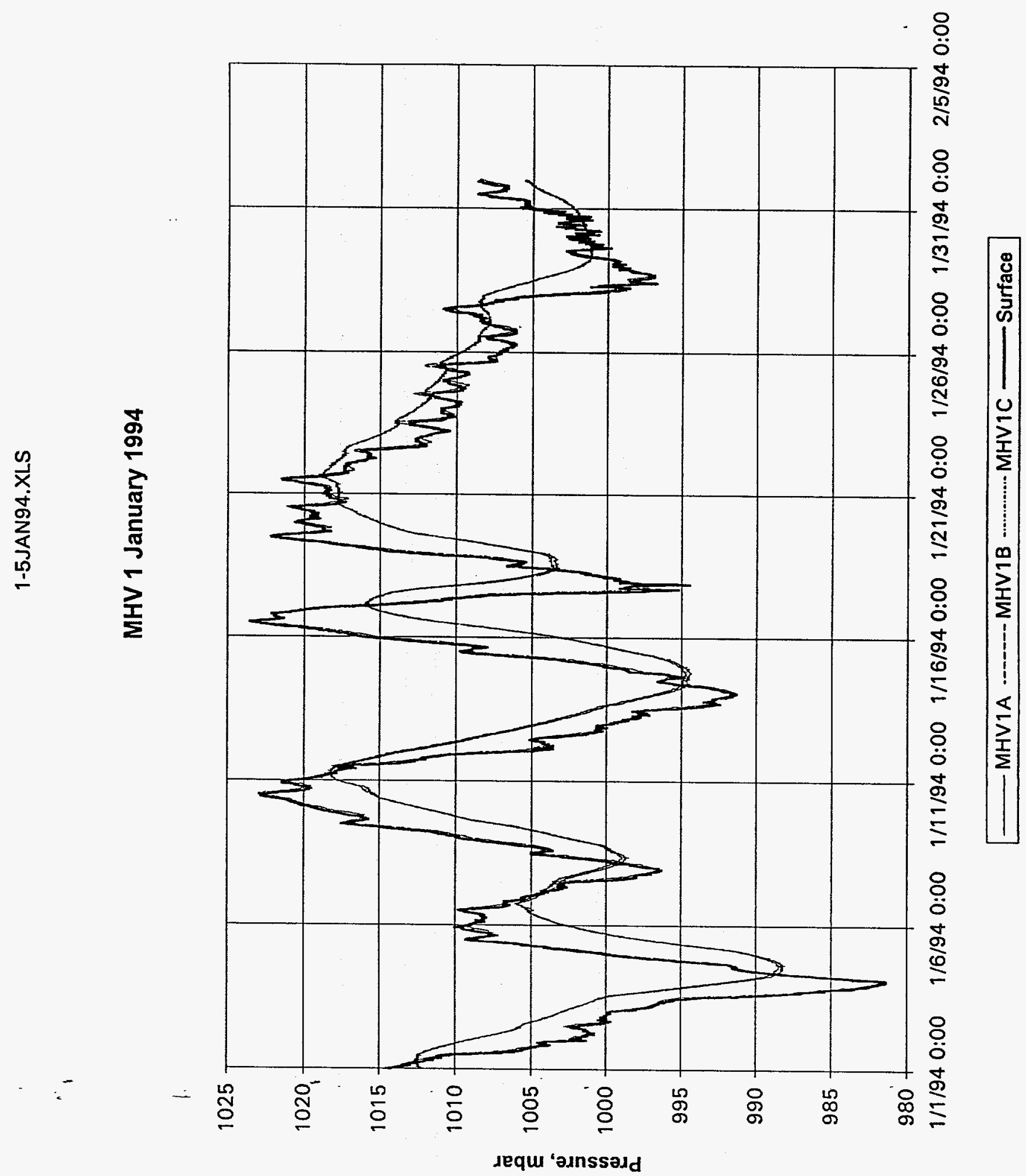




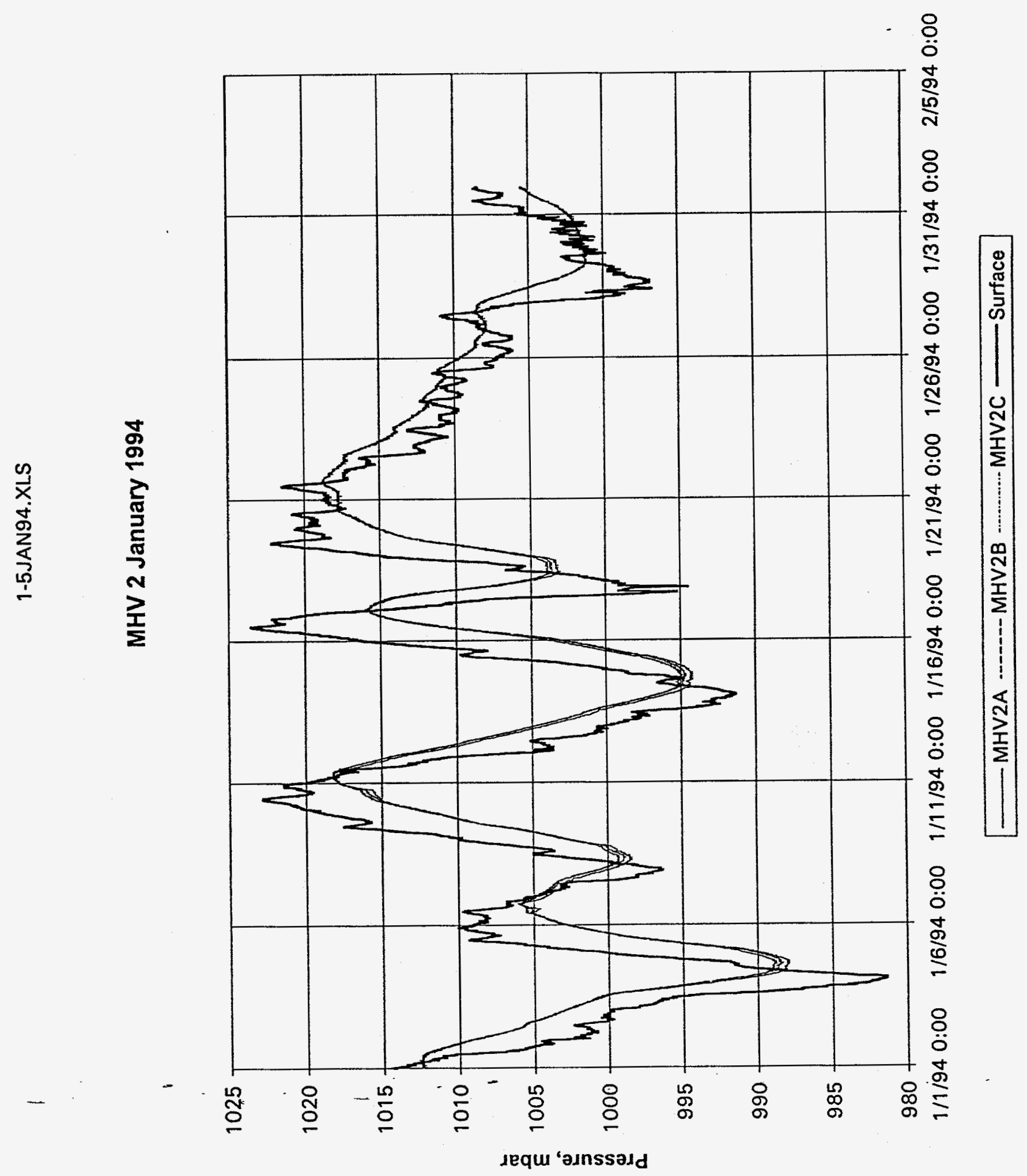




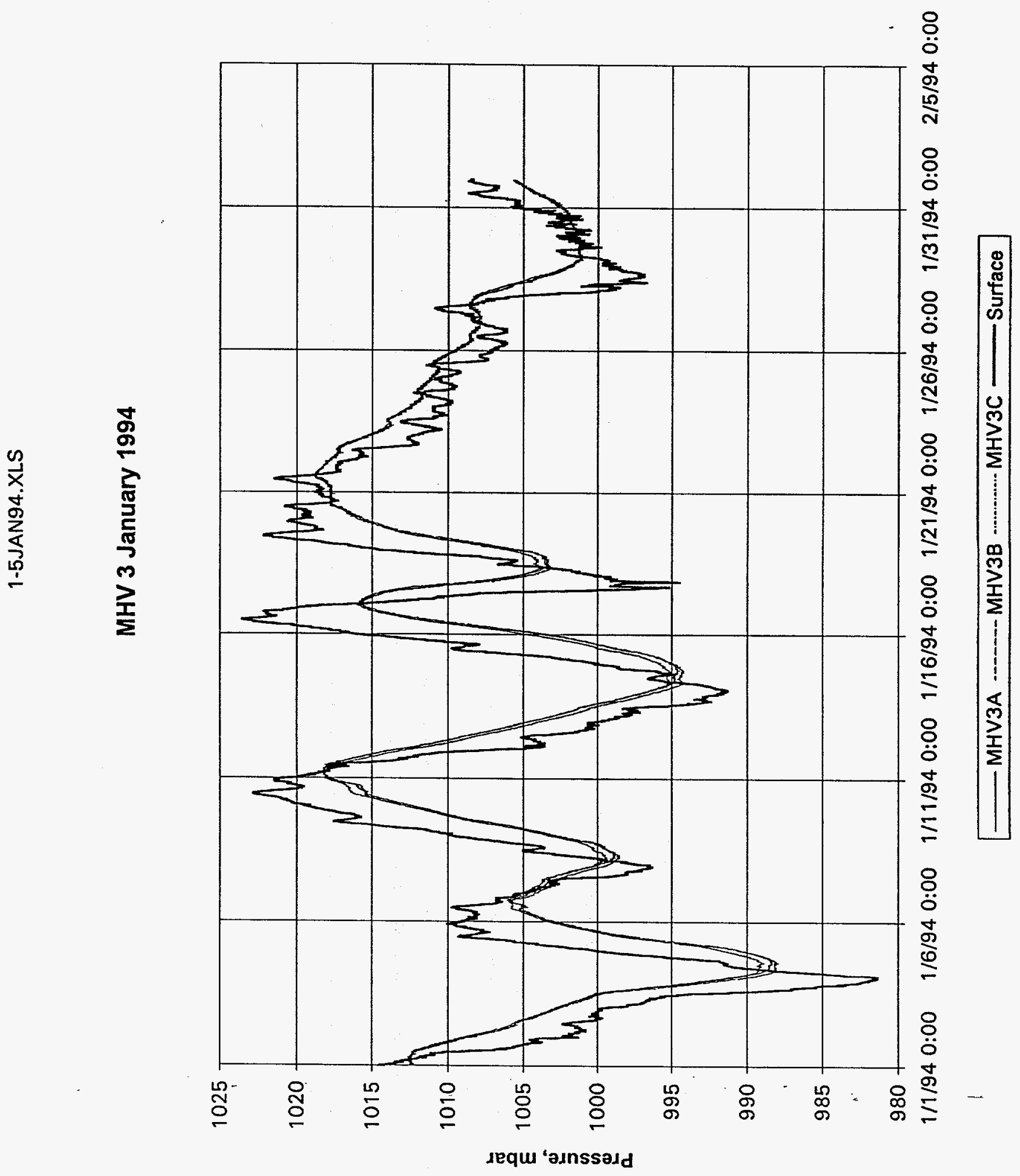




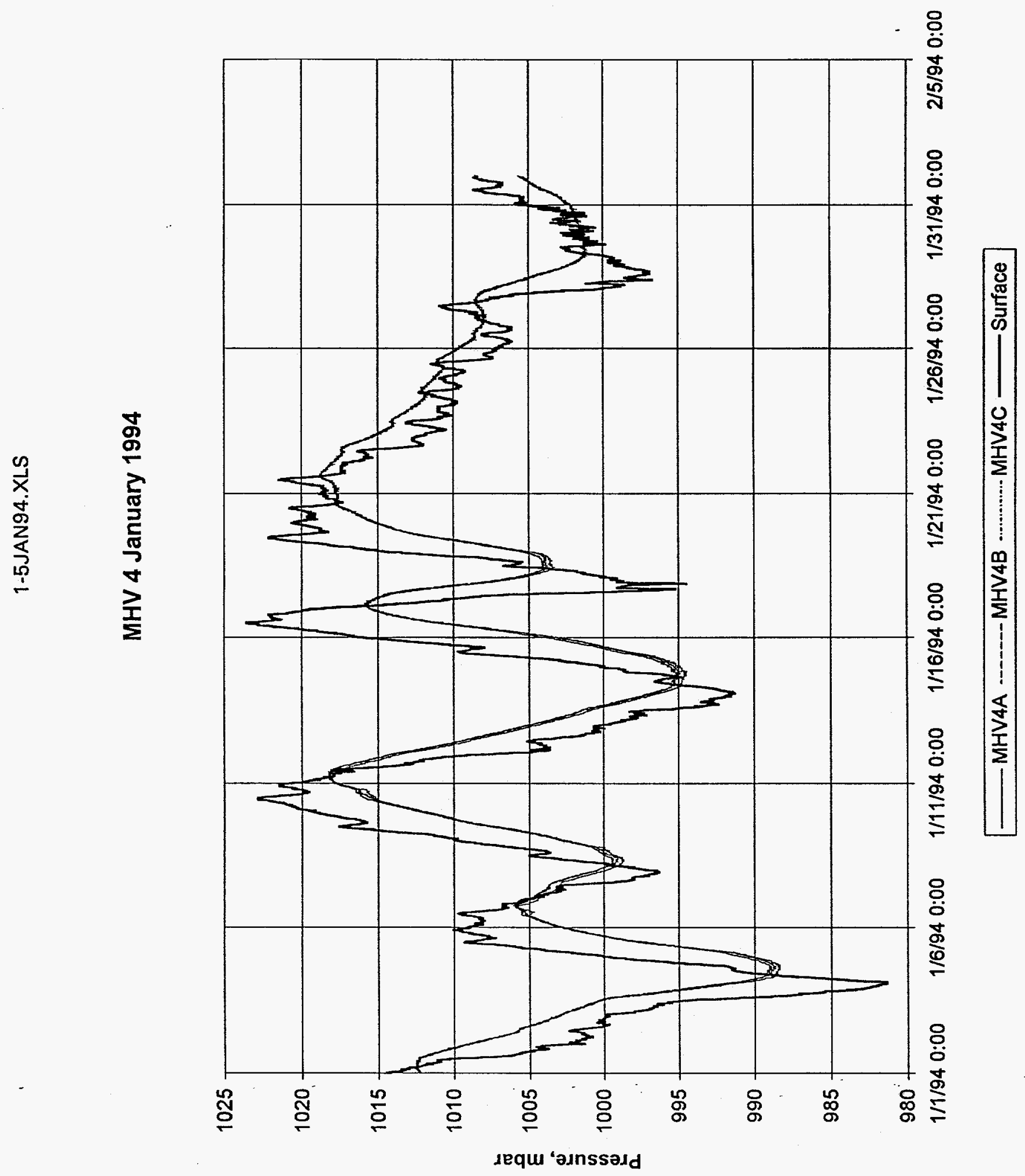




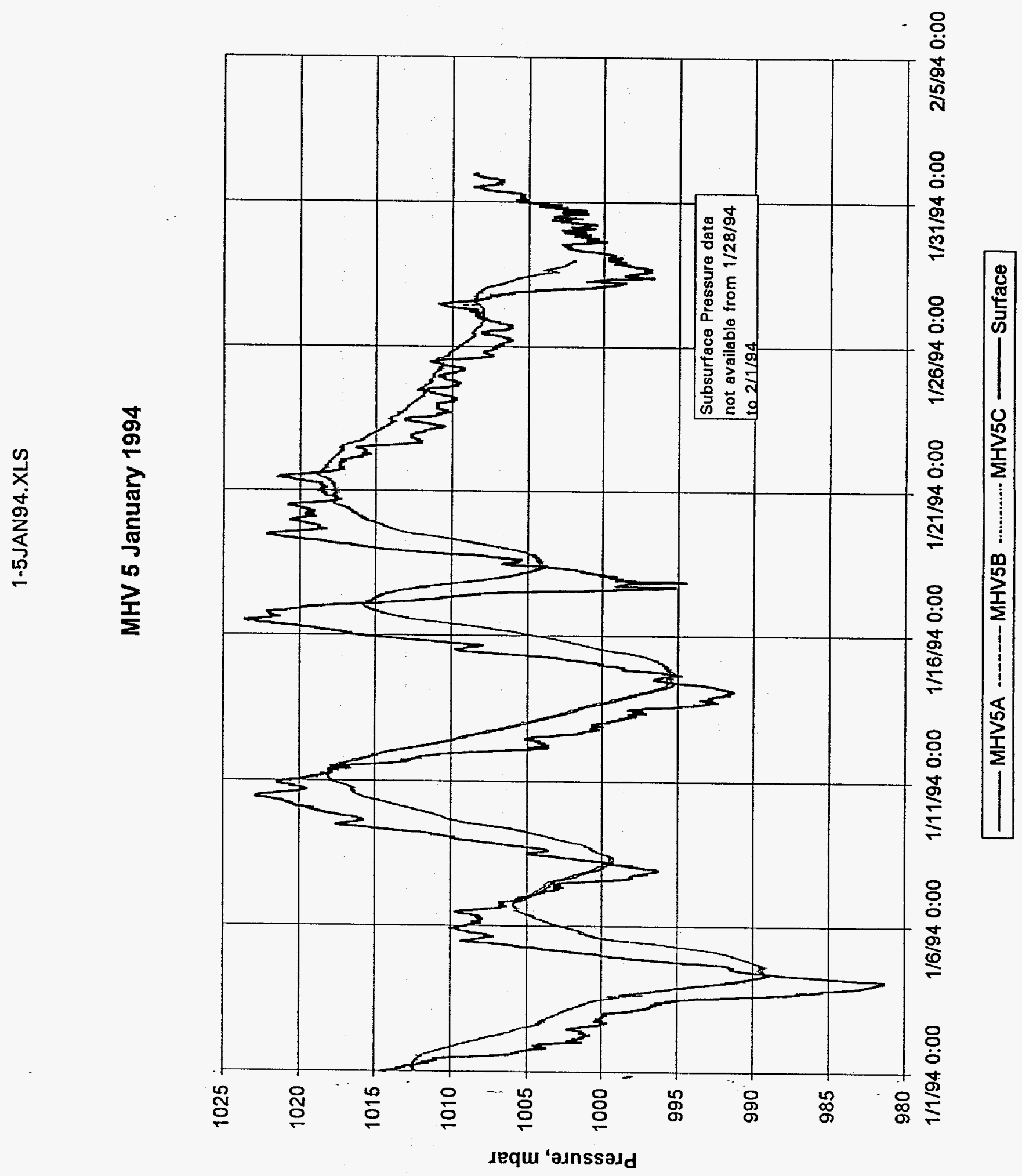




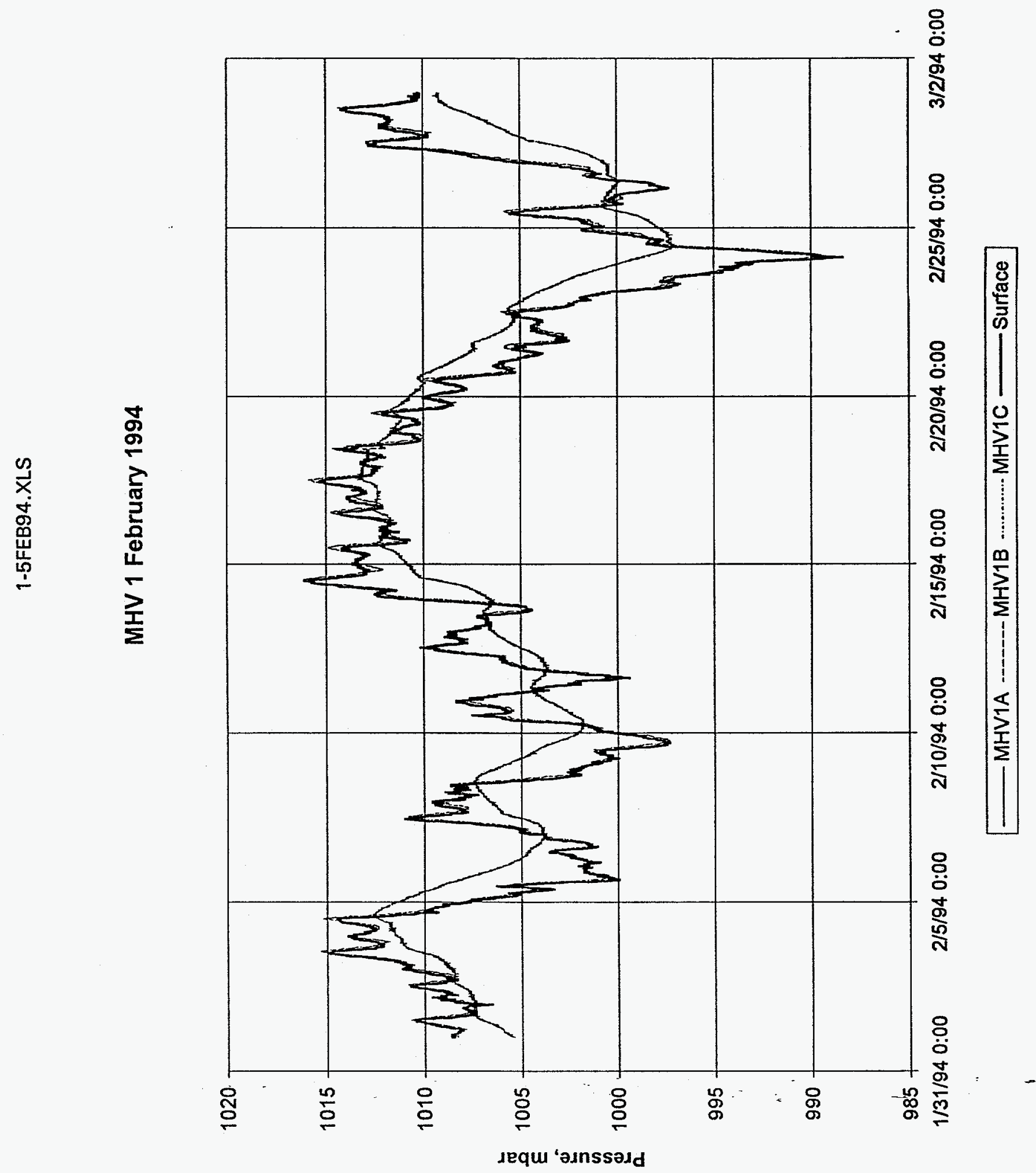




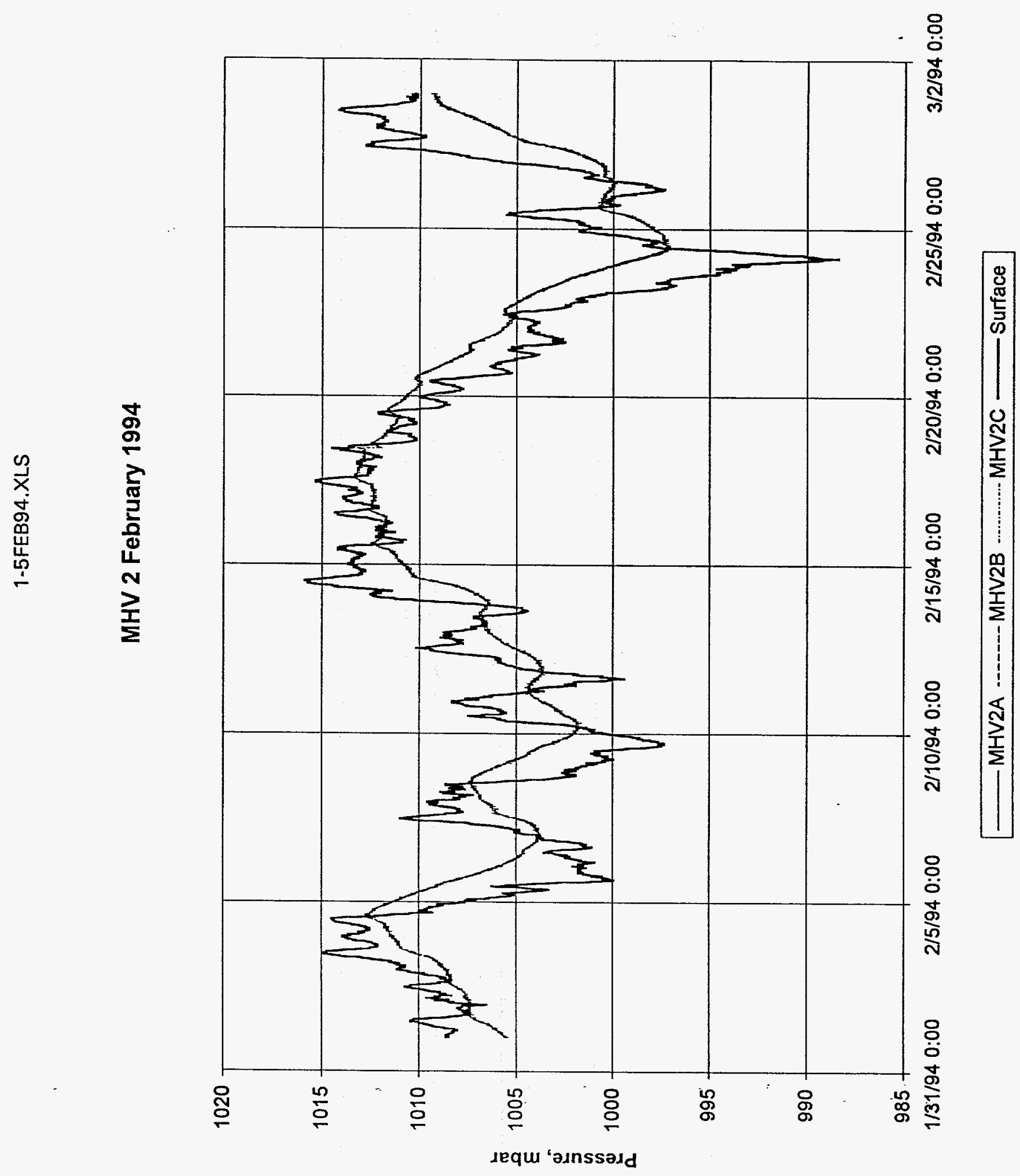




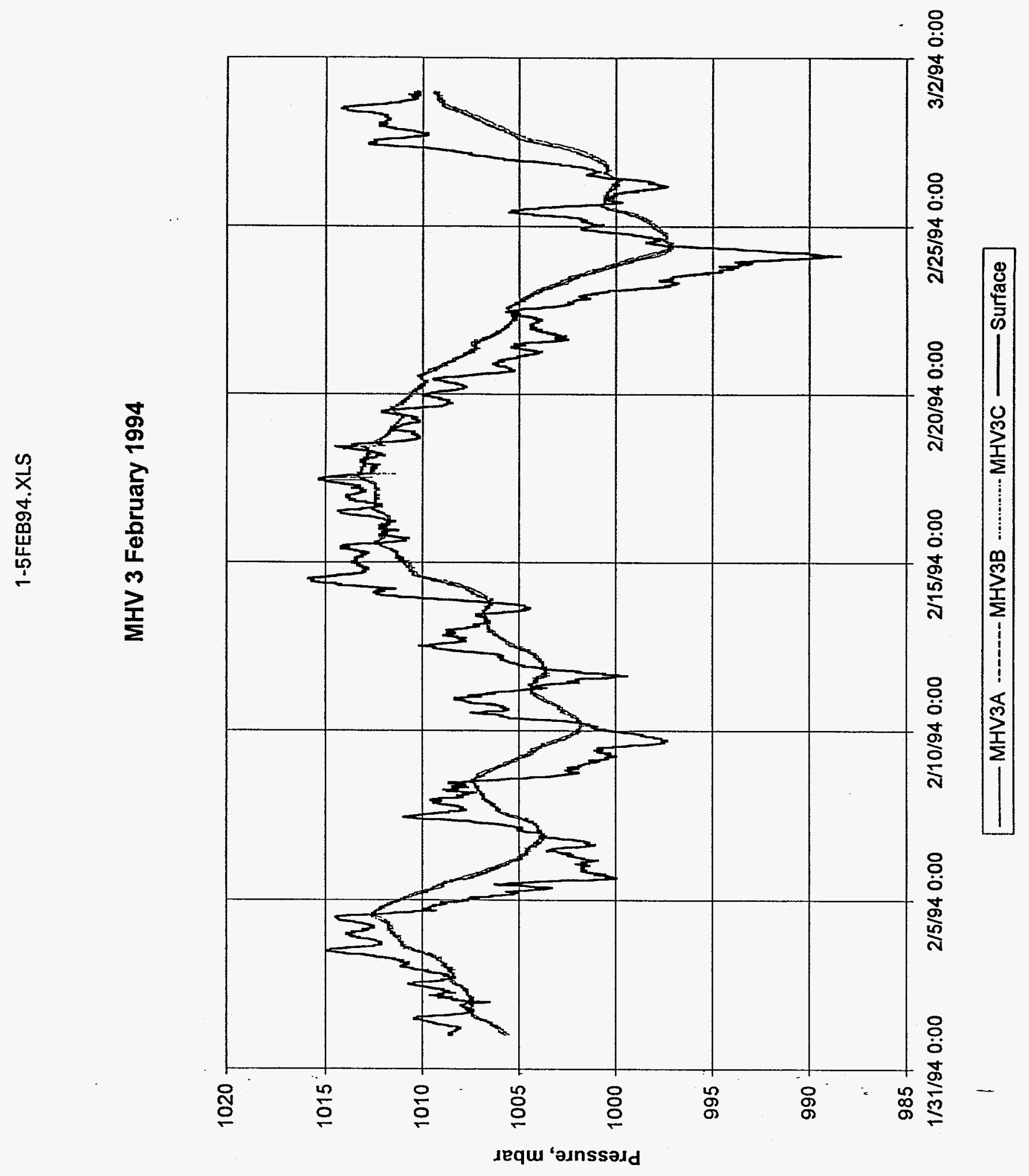




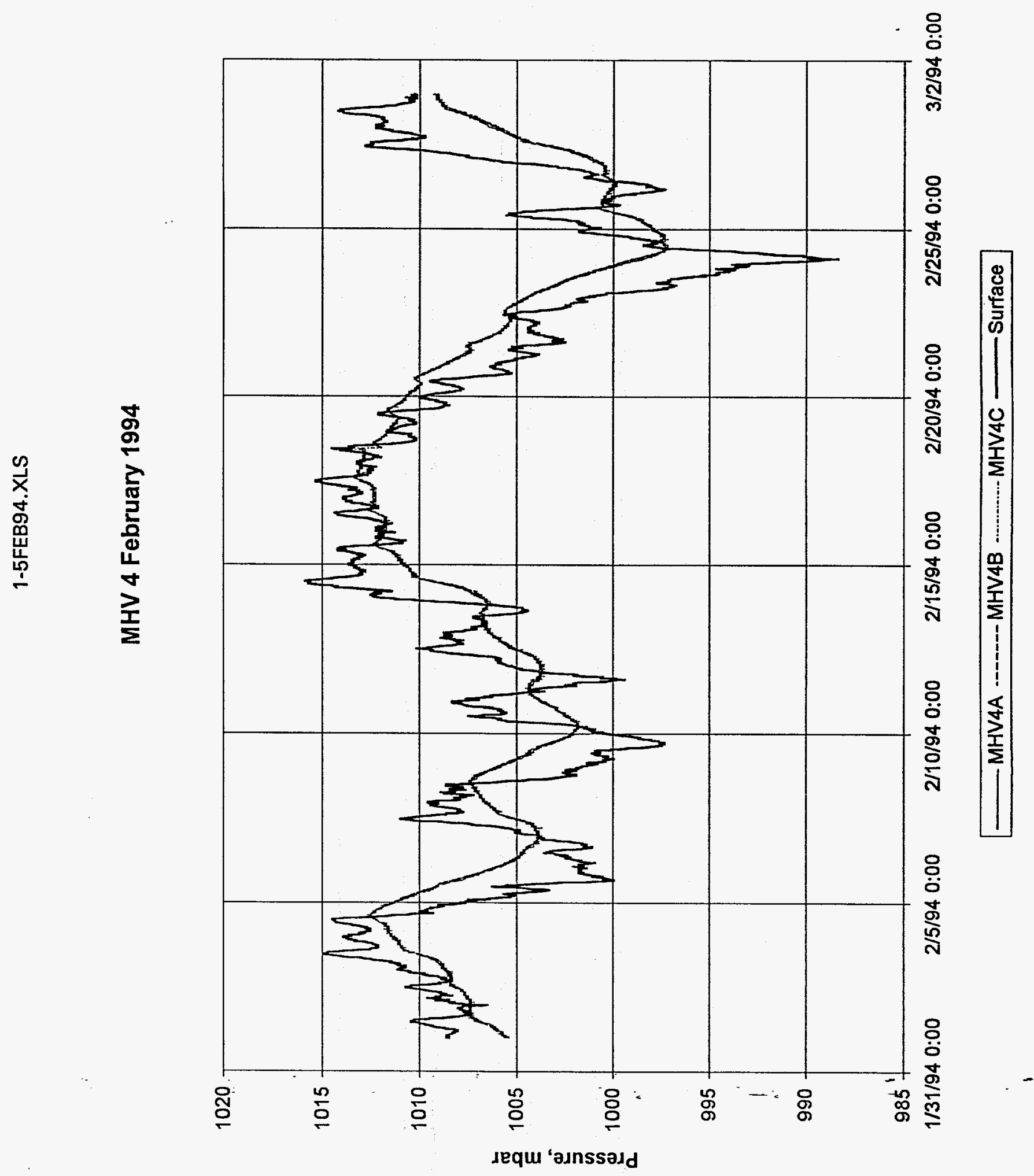




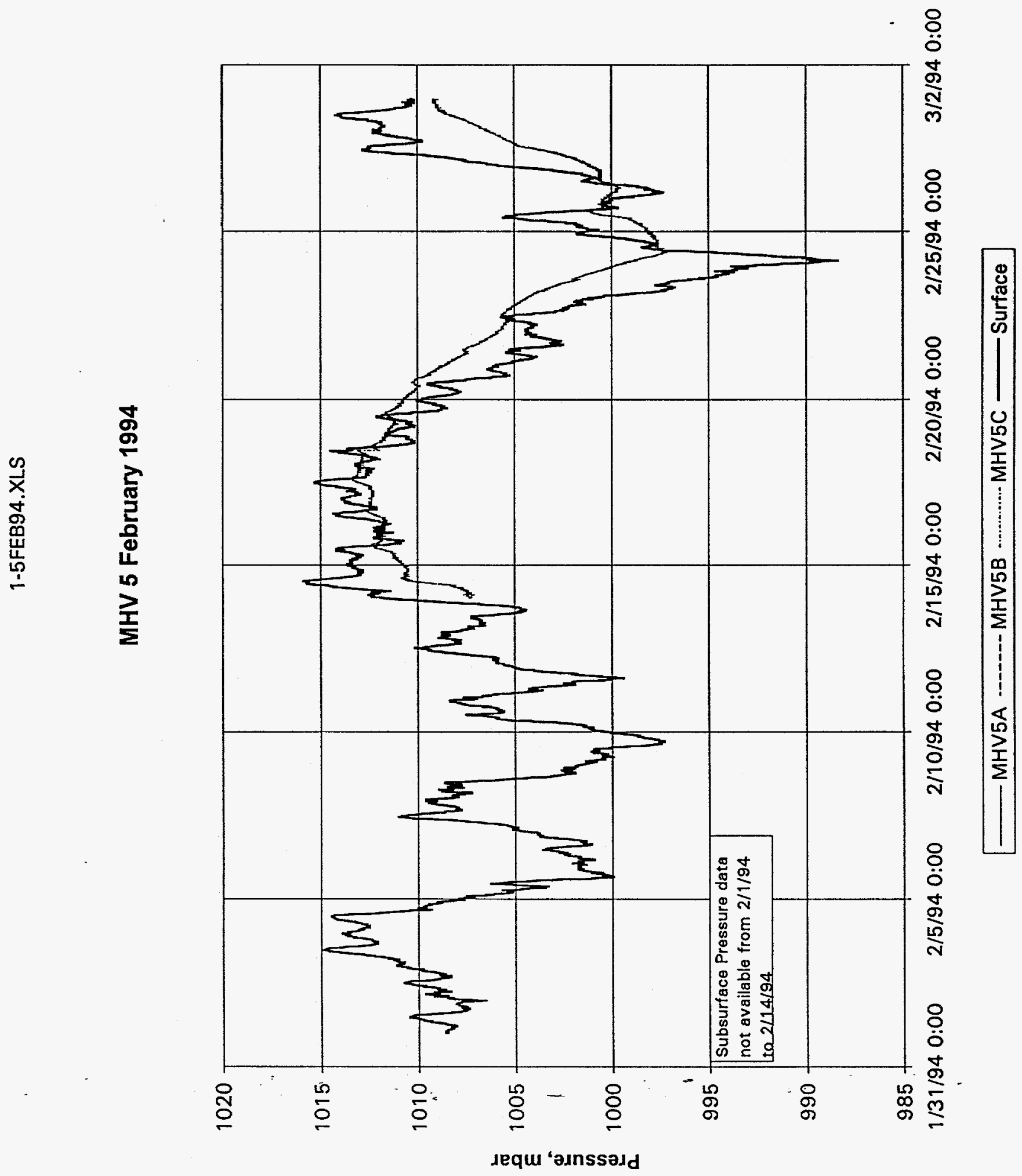




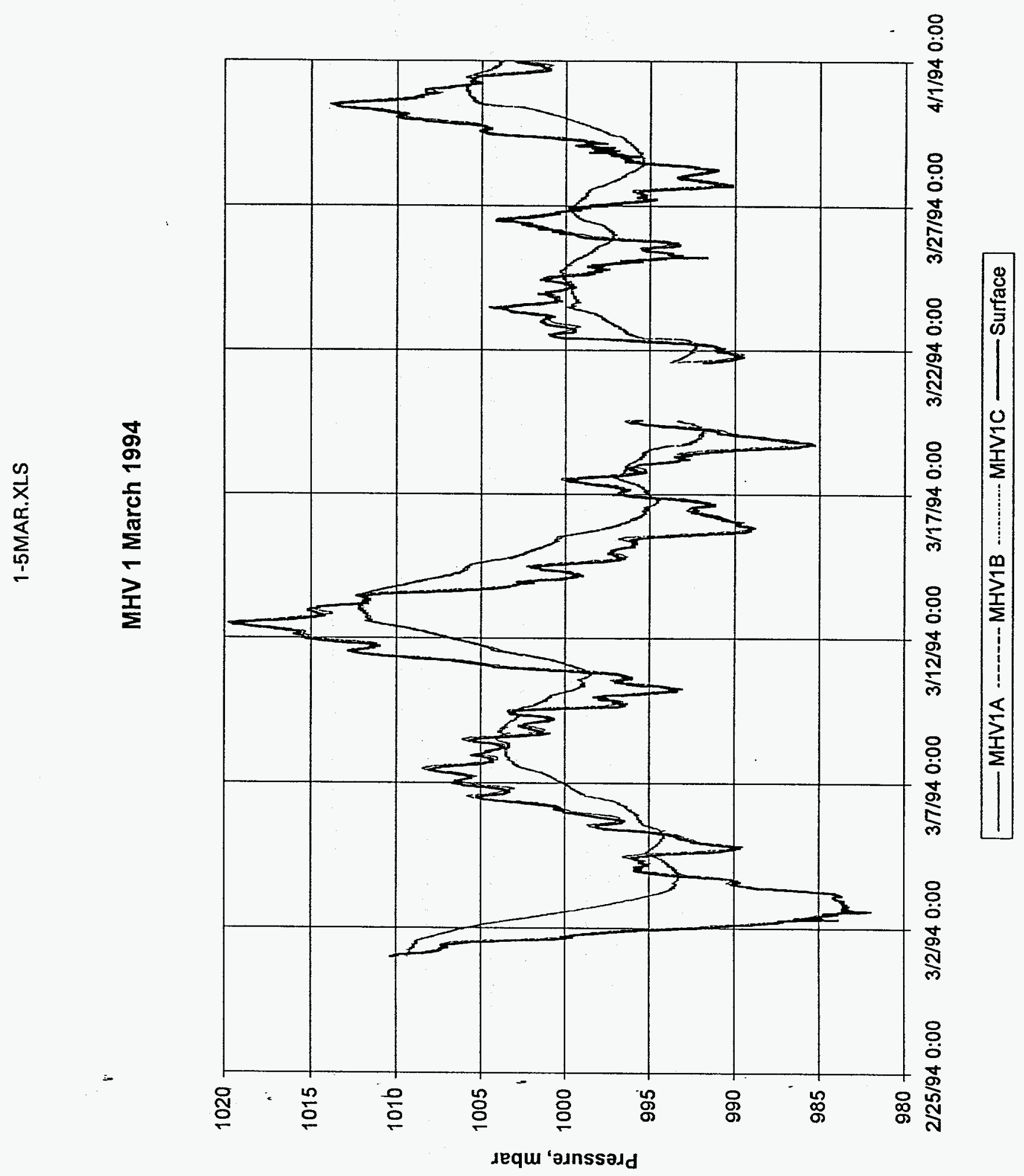




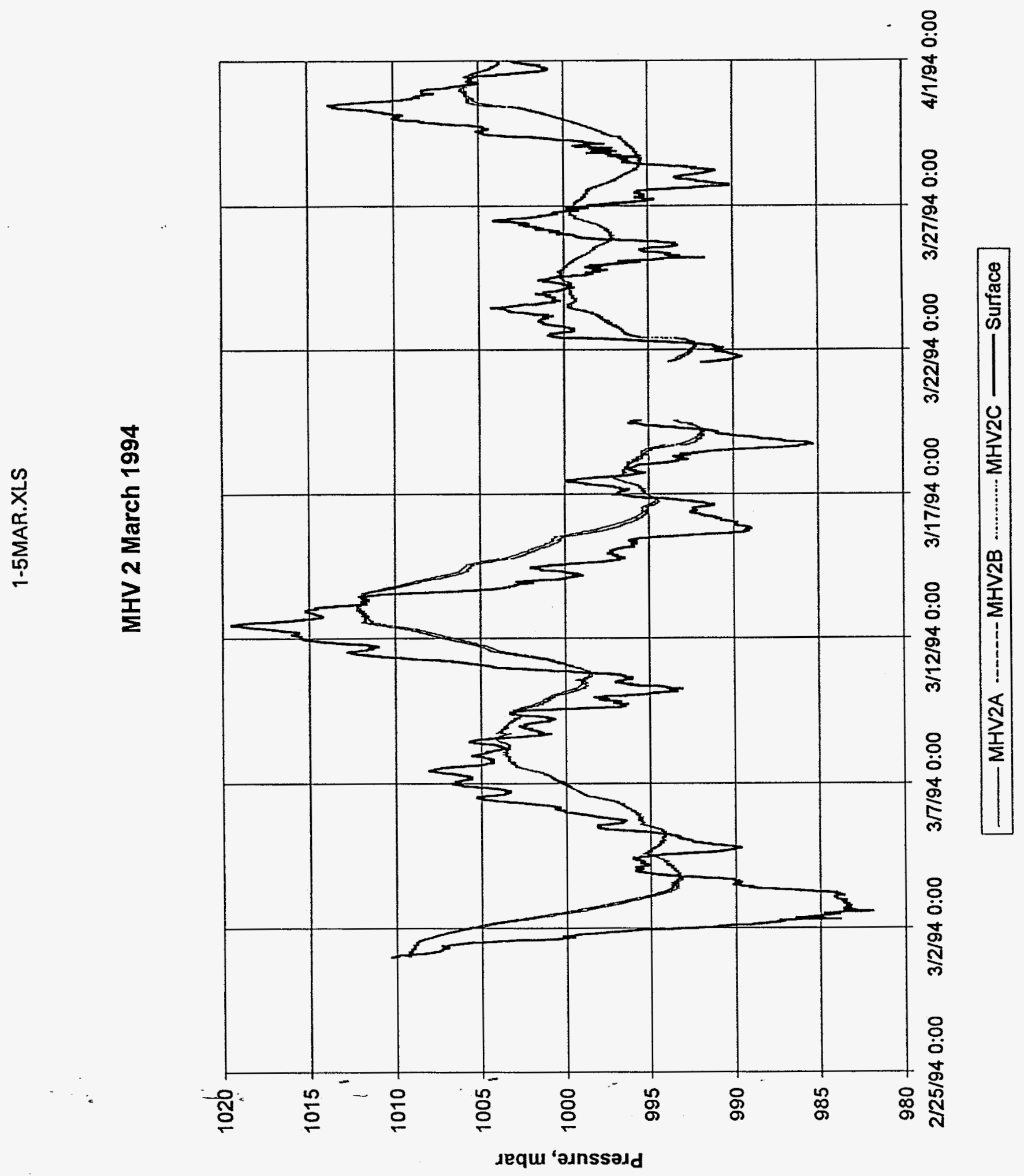




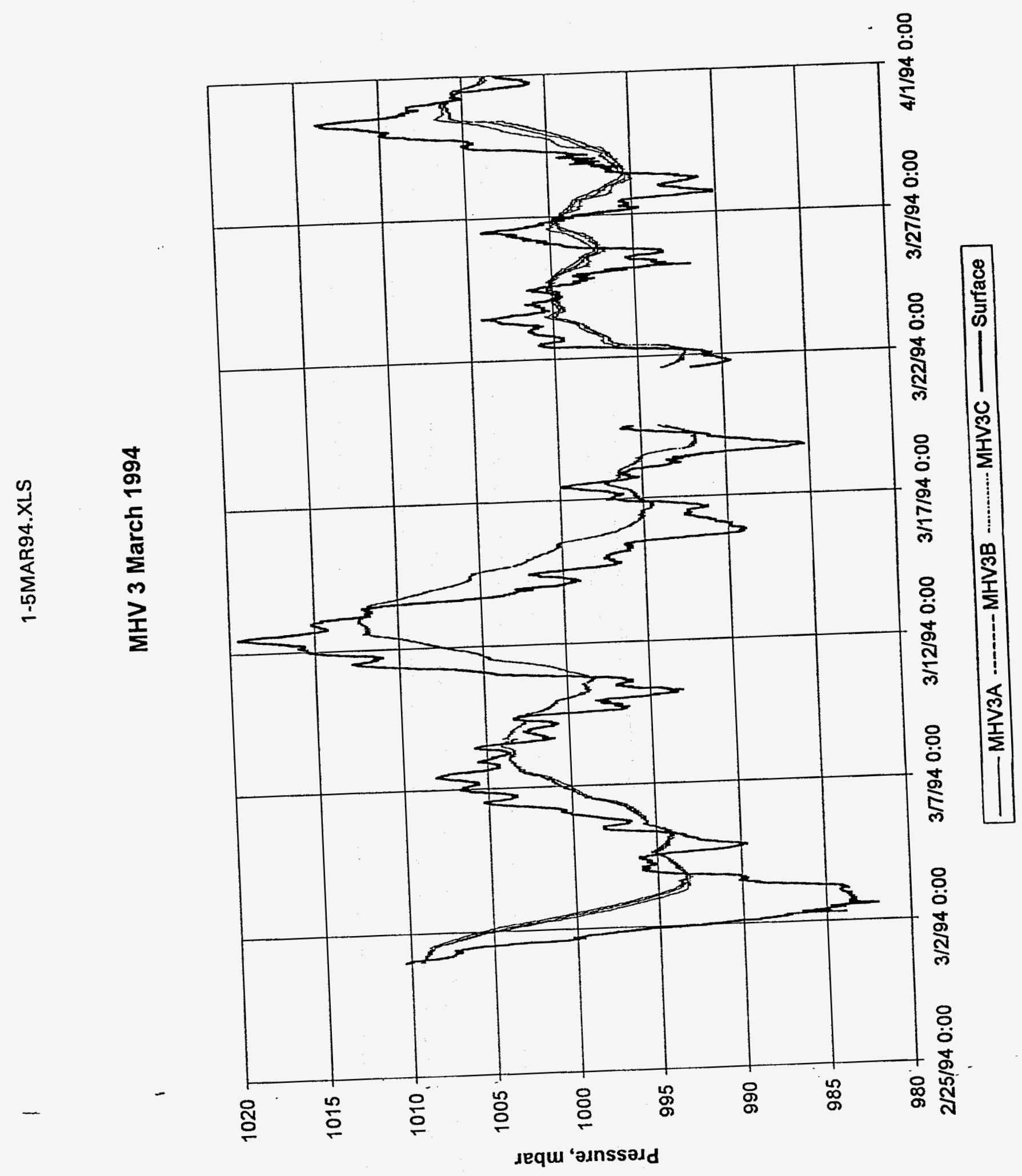




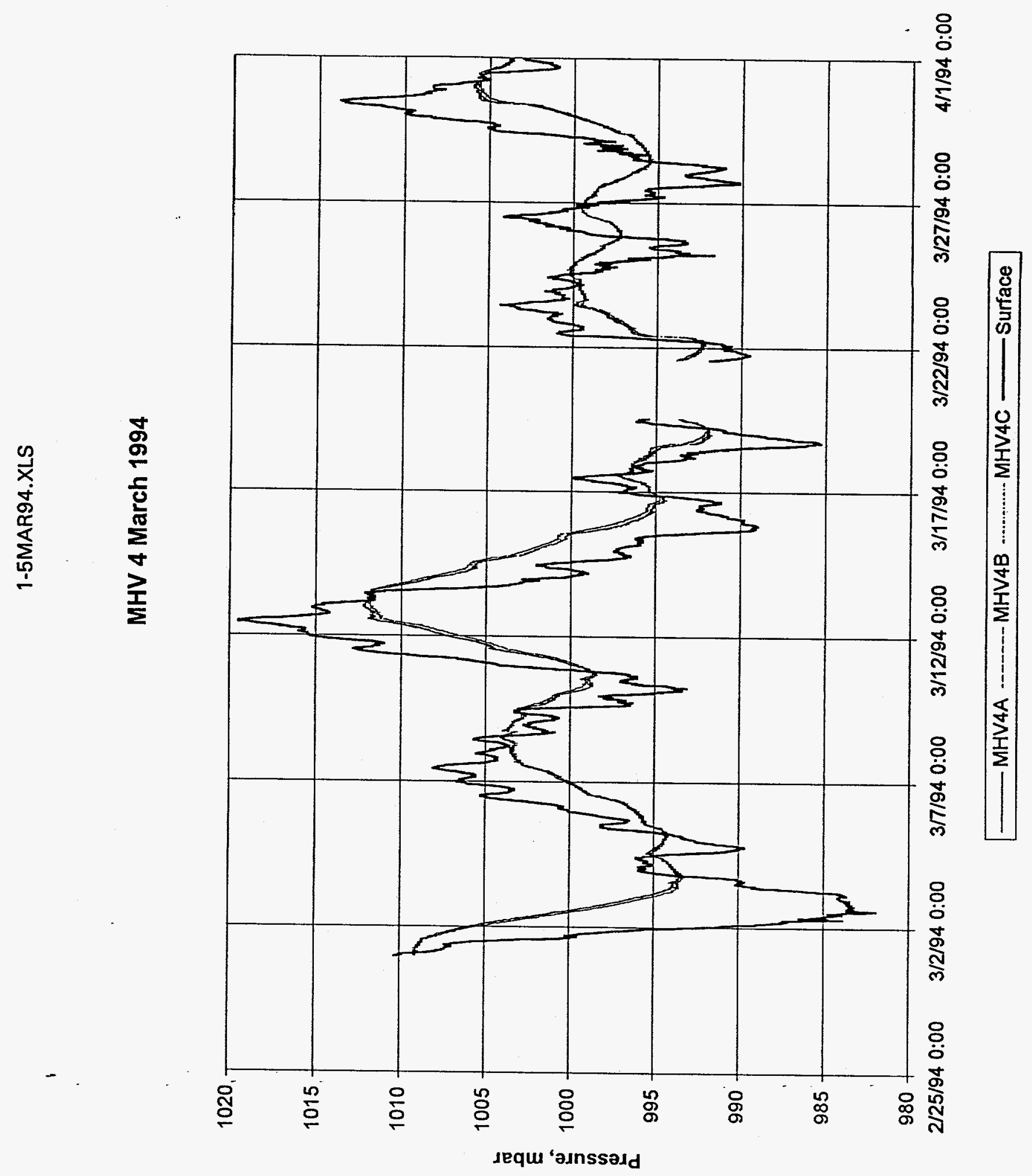




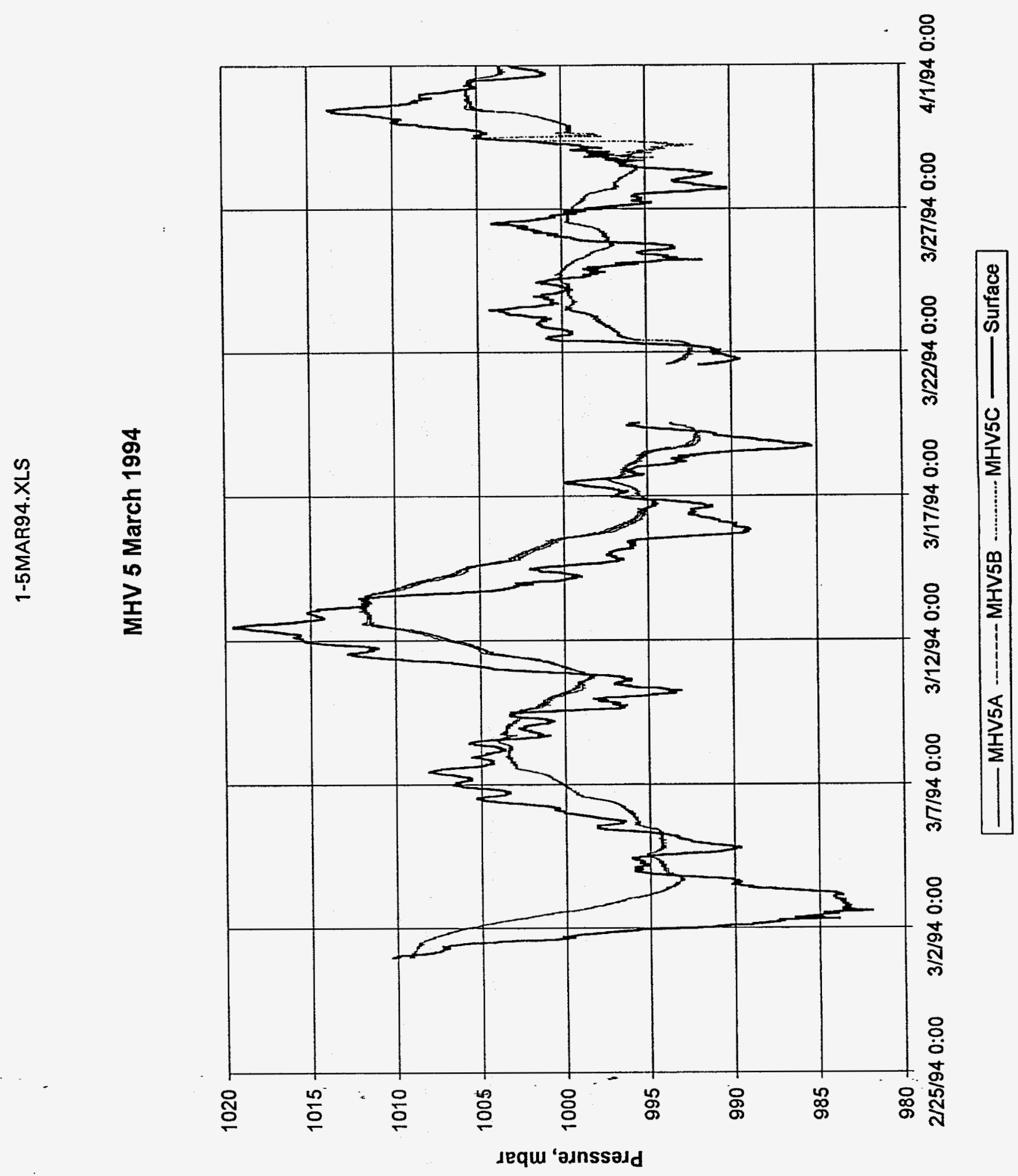




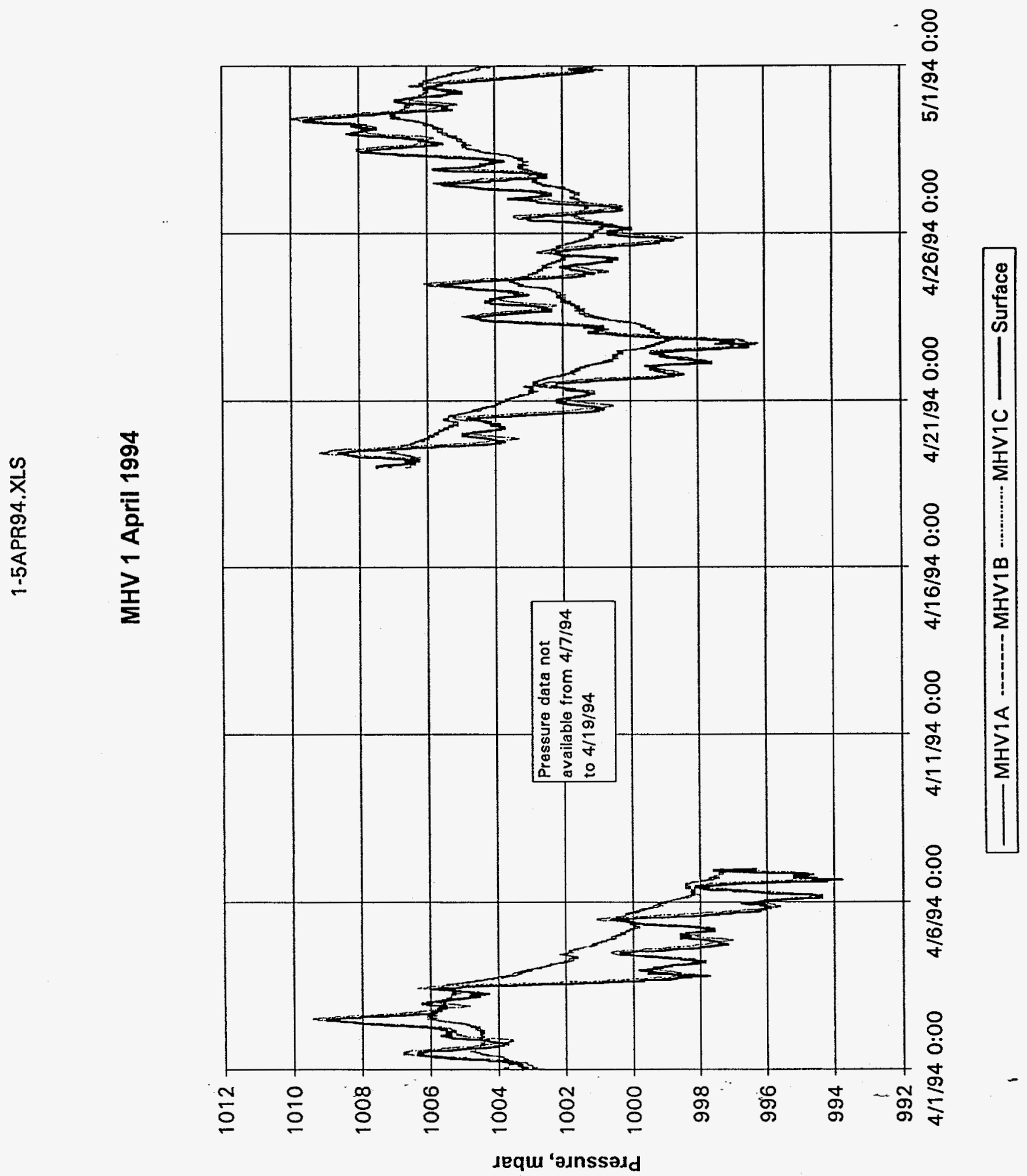




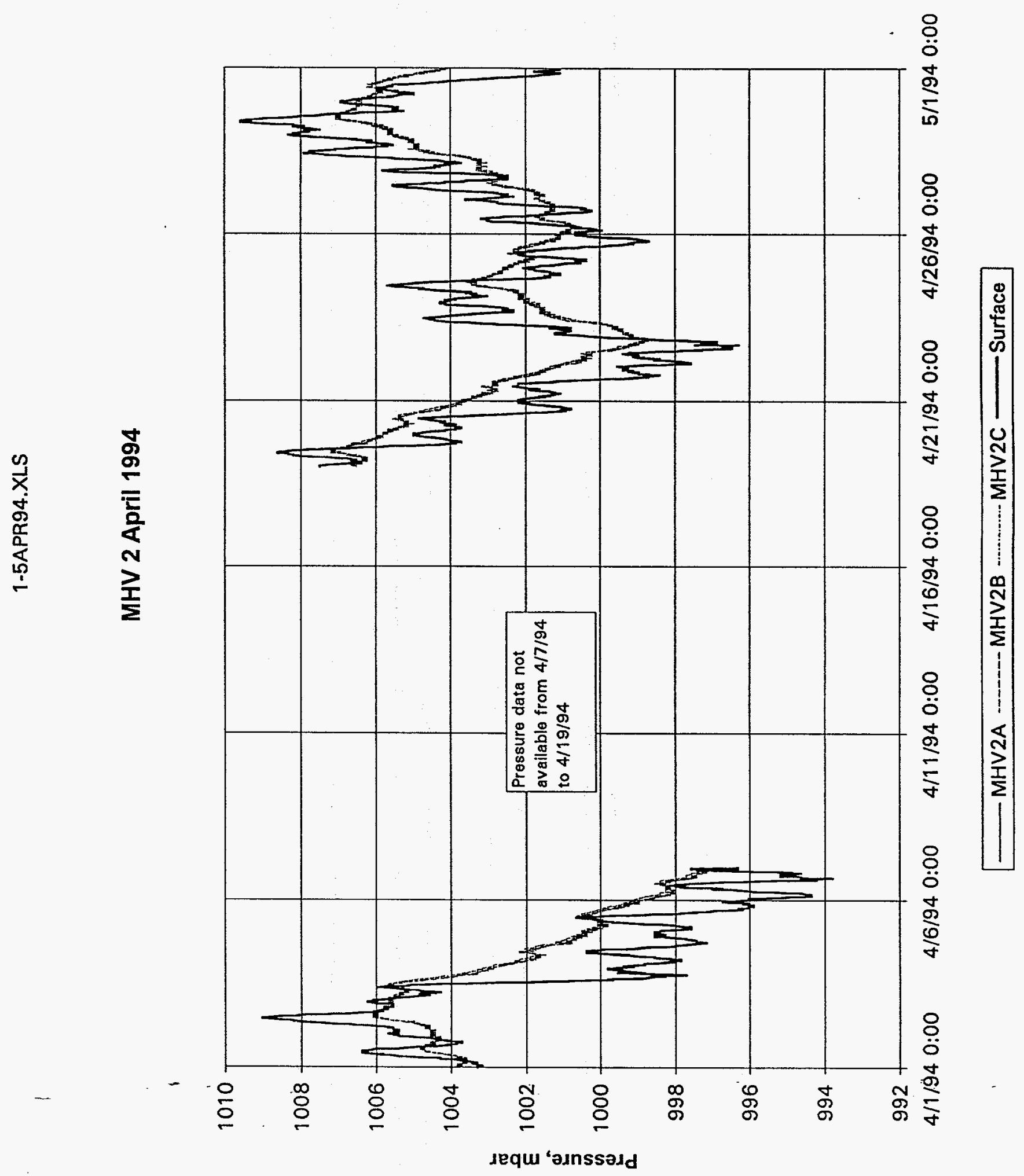




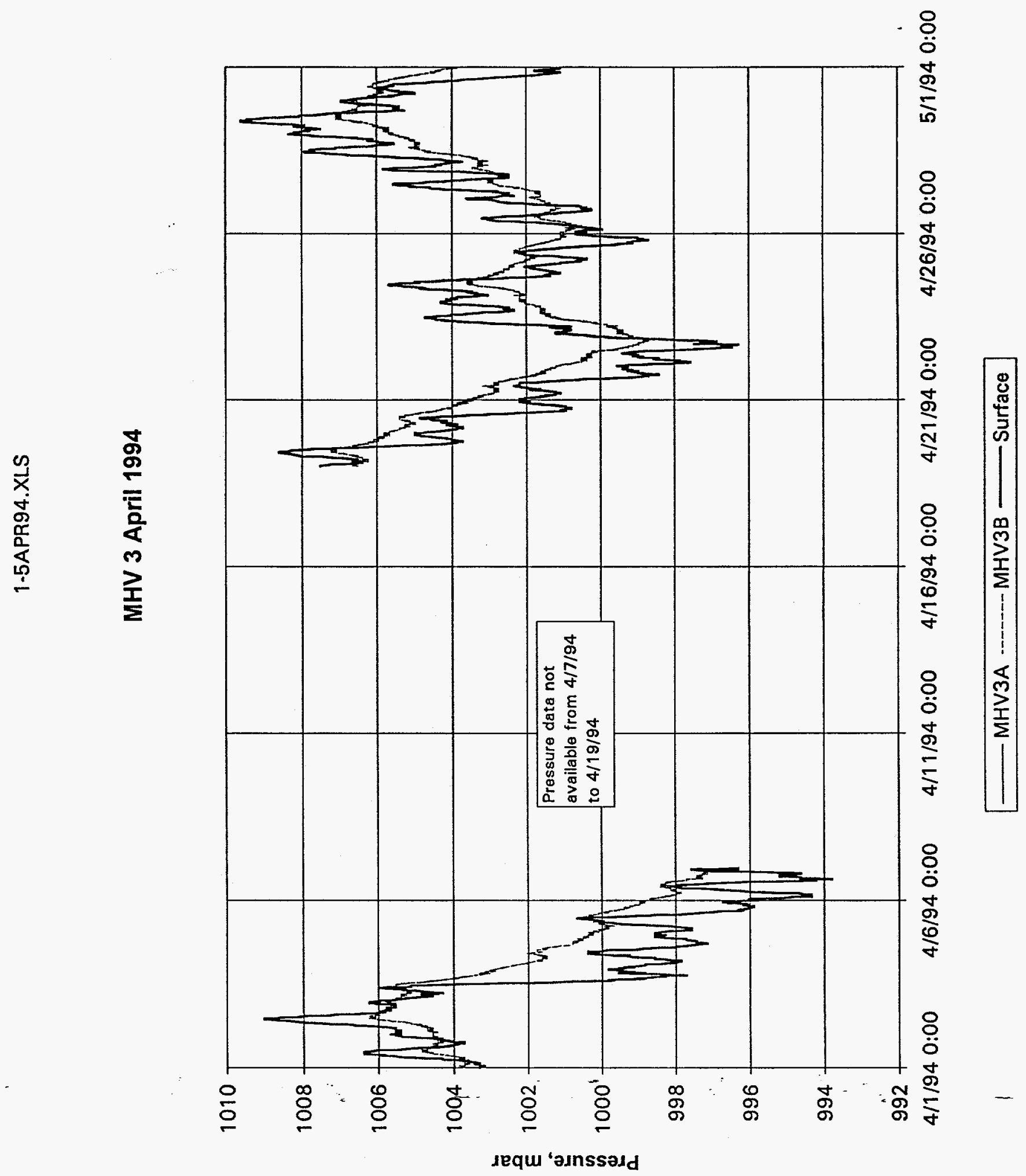




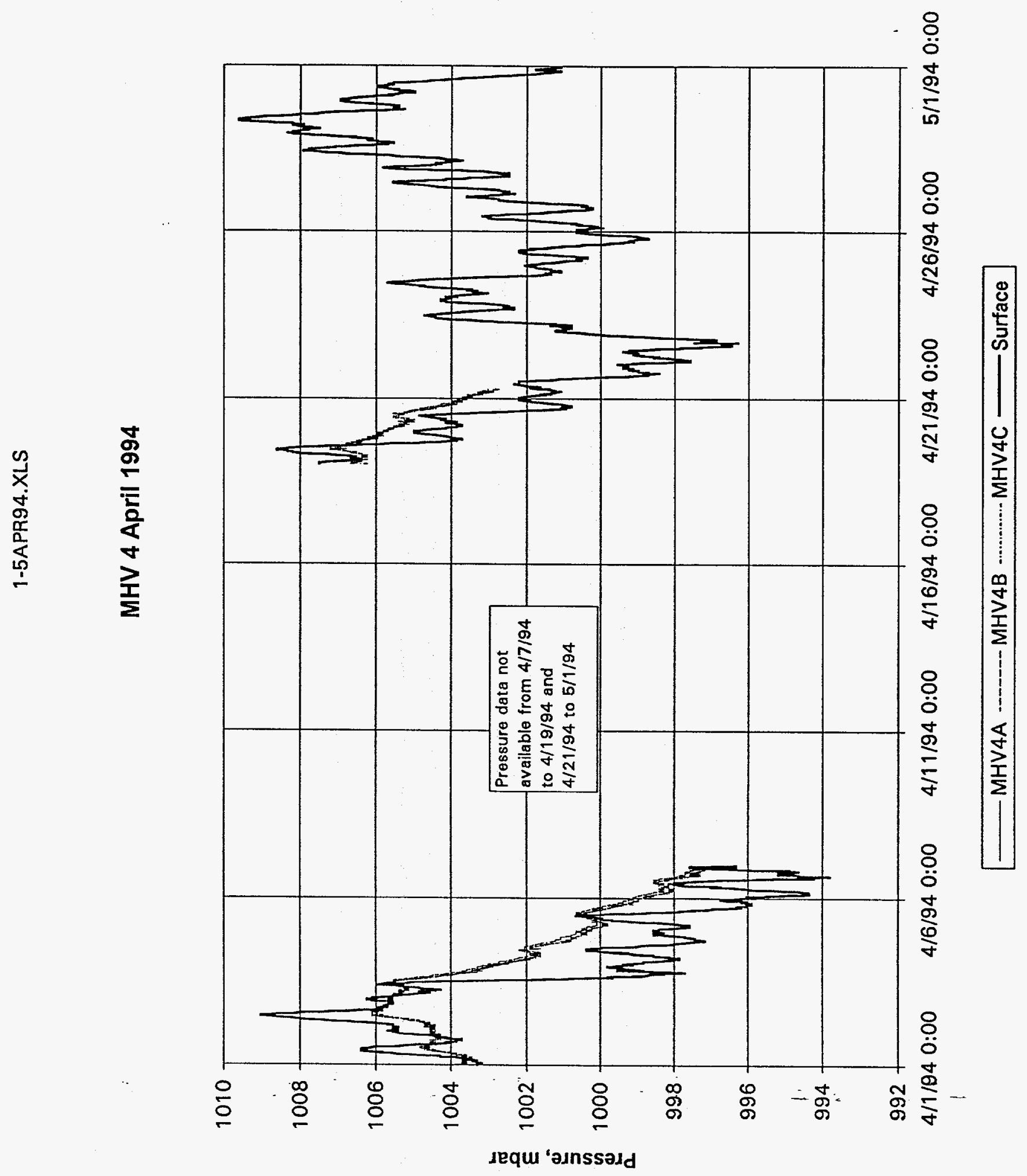




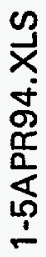

$\frac{8}{8}$
$\frac{8}{2}$
$\frac{2}{4}$
$\frac{1}{5}$

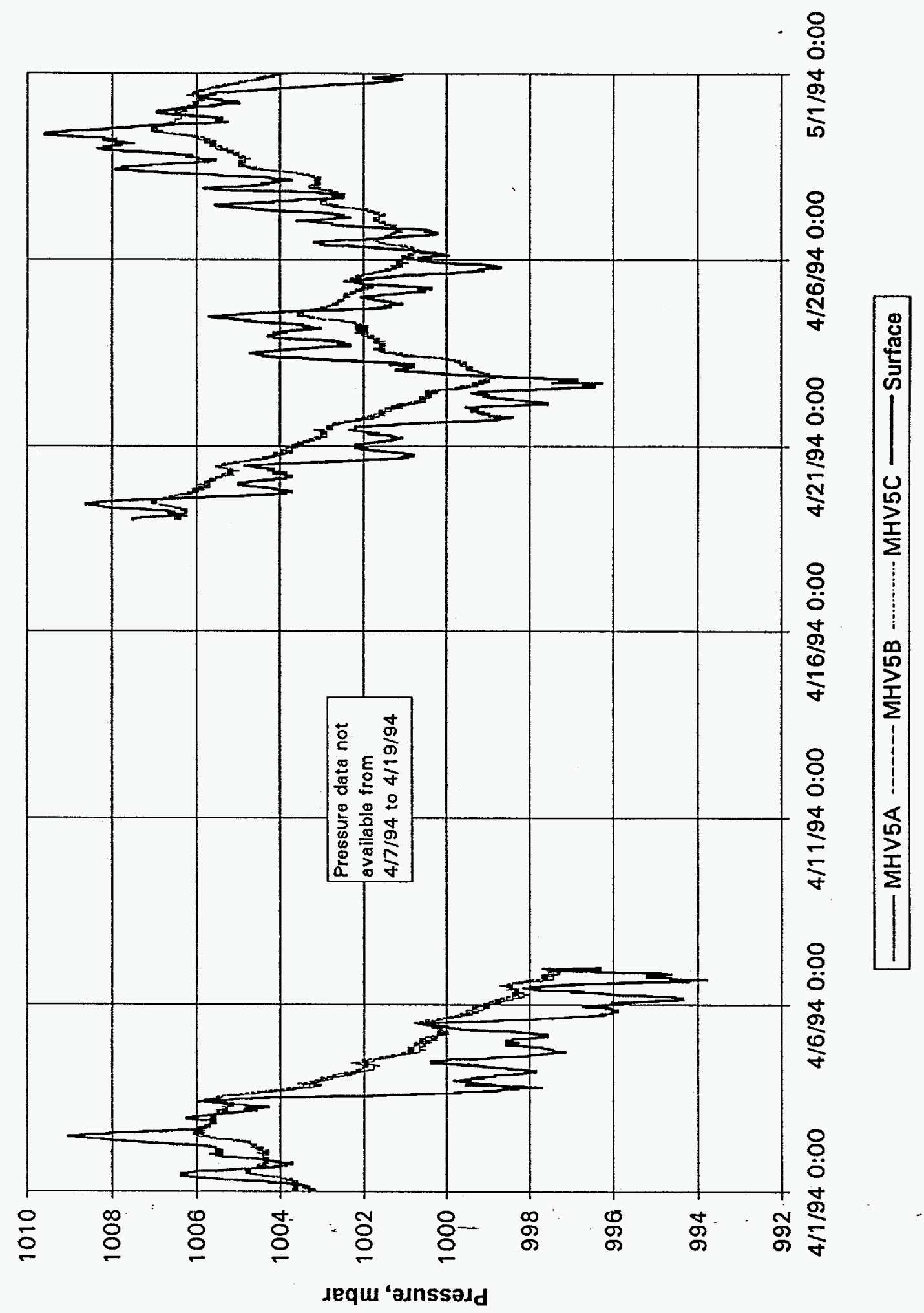




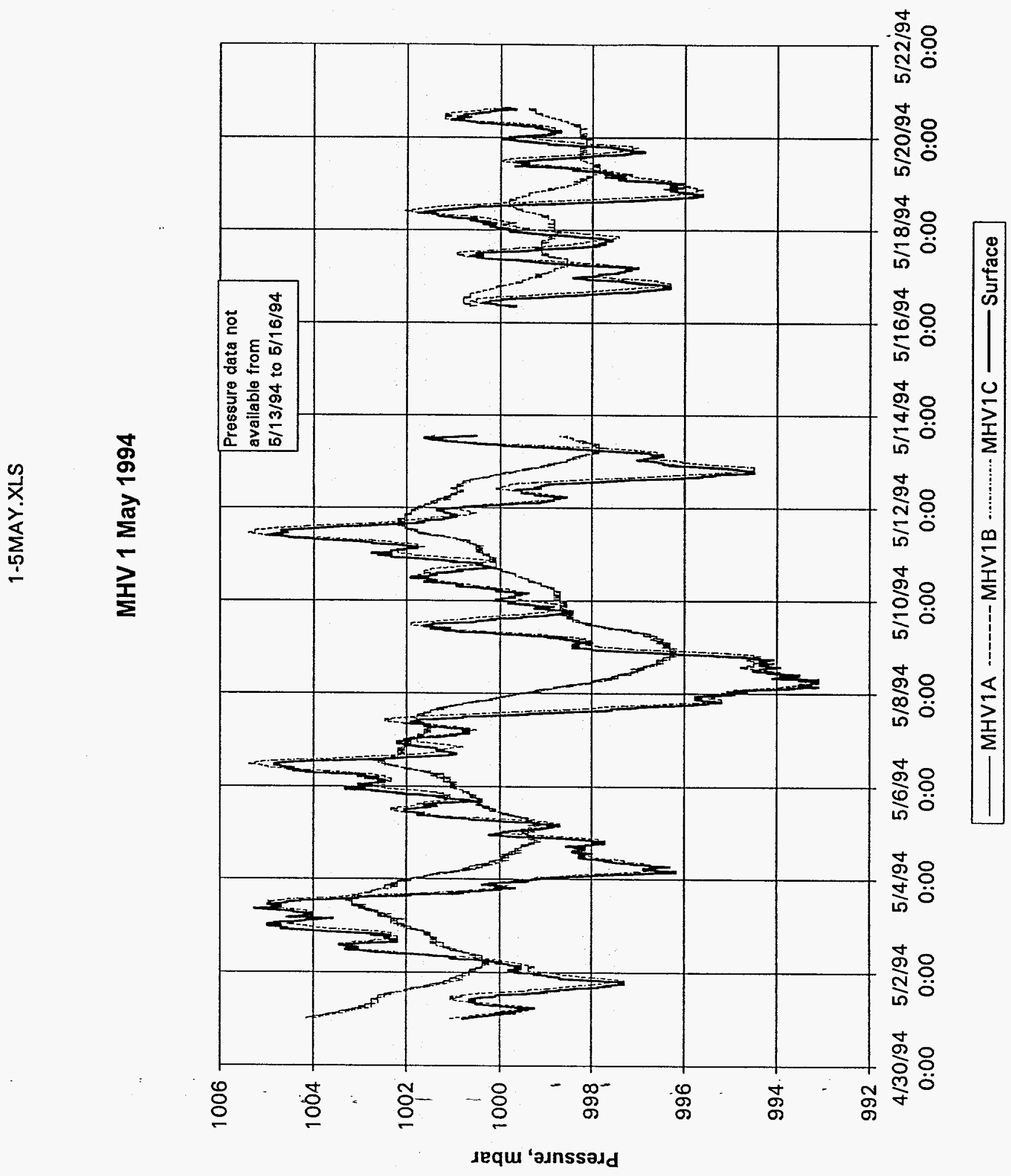



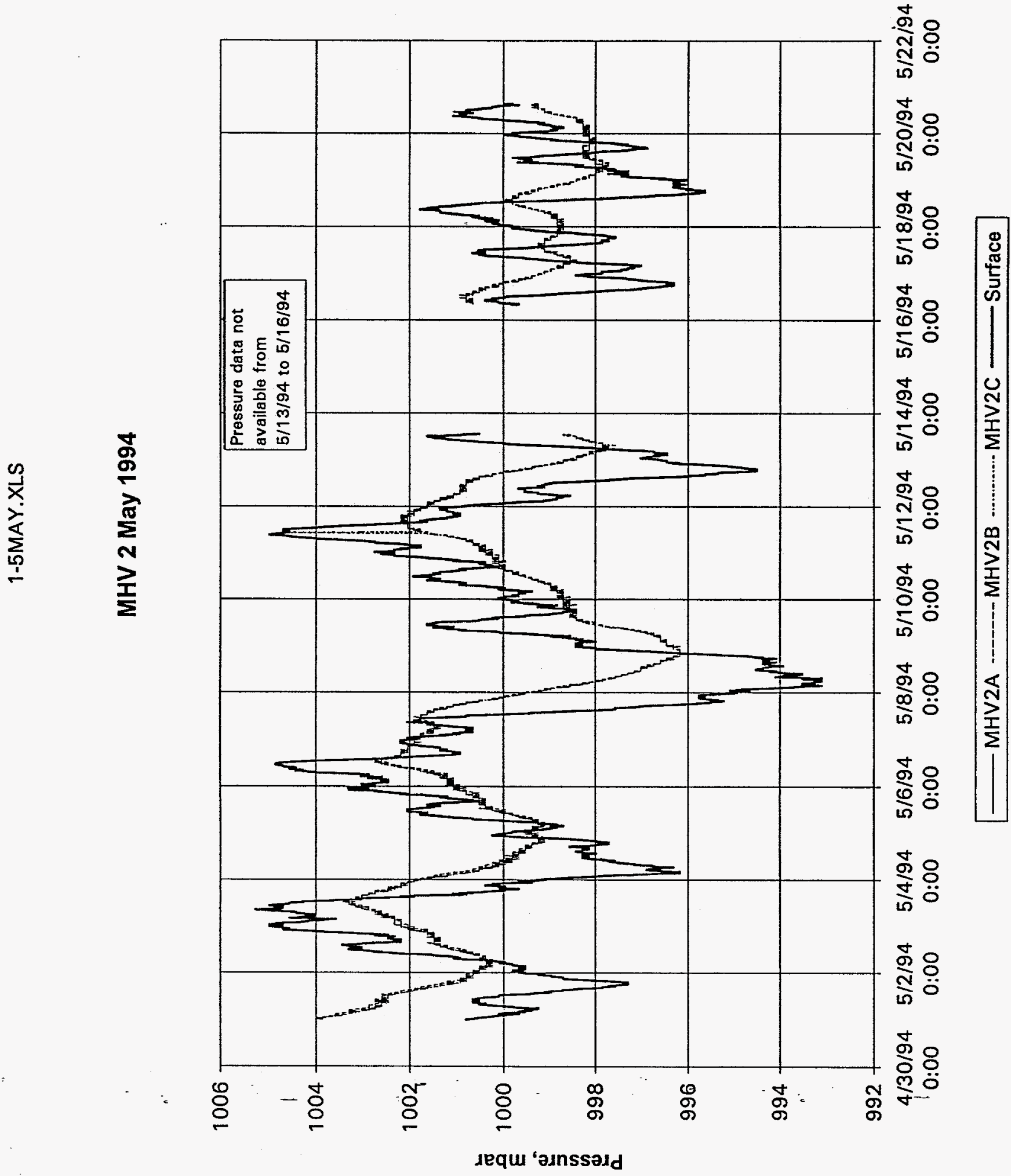


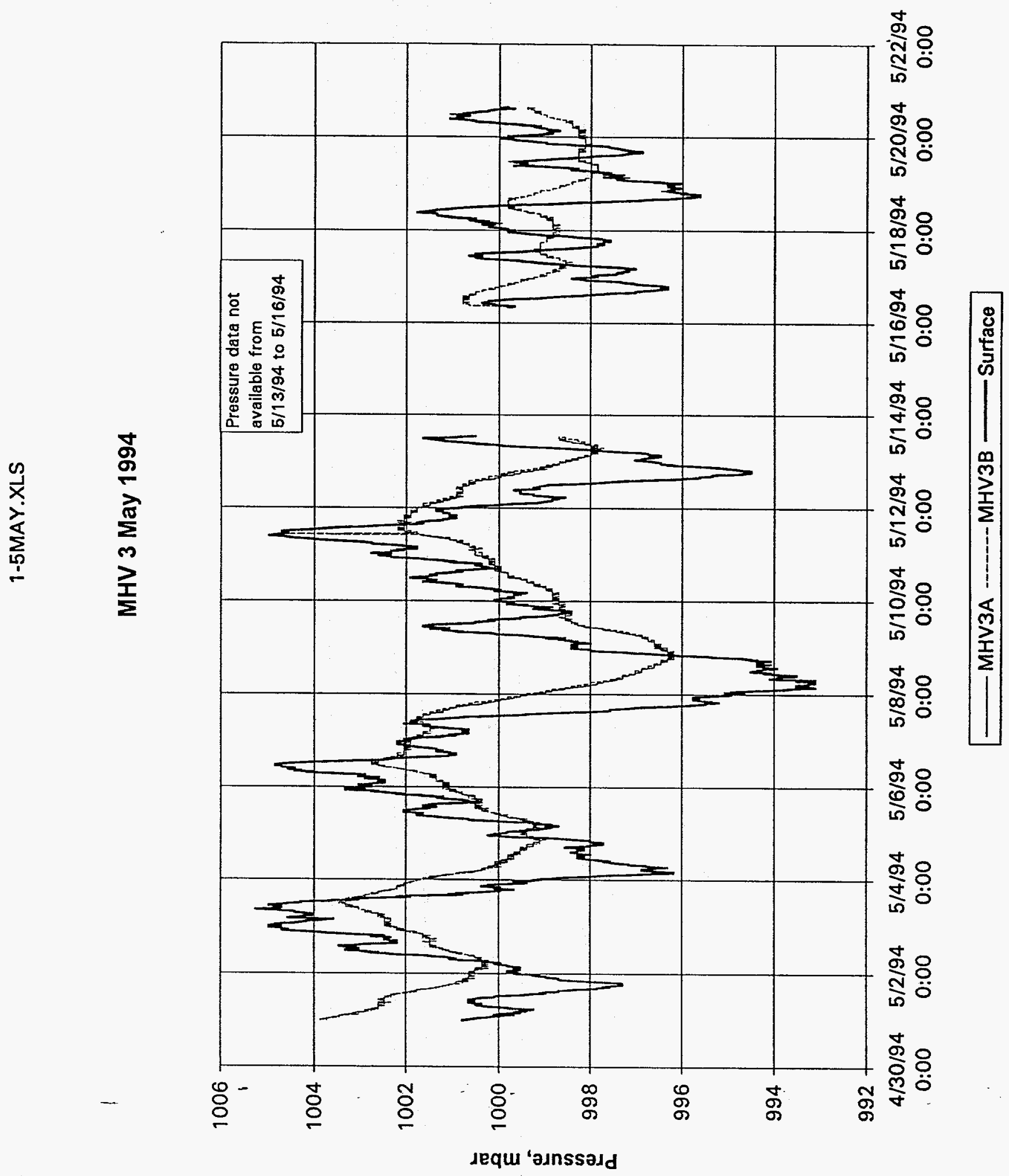




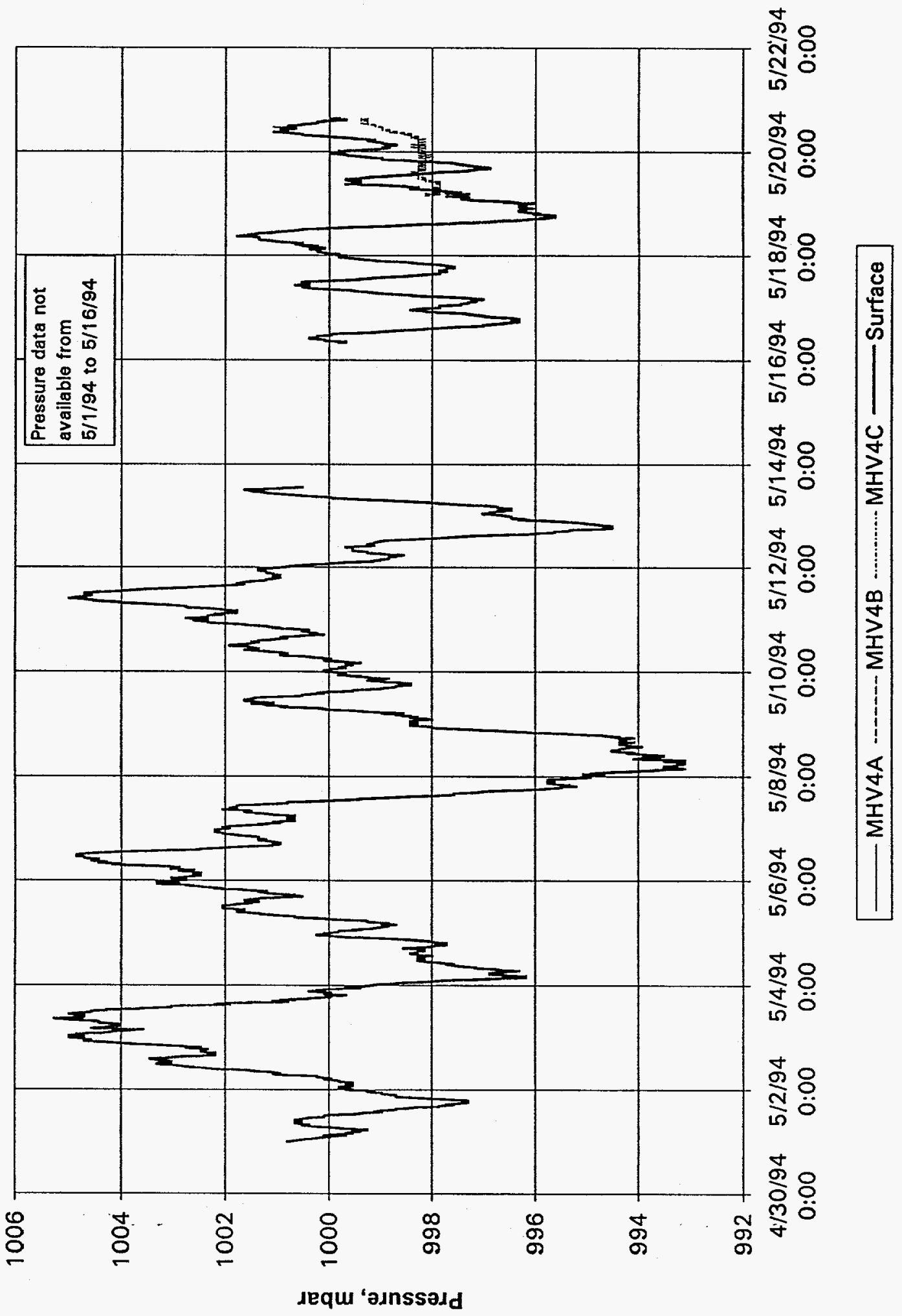



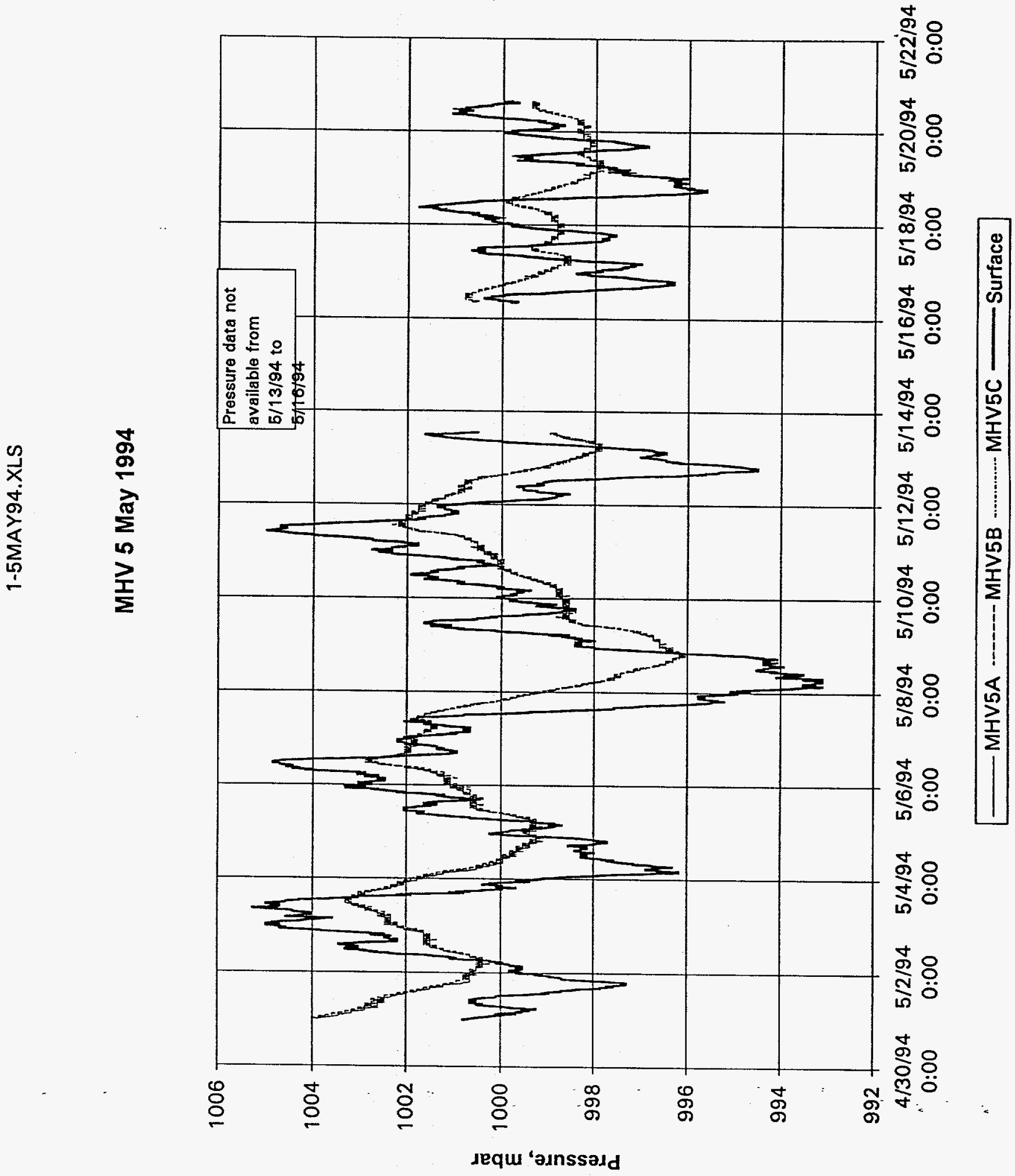


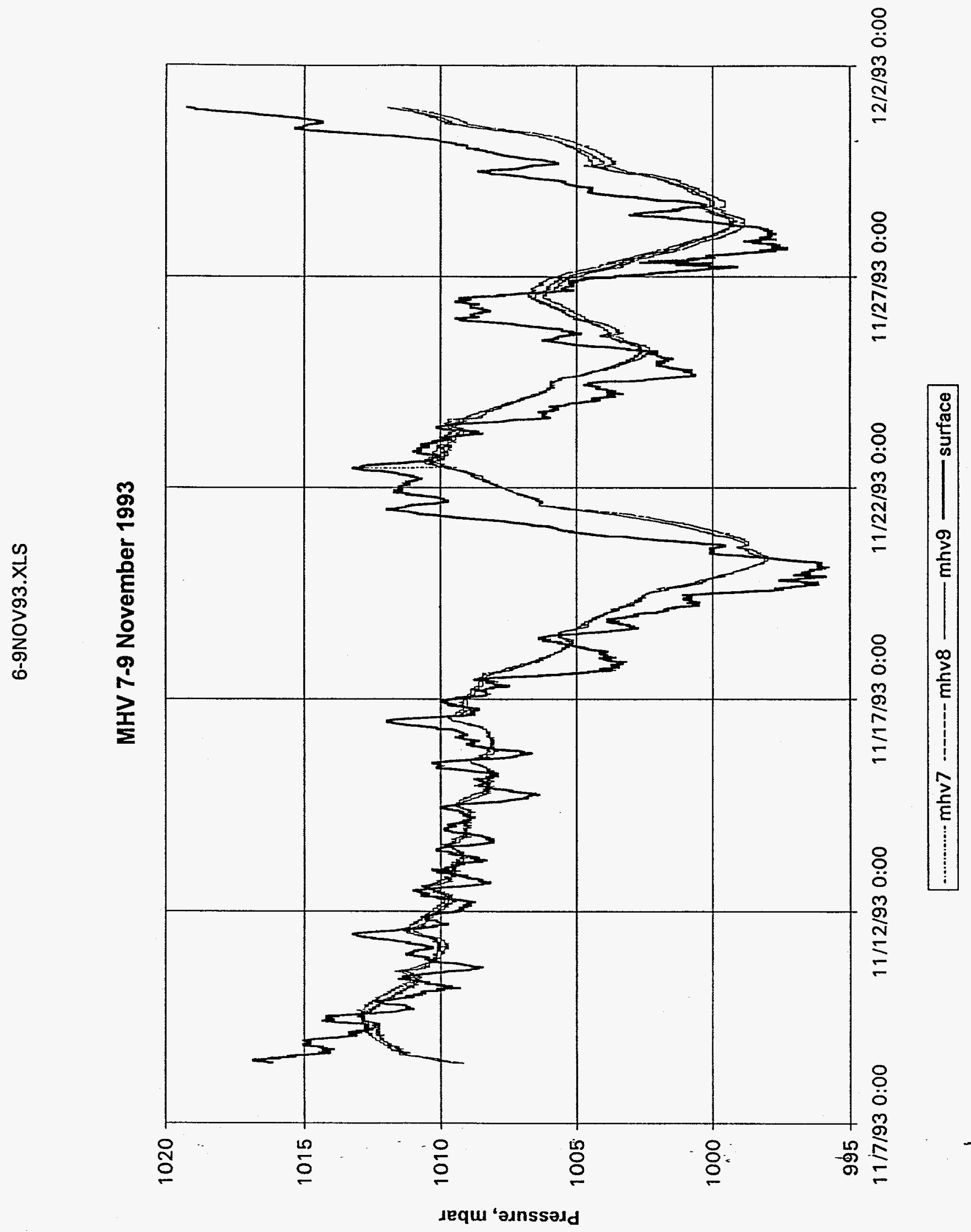




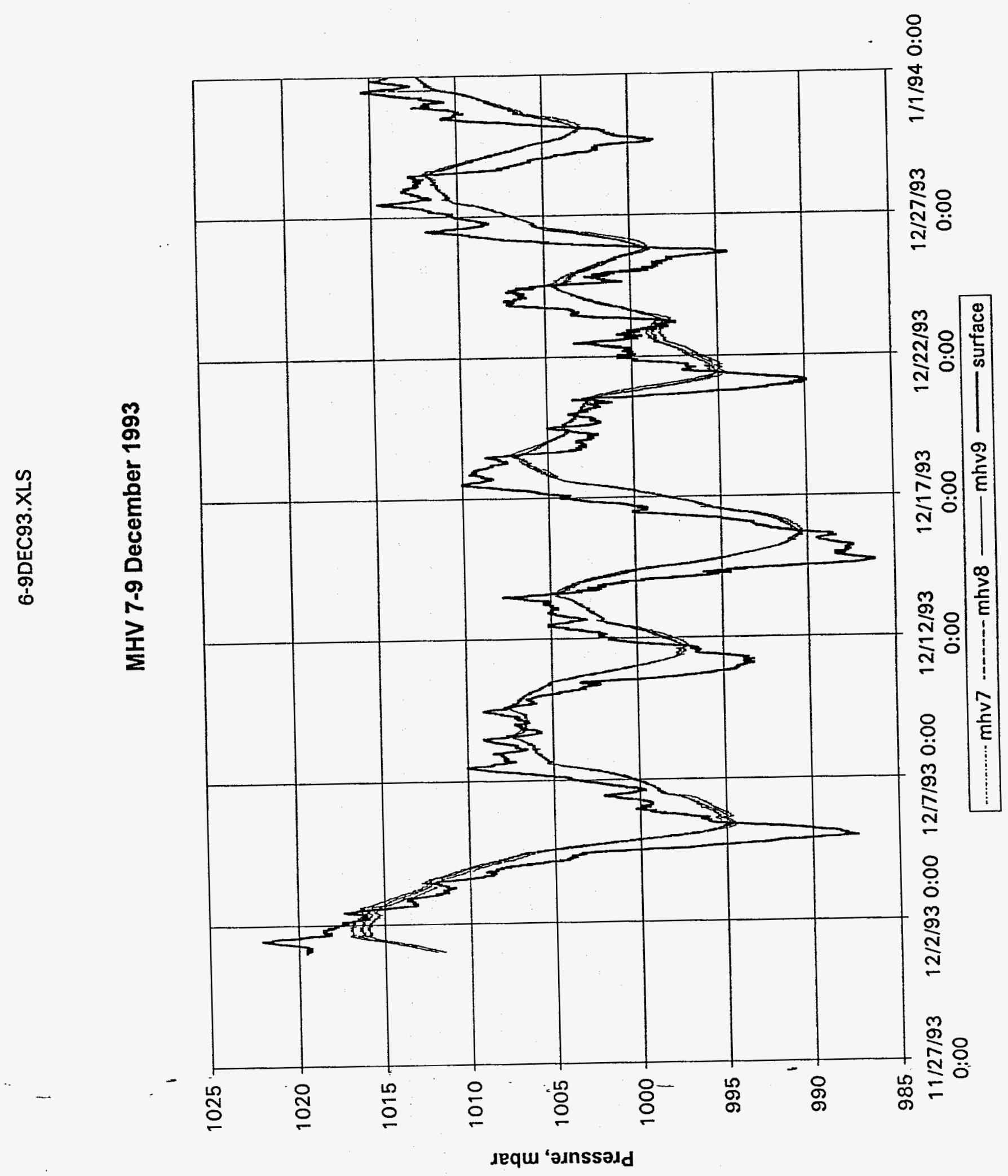




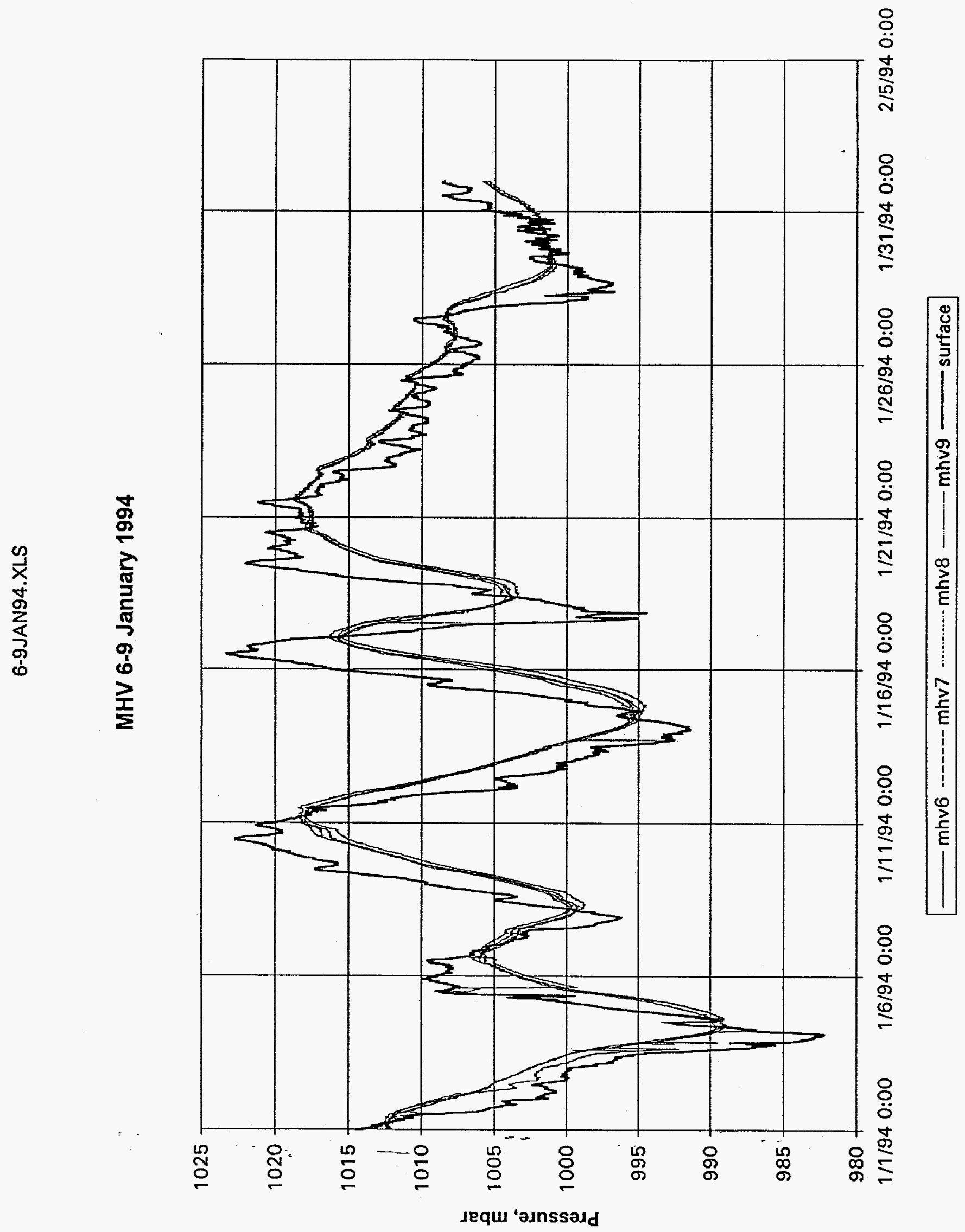




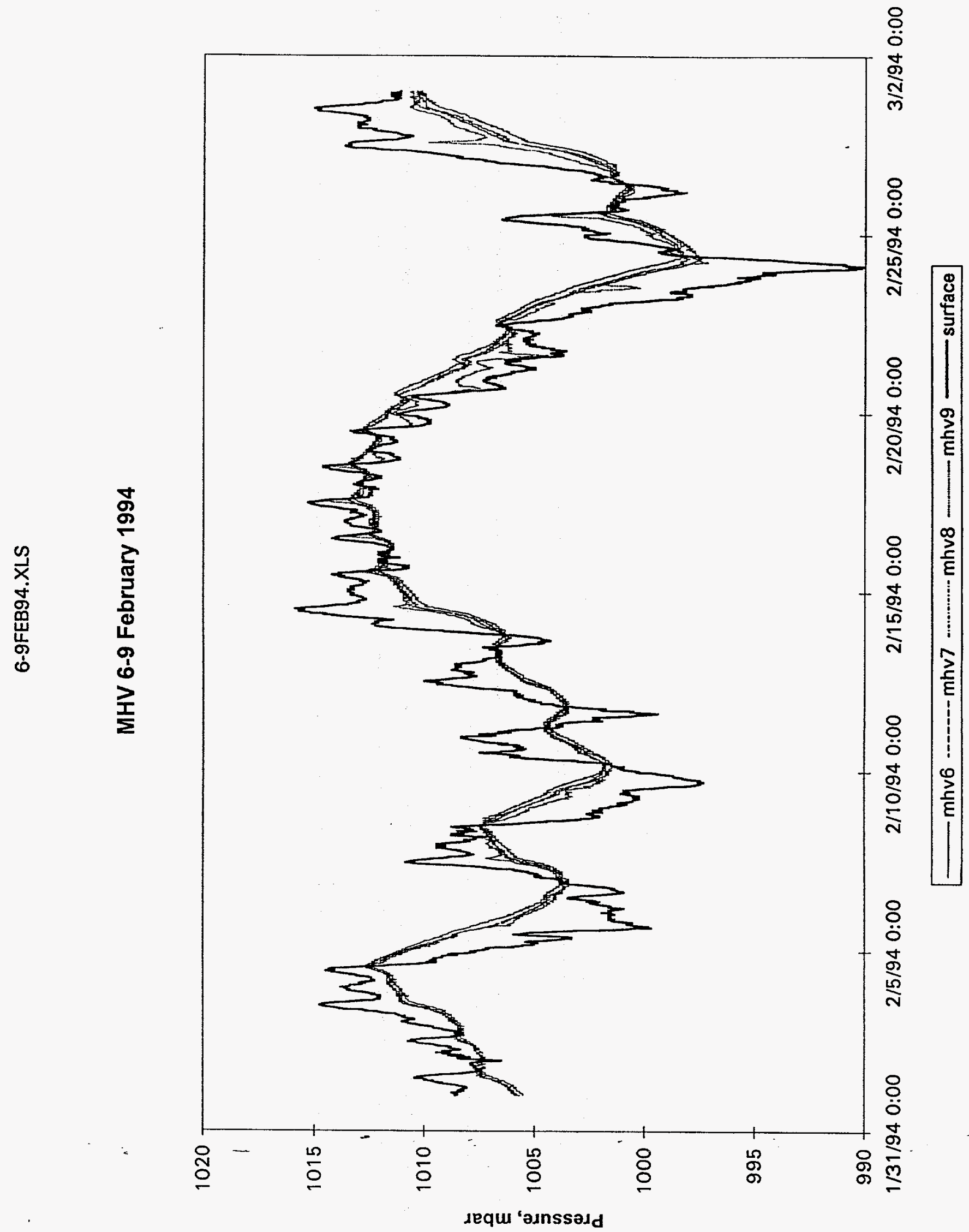




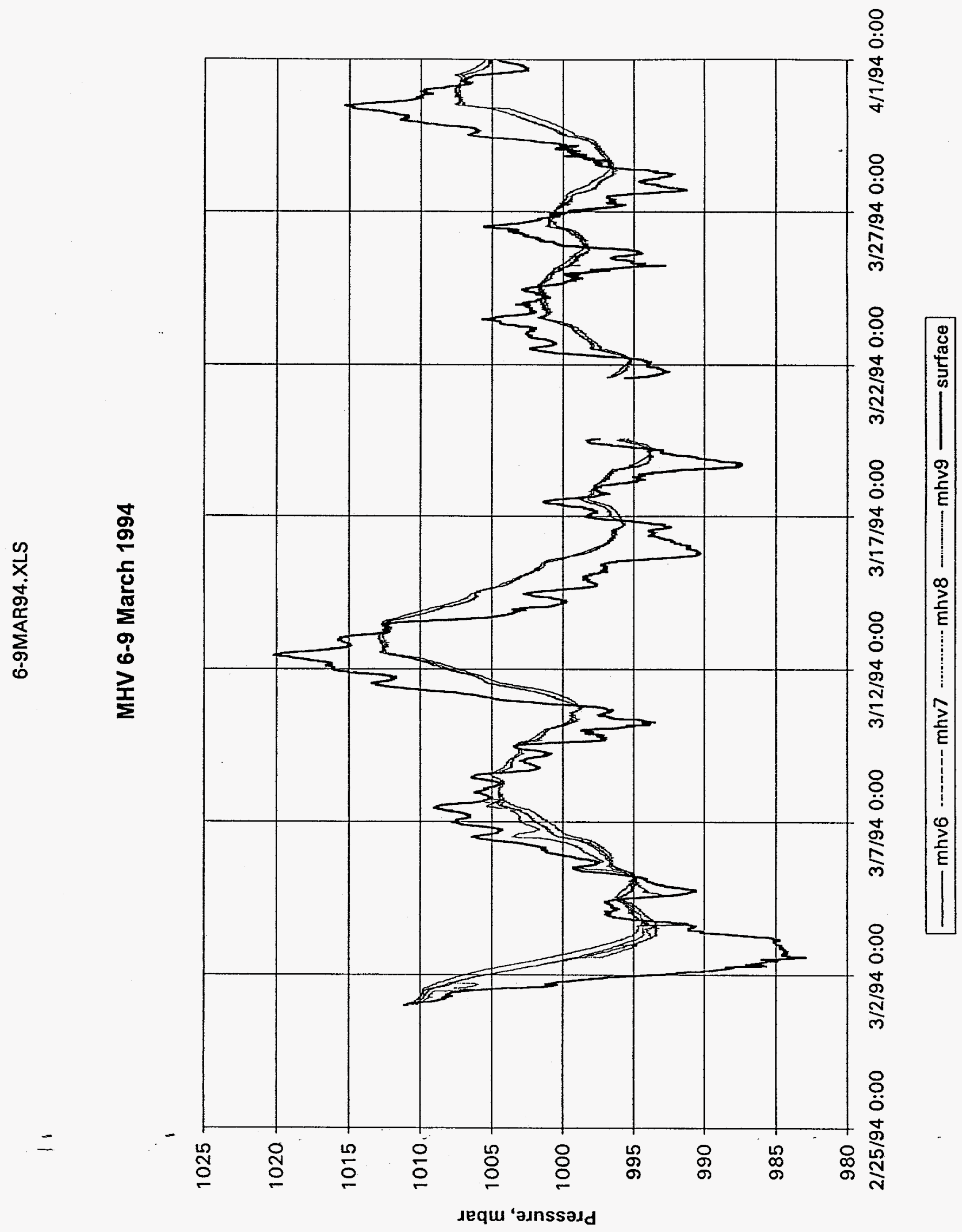




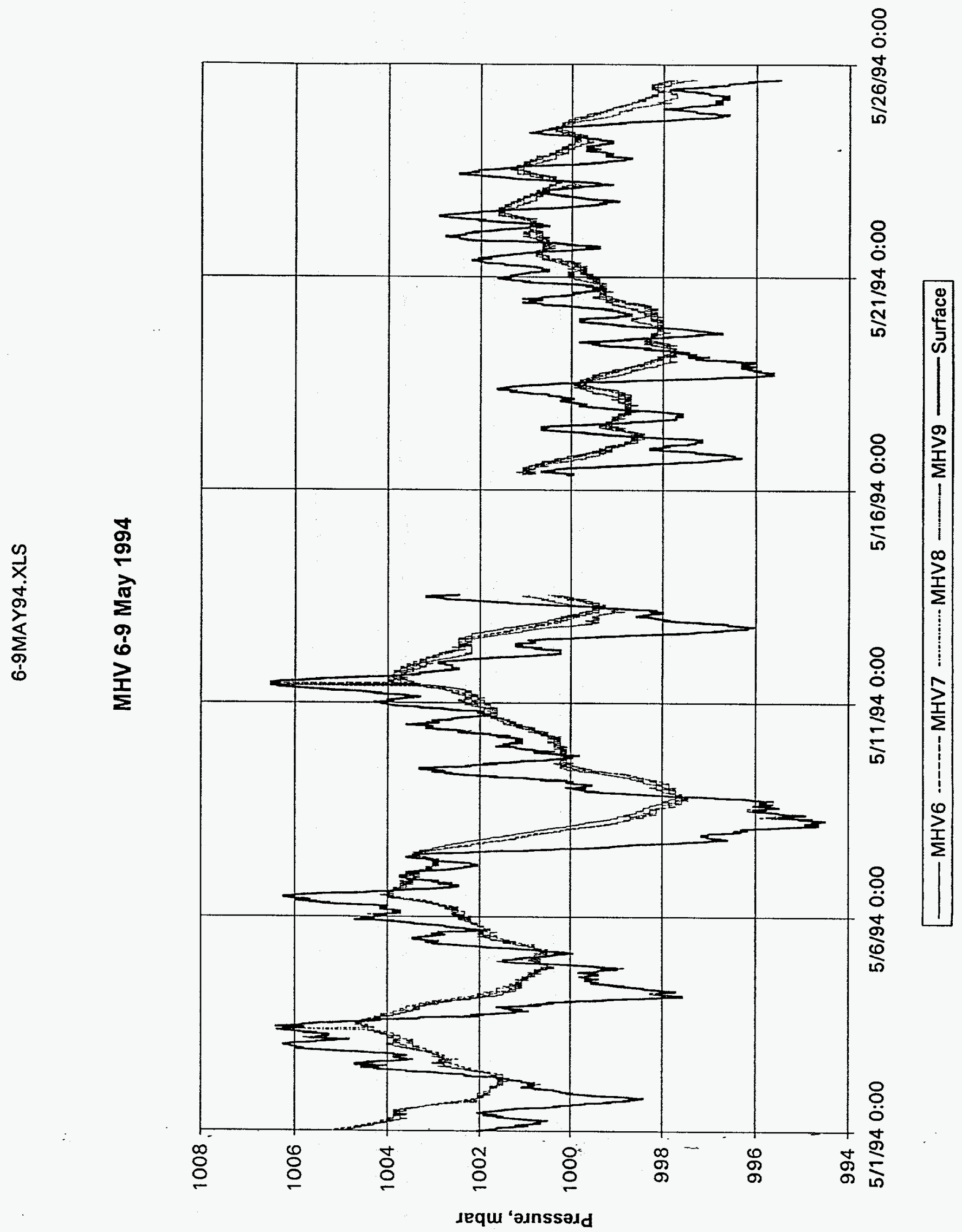




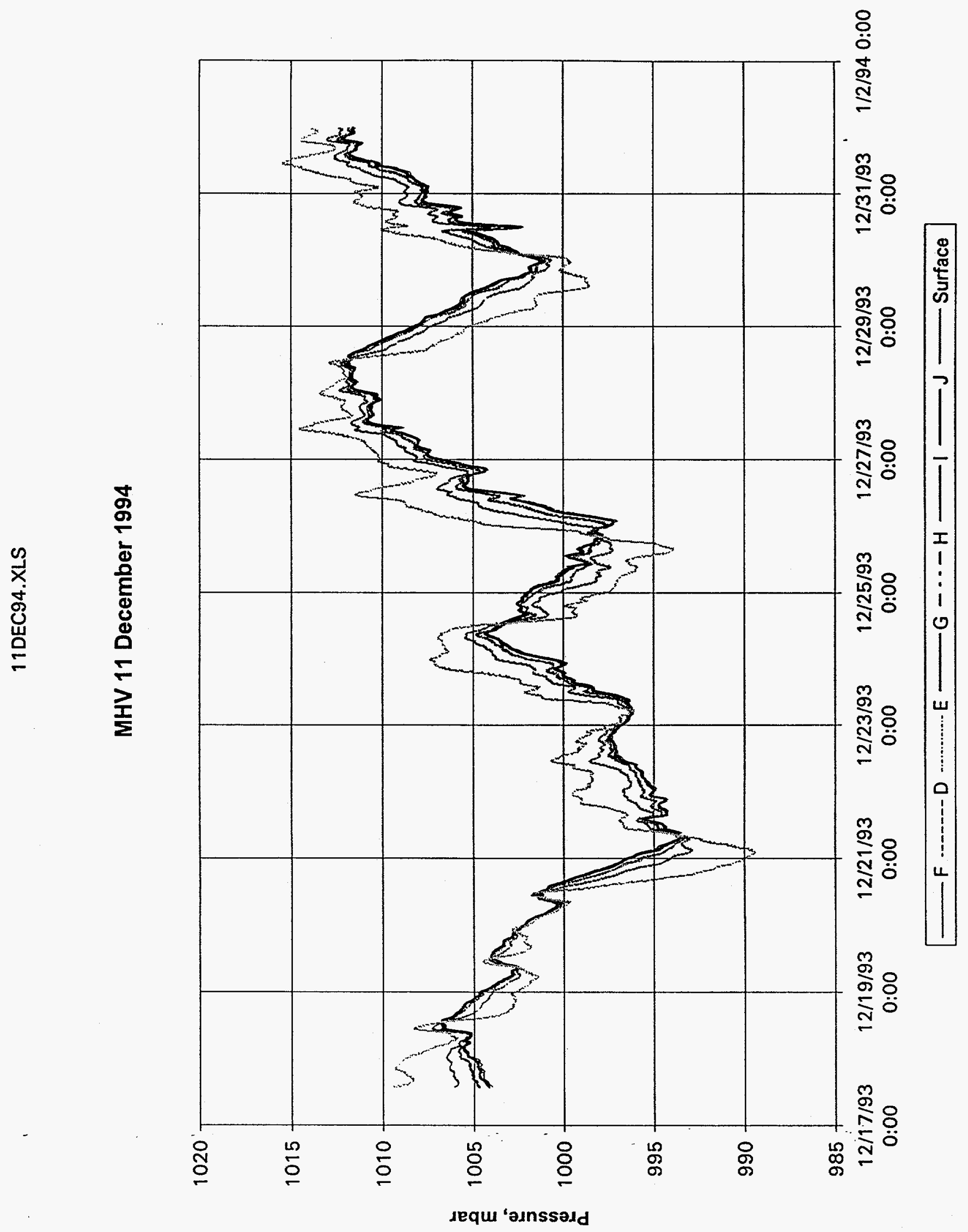




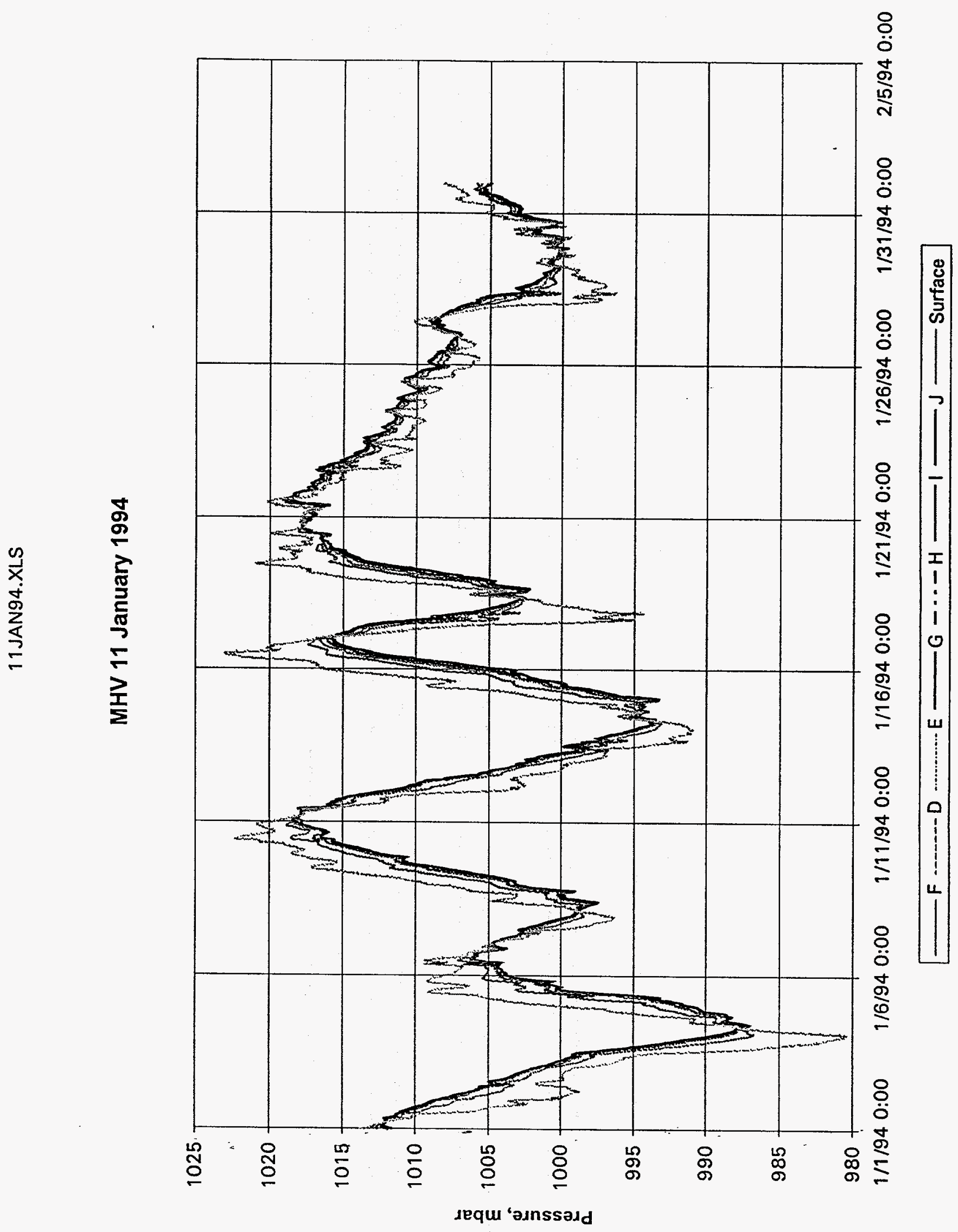




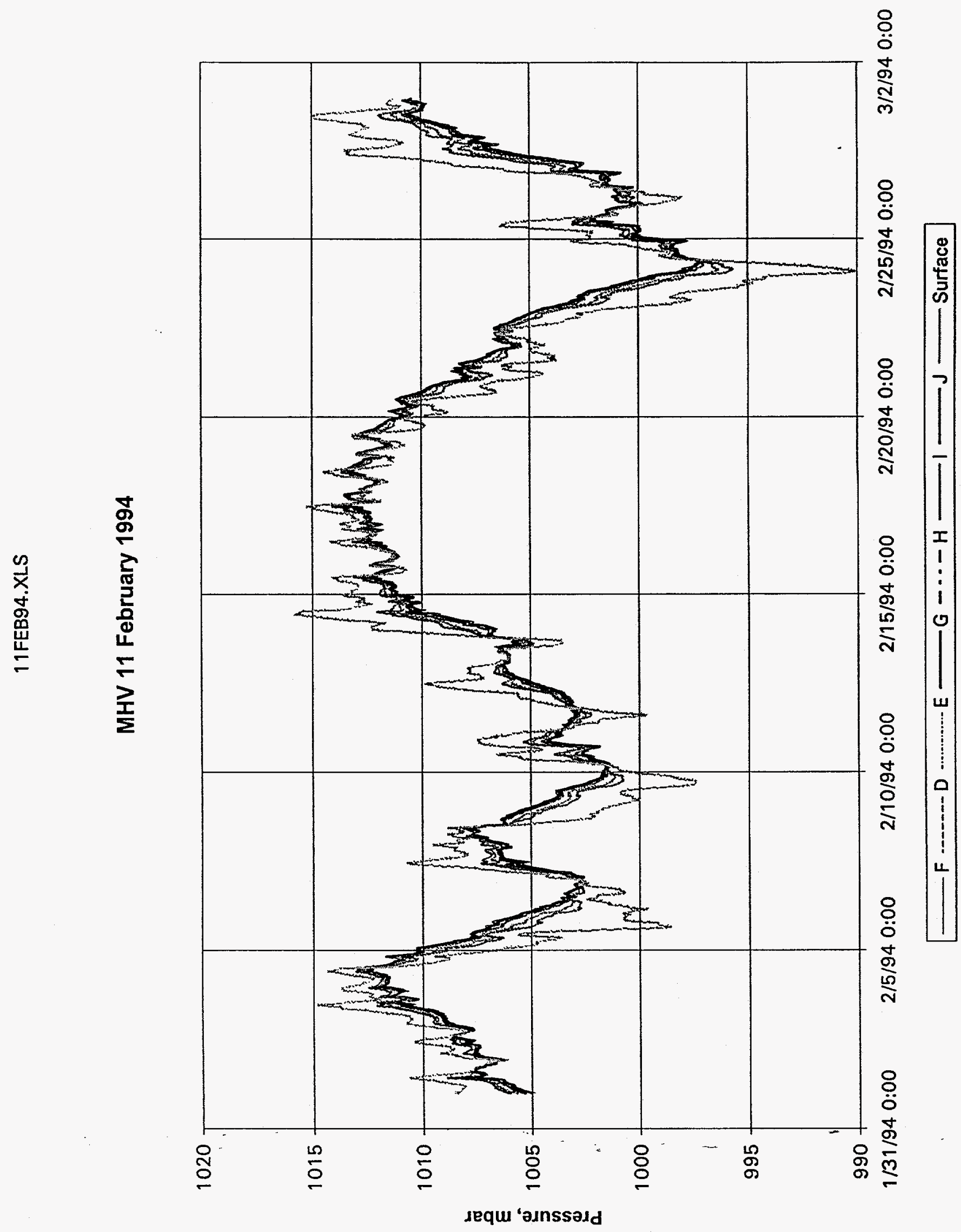




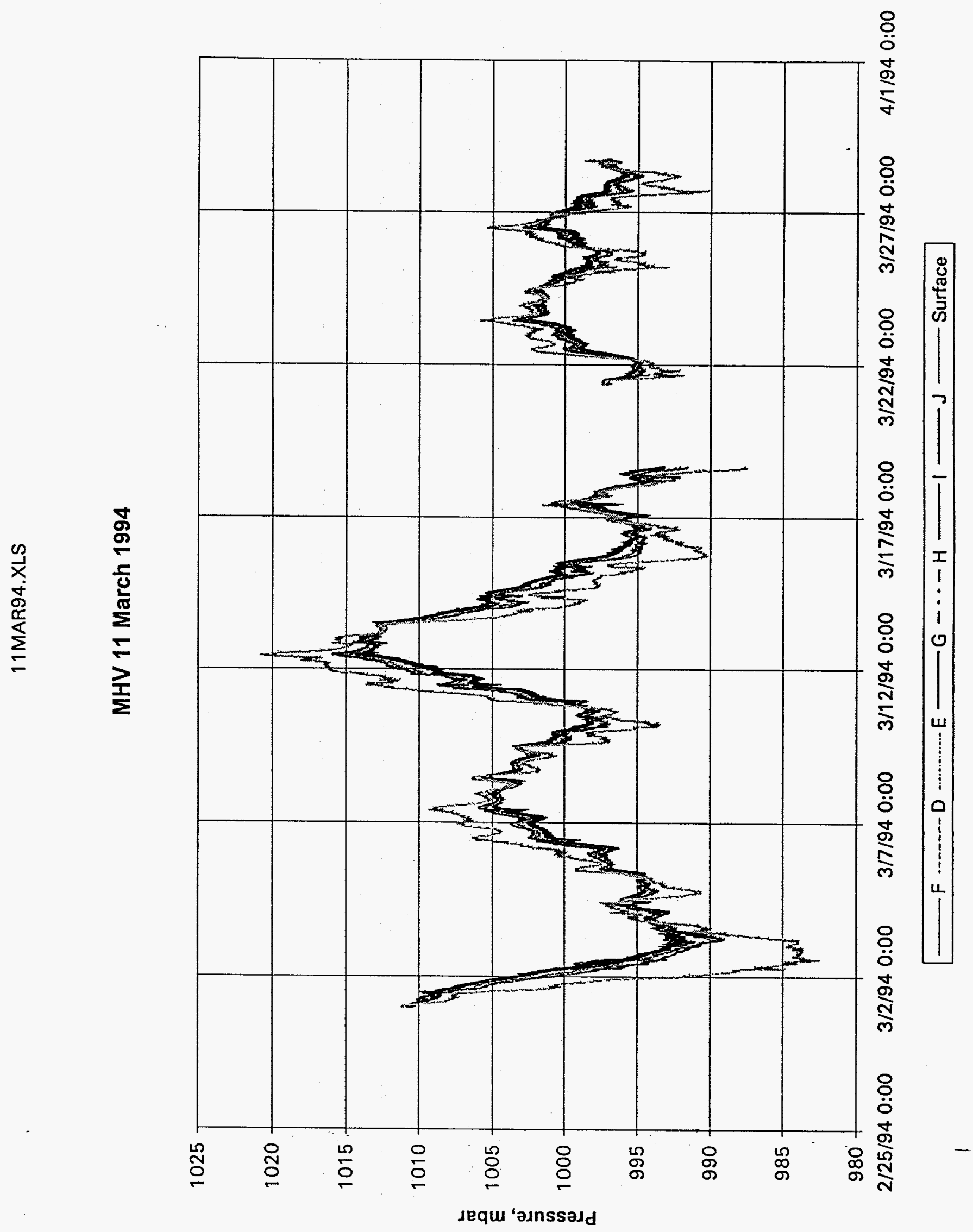


APPENDIX A - Flow and Concentration Profiles 


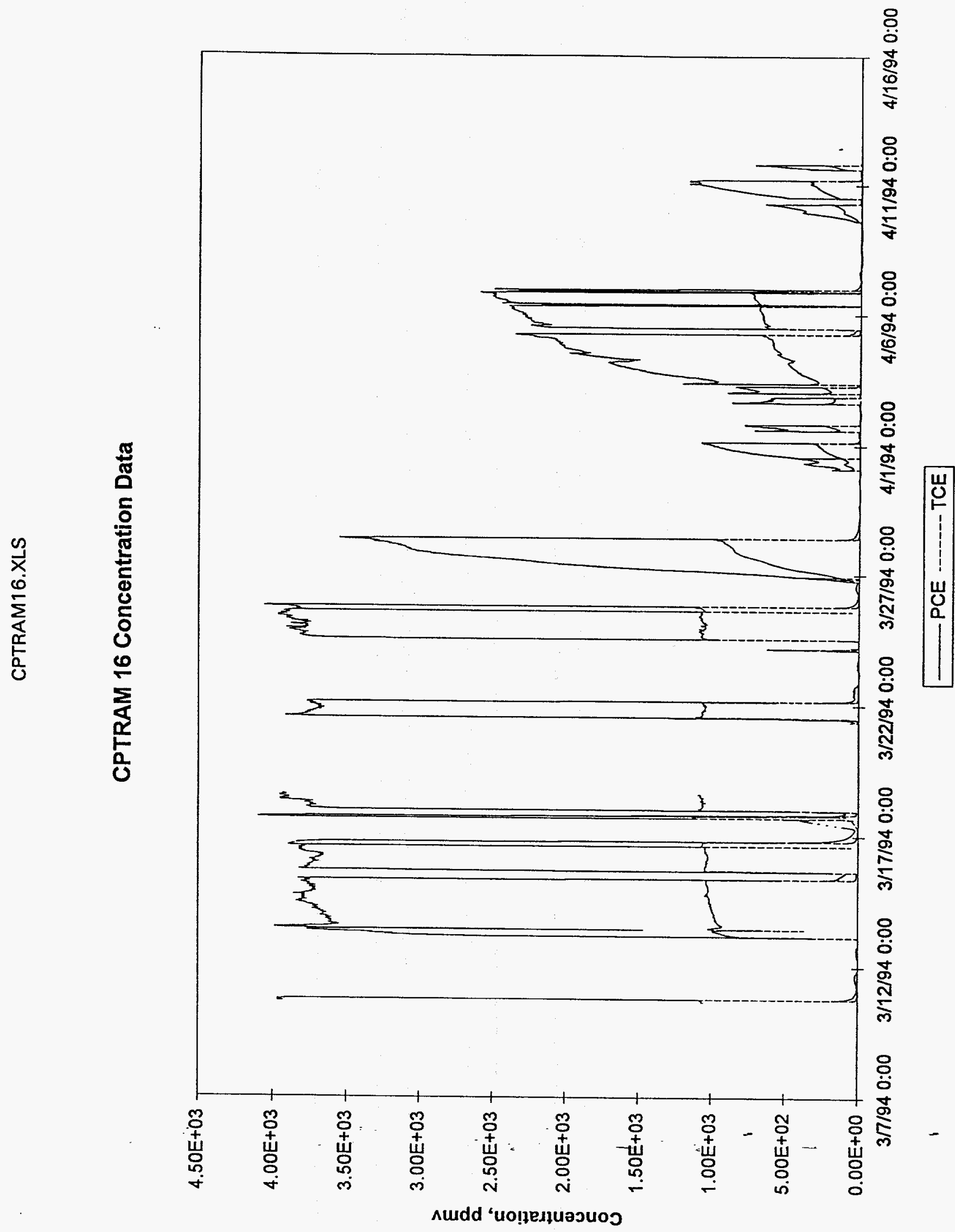




\section{CPTRAM 16 Pressure Data}

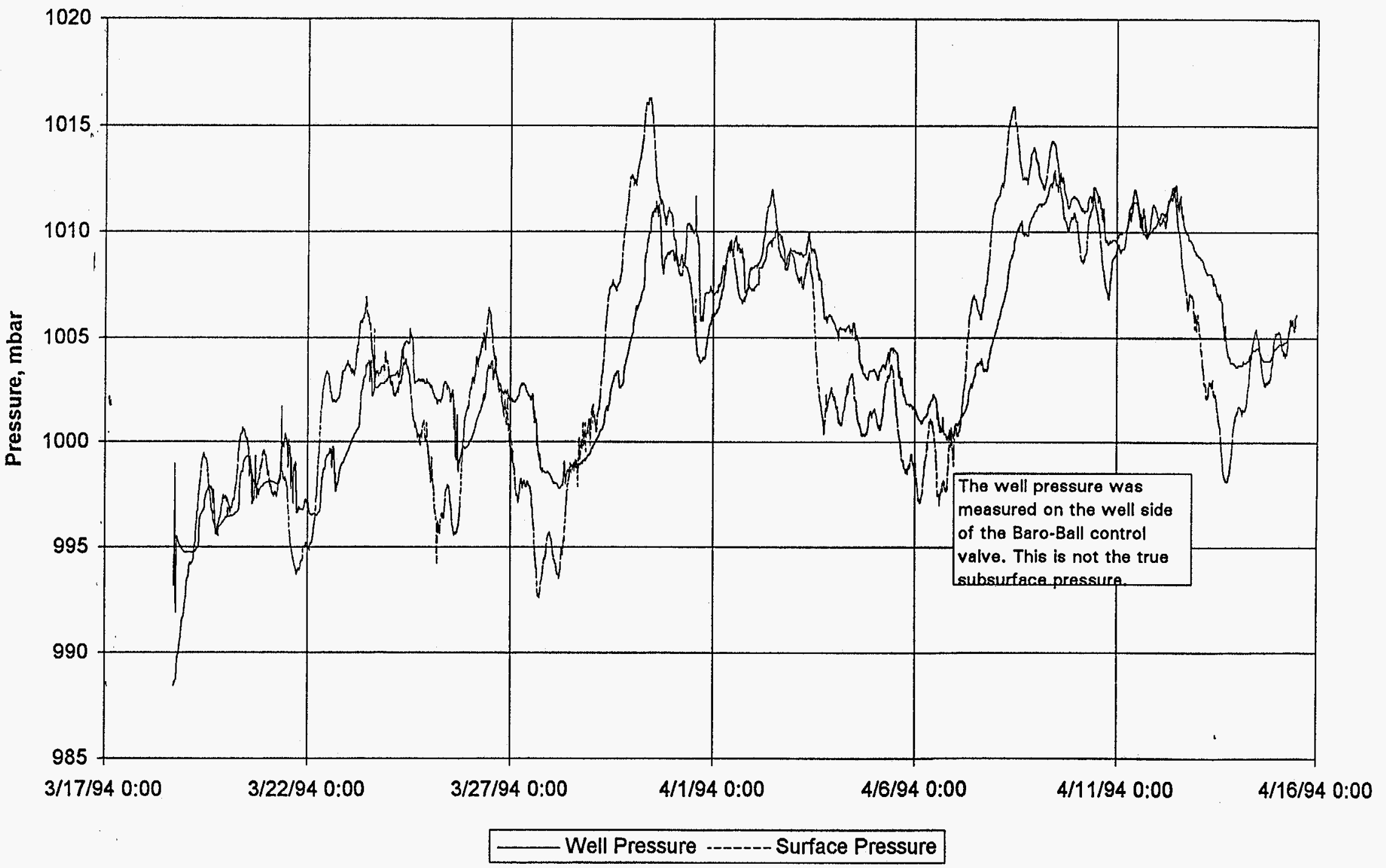




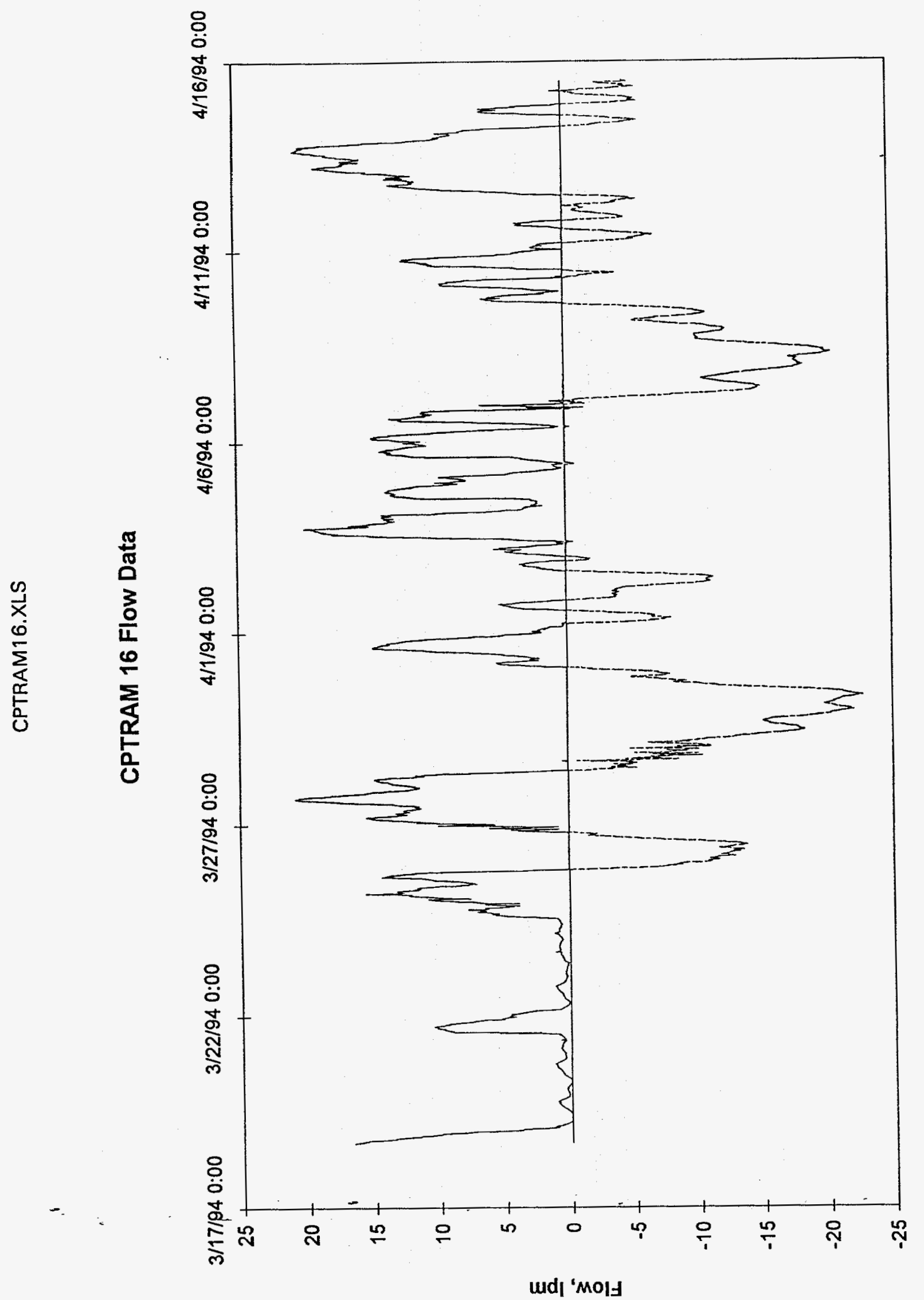




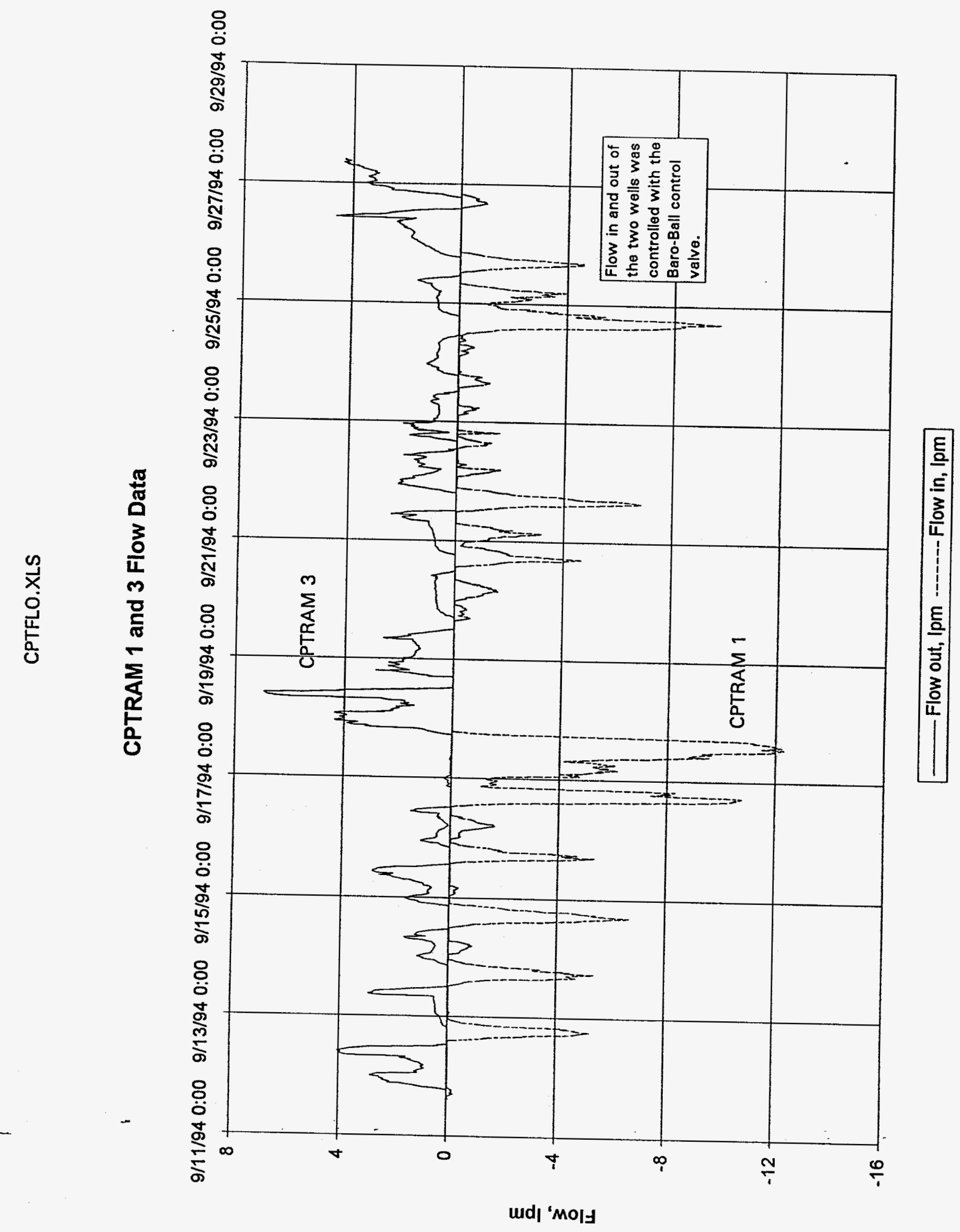




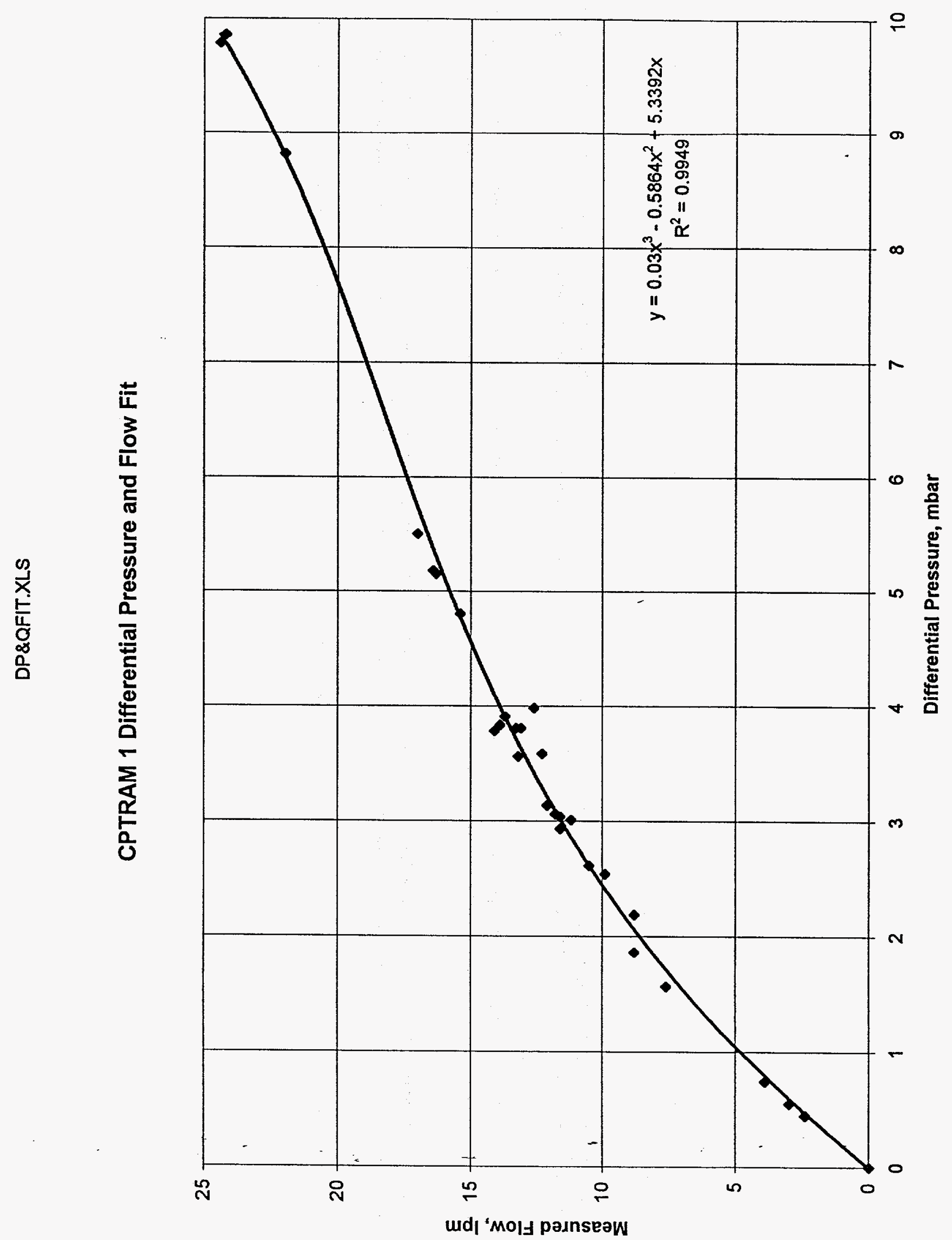


CPTRAM 3 Differential Pressure and Flow Fit

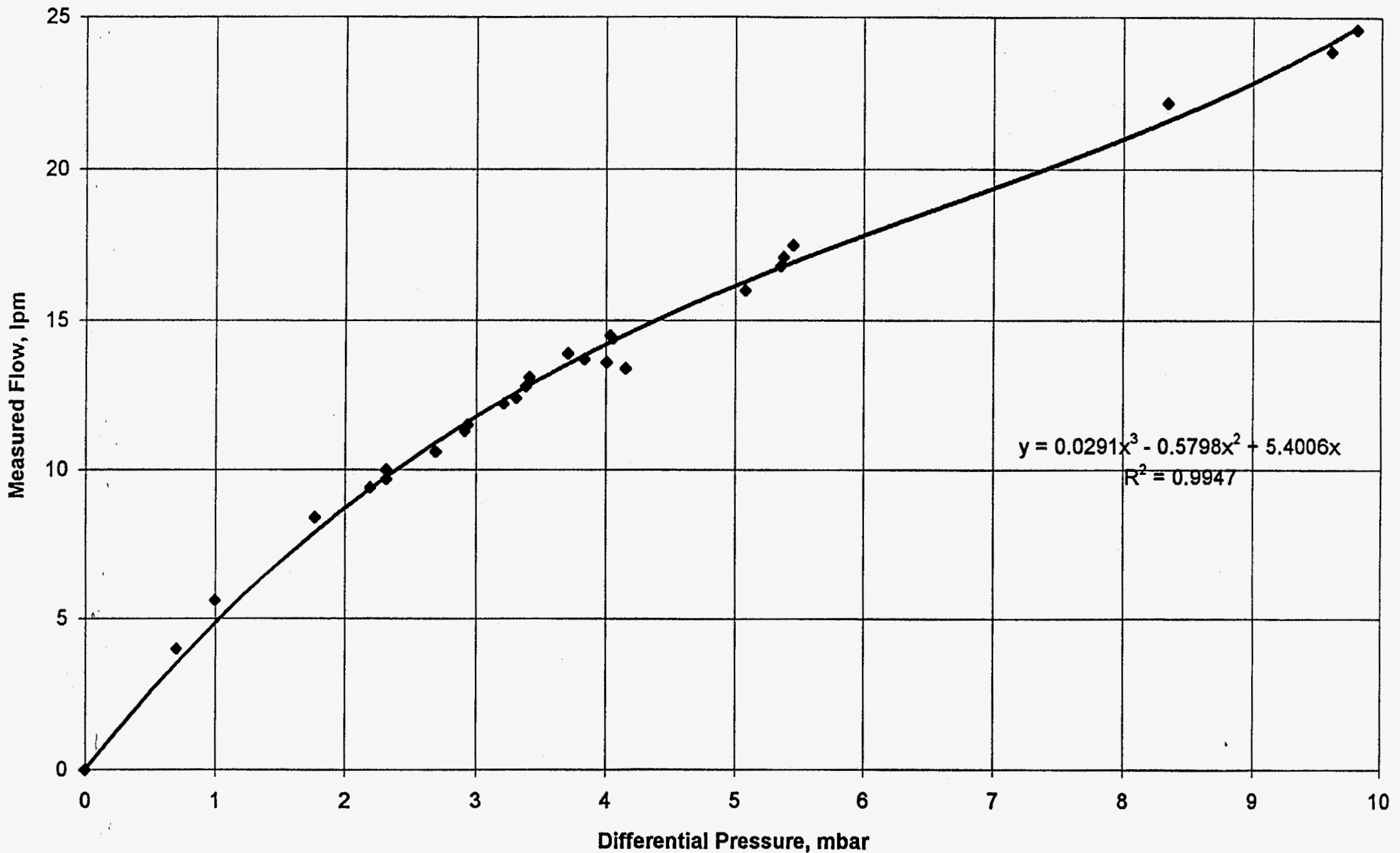




\section{DP\&QFIT.XLS}

CPTRAM 4 Differential Pressure and Flow Fit

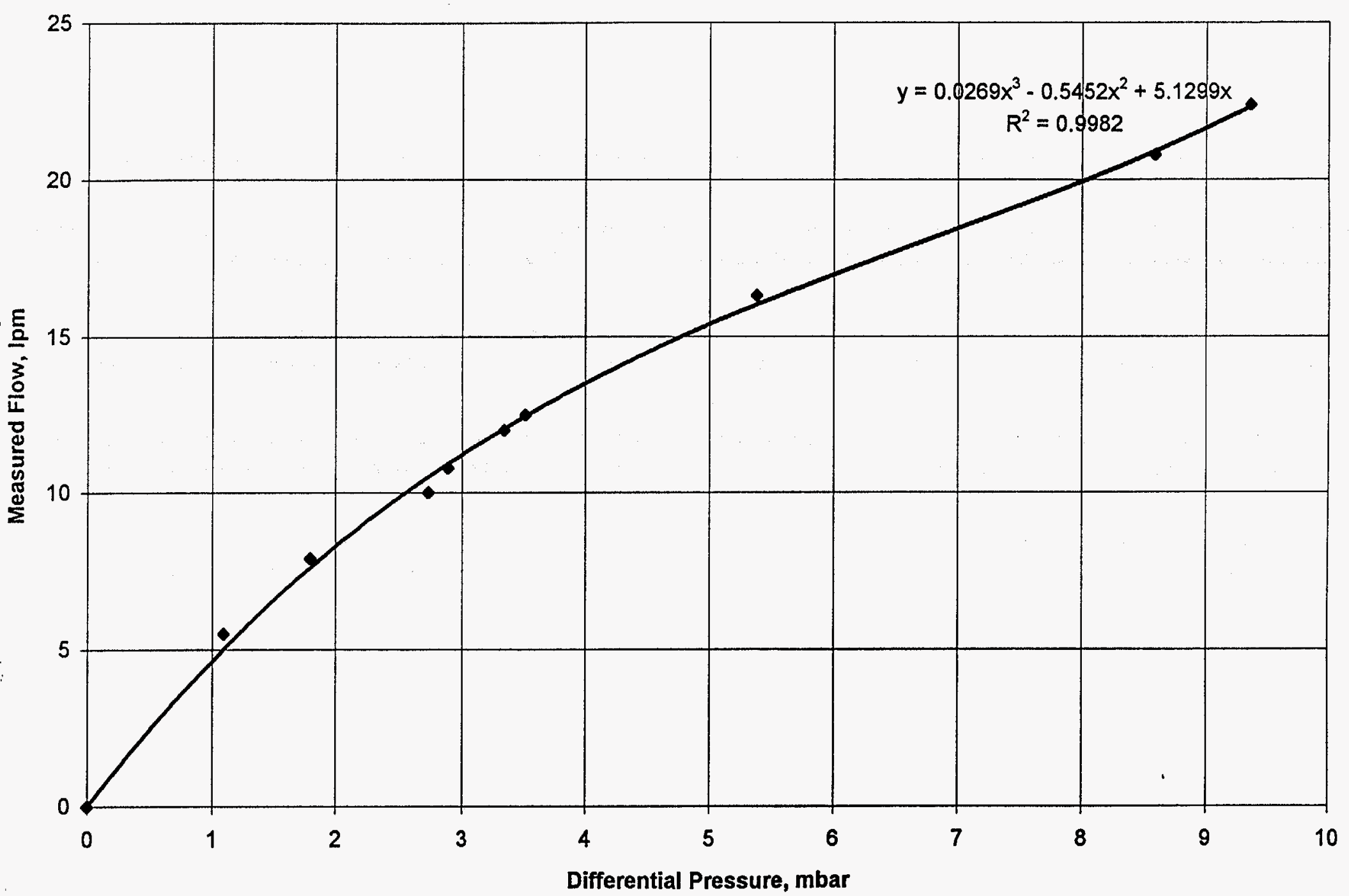




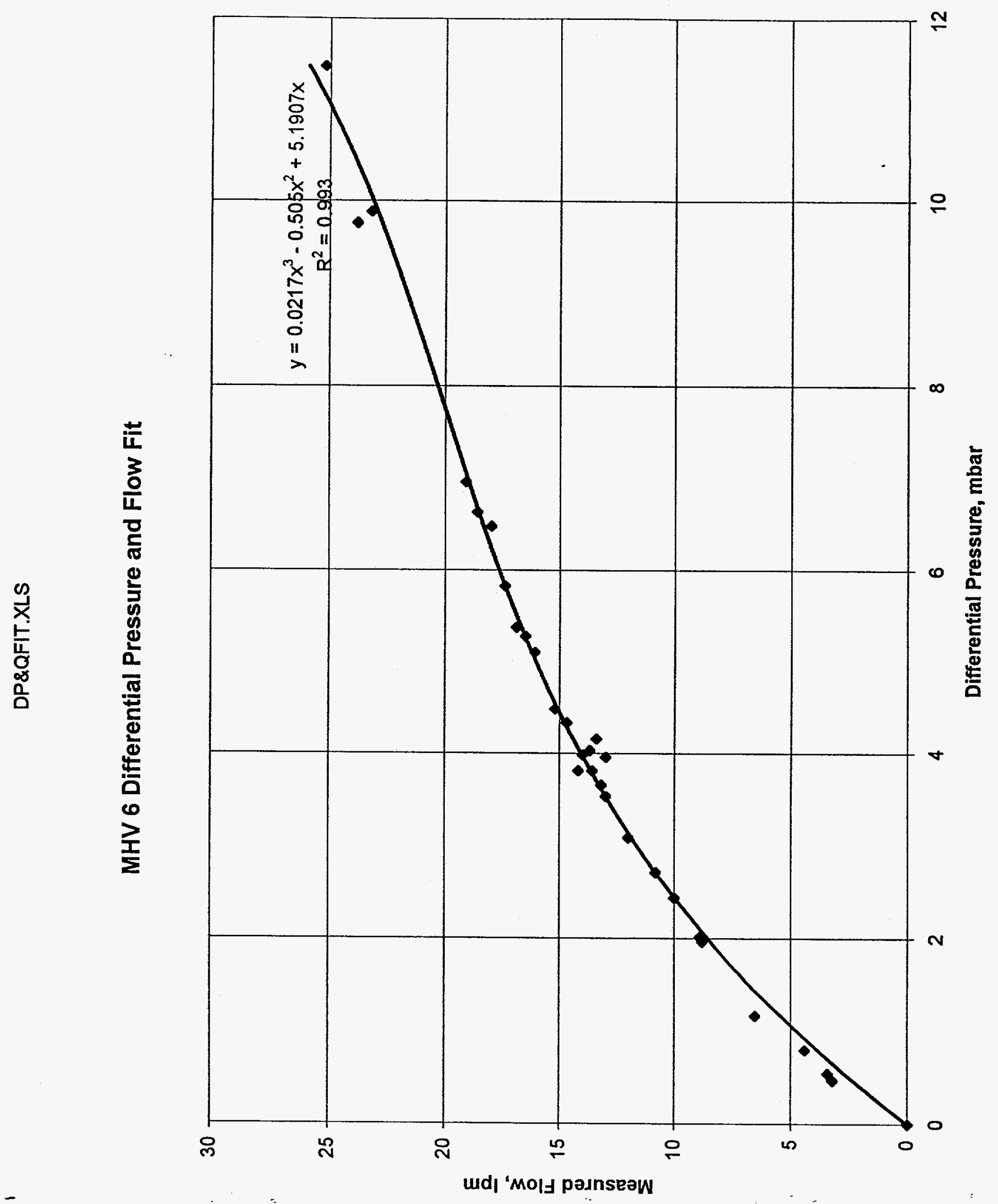




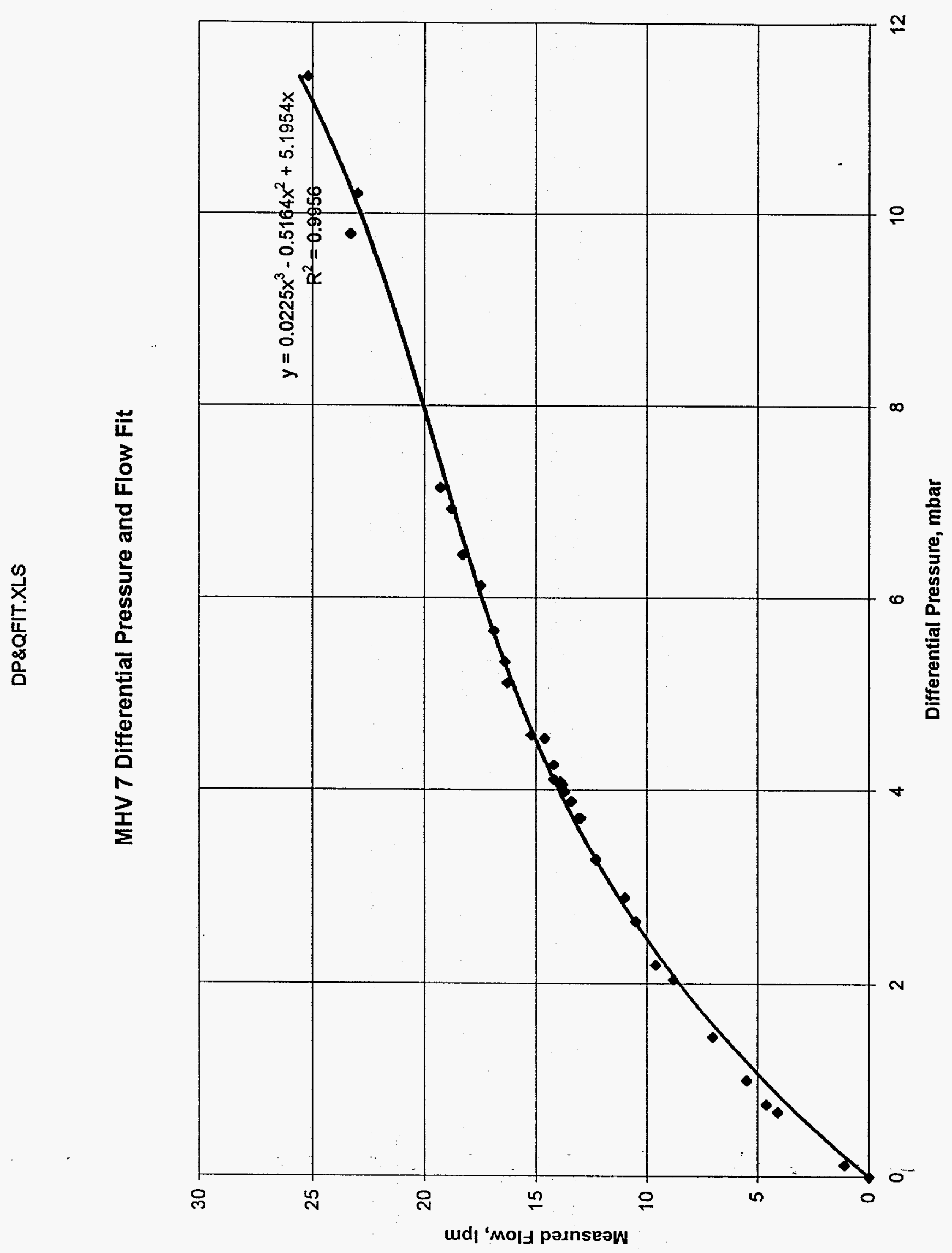




\section{CPTRAM 1 Estimated Flow}

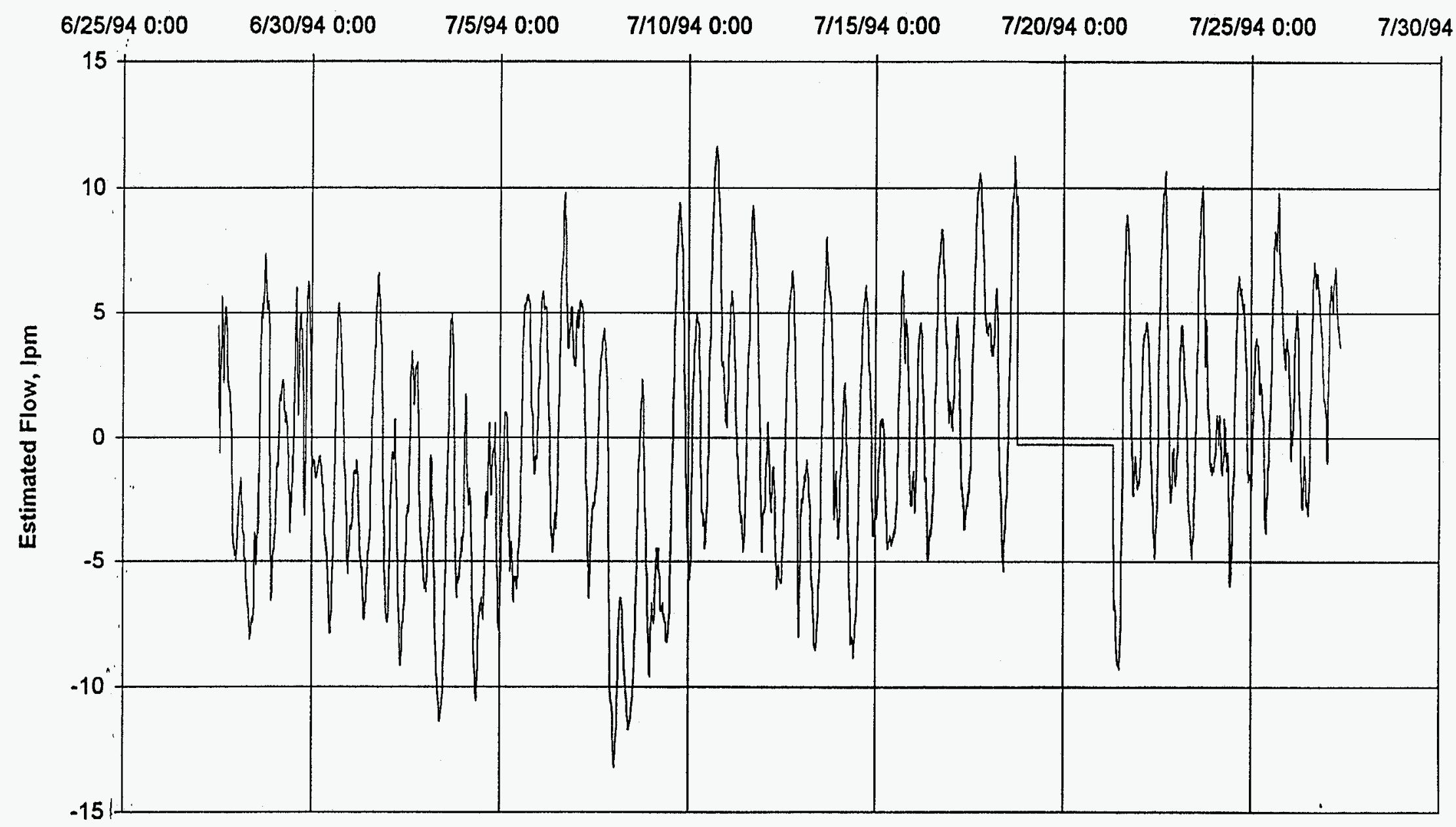


FLOW134G.XLS

CPTRAM 3 Estimated Flow

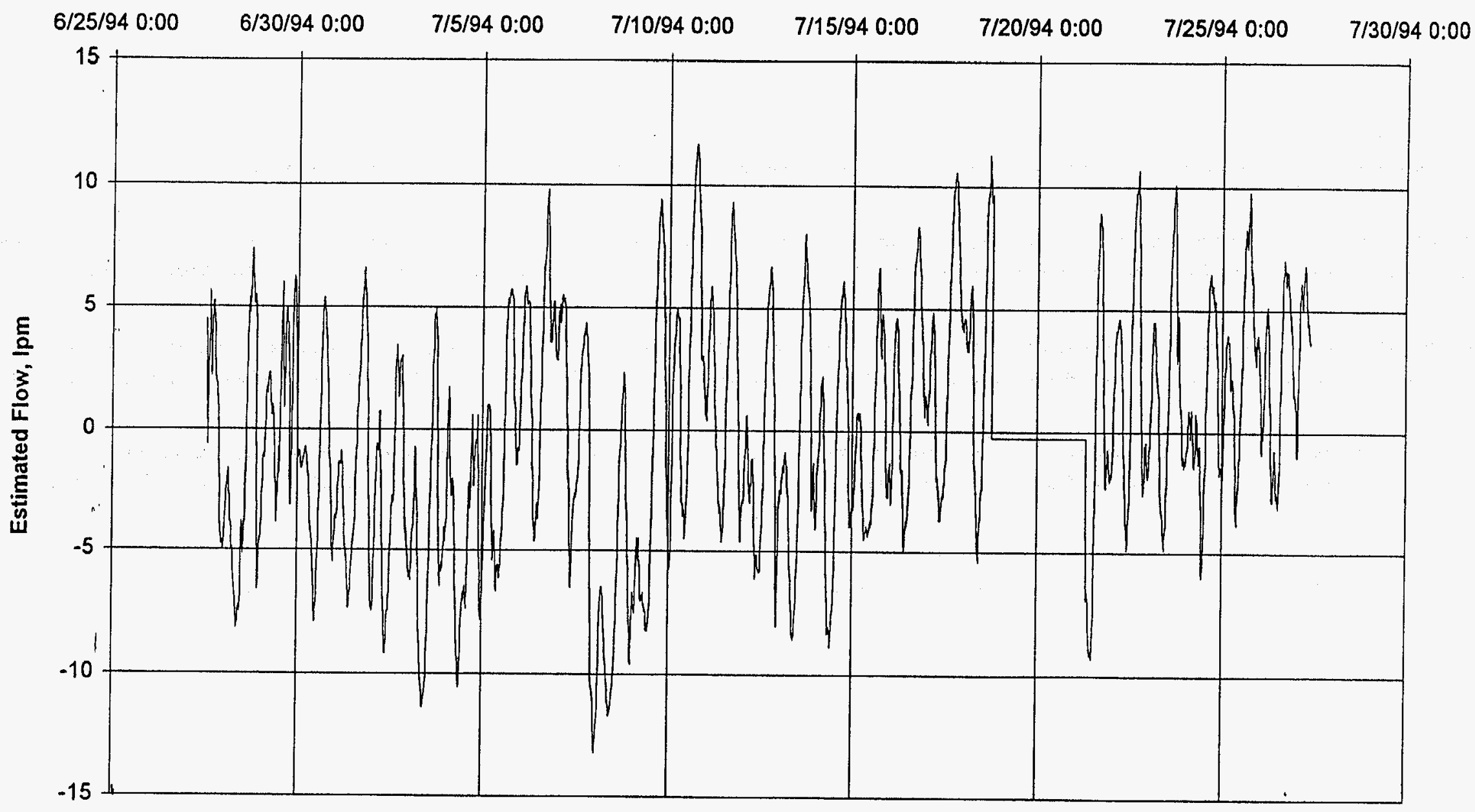




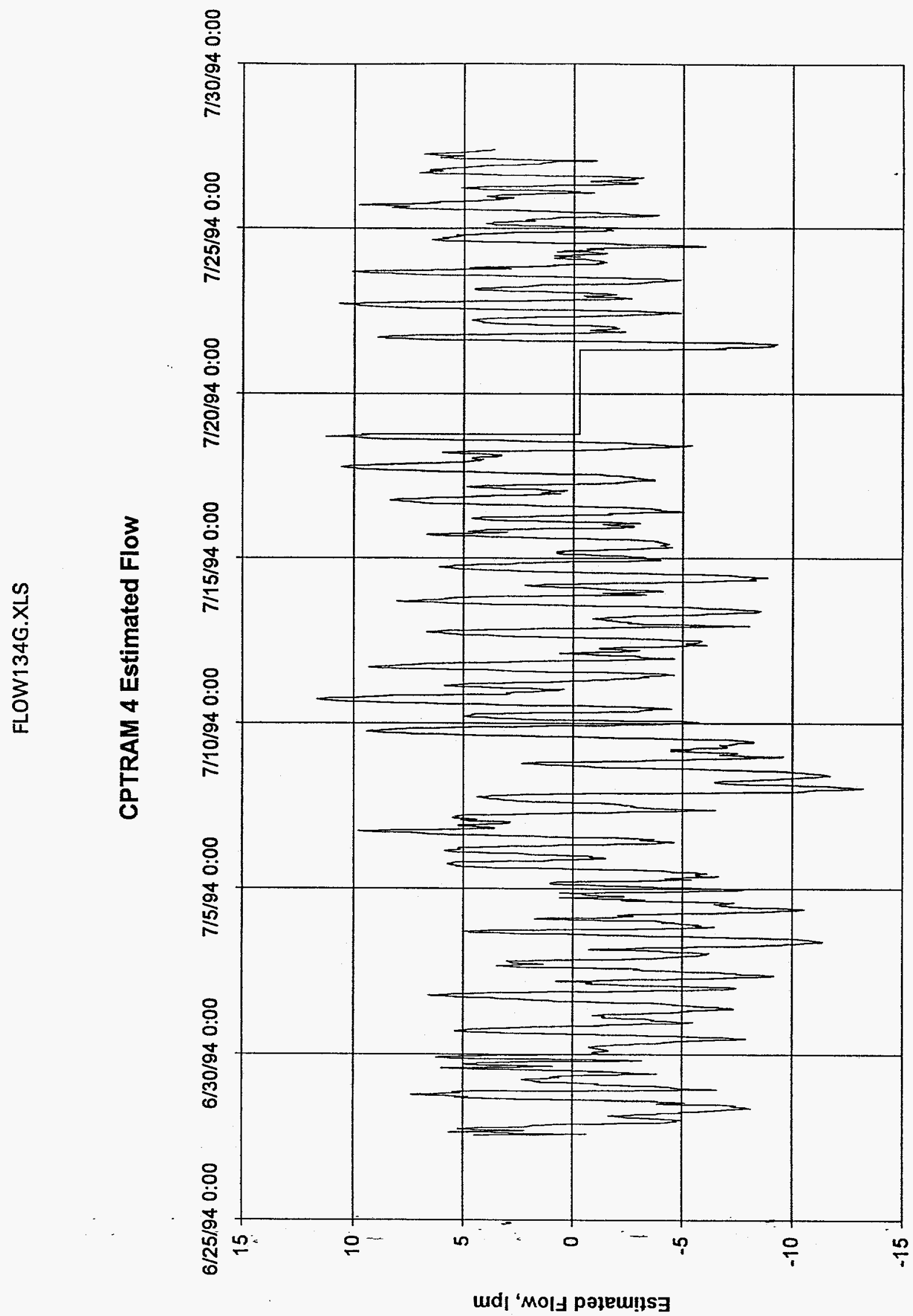




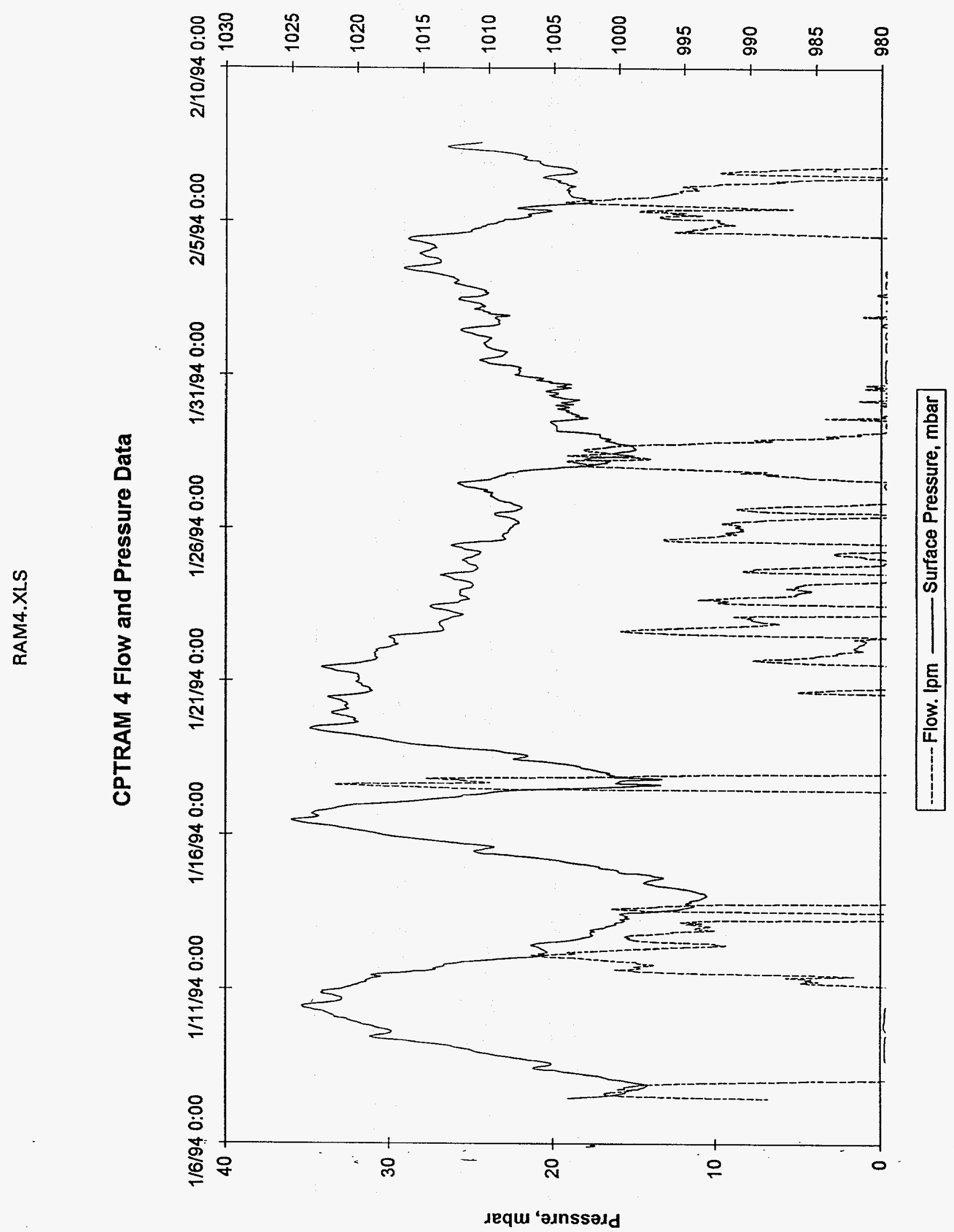


APPENDIX A - Concentration Data 


\begin{tabular}{|c|c|c|c|c|c|c|c|c|c|c|c|c|}
\hline \multirow[b]{2}{*}{ Well Number } & \multicolumn{2}{|l|}{$6 / 25 / 93$} & \multicolumn{2}{|l|}{$7 / 20 / 93$} & \multicolumn{2}{|l|}{$8 / 11 / 93$} & \multicolumn{2}{|l|}{$7 / 29 / 94$} & \multicolumn{2}{|l|}{ TCE } & \multicolumn{2}{|l|}{ PCE } \\
\hline & TCE ppmv & PCE ppmv & TCE ppmv & PCE ppmv & TCE ppmv & PCE ppmv & TCE ppmv & PCE ppmv & Average & Stdv & Average & Stdv \\
\hline$M H V-1 A$ & 55.63 & 34.43 & 43.41 & 26.33 & 44.12 & 28.48 & 46.89 & 23.30 & 47.51 & 5.61 & 28.14 & 4.71 \\
\hline MHV-1B & 17.07 & 6.84 & 15.49 & 6.67 & 17.62 & 8.24 & 47.49 & 21.85 & 24.42 & 15.41 & 10.90 & 7.33 \\
\hline MHV-1C & 2.97 & 1.46 & 1.19 & 7.77 & N/A & N/A & 0.00 & 0.21 & 1.39 & 1.50 & 3.15 & 4.05 \\
\hline MHV-2A & 33.94 & 22.08 & 33.96 & 20.27 & 37.57 & 23.02 & 30.12 & 16.26 & 33.90 & 3.04 & 20.41 & 2.99 \\
\hline MHV-2B & 25.55 & 13.18 & 24.38 & 12.46 & 30.75 & 14.39 & 14.80 & 9.50 & 23.87 & 6.65 & 12.38 & 2.08 \\
\hline MHV-2C & 9.51 & 5.48 & 8.51 & 5.04 & 8.73 & 6.66 & 1.67 & 1.50 & 7.10 & 3.65 & 4.67 & 2.22 \\
\hline MHV-3A & 51.16 & 19.87 & 77.93 & 40.13 & 83.24 & 48.95 & 80.27 & 38.71 & 73.15 & 14.82 & 36.92 & 12.23 \\
\hline MHV-3B & 39.91 & 9.85 & 45.09 & 12.14 & 58.50 & 18.11 & 61.66 & 19.66 & 51.29 & 10.45 & 14.94 & 4.70 \\
\hline MHV-3C & 0.00 & 0.72 & 63.98 & 26.22 & 64.70 & 24.35 & 1.70 & 1.04 & 32.59 & 36.66 & 13.08 & 14.11 \\
\hline $\mathrm{MHV}-4 \mathrm{~A}$ & 541.54 & 91.53 & 844.46 & 154.09 & 1298.16 & 195.79 & 429.37 & 119.12 & 778.38 & 388.35 & 140.13 & 45.08 \\
\hline$M H V-4 B$ & 310.40 & 194.45 & 279.20 & 155.22 & 356.60 & 182.51 & 212.00 & 11.47 & 289.55 & 60.70 & 135.91 & 84.57 \\
\hline MHV-4C & 601.65 & 483.64 & 524.35 & 395.10 & 733.04 & 583.65 & 571.36 & 976.87 & 607.60 & 89.47 & 609.81 & 256.54 \\
\hline MHV-5A & 21.10 & 15.92 & 27.60 & 22.56 & 31.18 & 23.99 & 62.51 & 51.24 & 35.60 & 18.42 & 28.43 & 15.61 \\
\hline MHV-5B & 0.00 & 1.07 & 7.23 & 4.54 & 8.14 & 5.60 & 14.31 & 9.84 & 7.42 & 5.86 & 5.26 & 3.61 \\
\hline MHV $: 5 \mathrm{C}$ & 0.00 & 0.59 & 34.28 & 25.44 & 39.57 & 29.23 & 35.83 & 34.92 & 27.42 & 18.41 & 22.54 & 15.14 \\
\hline
\end{tabular}


MHV7-9

\begin{tabular}{|c|c|c|c|c|c|c|c|c|}
\hline \multirow[b]{2}{*}{ Well Number } & \multicolumn{2}{|l|}{$1 / 3 / 94$} & \multicolumn{2}{|l|}{$7 / 29 / 94$} & \multicolumn{2}{|l|}{ TCE } & \multicolumn{2}{|l|}{ PCE } \\
\hline & TCE ppmv & PCE ppmv & TCE ppmv & PCE ppmv & Average & Stdv & Average & Stdv \\
\hline MHV-7 & 40.11 & 67.99 & 8.82 & 3.99 & 24.47 & 22.13 & 35.99 & 45.25 \\
\hline MHV-8 & 5.97 & 6.68 & 0.91 & 0.69 & 3.44 & 3.58 & 3.69 & 4.24 \\
\hline MHV-9 & 16.89 & 8.93 & 0.00 & 0.40 & 8.45 & 11.94 & 4.67 & 6.03 \\
\hline
\end{tabular}




\begin{tabular}{|c|c|c|c|c|c|c|c|c|}
\hline \multirow[b]{2}{*}{ Well Number } & \multicolumn{2}{|l|}{$1 / 3 / 94$} & \multicolumn{2}{|l|}{$3 / 9 / 94$} & \multicolumn{2}{|l|}{$3 / 14 / 94$} & \multicolumn{2}{|l|}{$3 / 21 / 94$} \\
\hline & TCE ppmv & PCE ppmv & TCE ppmv & PCE ppmv & TCE ppmv & PCE ppmv & TCE ppmv & PCE ppmv \\
\hline CPTRAM 1 & NA & NA & $\mathrm{NA}$ & $\mathrm{NA}$ & 159.32 & 396.46 & 147.90 & 330.19 \\
\hline CPTRAM 3 & NA & NA & NA & NA & 185.90 & 411.99 & 111.84 & 240.11 \\
\hline CPTRAM 4 & 206.37 & 562.18 & $\mathrm{NA}$ & NA & 321.09 & 859.56 & 425.86 & 1245.02 \\
\hline CPTRAM 15 & $\mathrm{NA}$ & $\mathrm{NA}$ & $\mathrm{NA}$ & $\mathrm{NA}$ & 40.42 & 66.96 & 23.19 & 21.29 \\
\hline CPTRAM 16 & 1015.92 & 3640.37 & 1274.06 & 4249.88 & 1246.72 & 4341.71 & 1172.11 & 4031.15 \\
\hline
\end{tabular}

\begin{tabular}{|c|c|c|c|c|c|c|}
\hline \multirow{2}{*}{ Well Number } & $7 / 15 / 94$ & \multicolumn{2}{|c|}{ TCE } & PCE \\
\cline { 2 - 7 } & TCE ppmv & PCE ppmv & Average & Stdv & Average & Stdv \\
\hline CPTRAM 1 & 319.29 & 816.25 & 208.84 & 95.83 & 514.30 & 263.59 \\
\hline CPTRAM 3 & 84.43 & 242.66 & 127.39 & 52.49 & 298.25 & 98.51 \\
\hline CPTRAM 4 & 388.53 & 1129.83 & 335.46 & 96.37 & 949.15 & 304.39 \\
\hline CPTRAM 15 & NA & NA & 31.81 & 12.18 & 44.13 & 32.29 \\
\hline CPTRAM 16 & NA & NA & 1177.20 & 115.83 & 4065.78 & 312.09 \\
\hline
\end{tabular}


APPENDIX B - Subsurface Pressure Models 


\title{
Subsurface Pressure Models: BAROSOLV and ATM_SUBA
}

Joe Rossabi

Brian D. Riha

Ron. W. Falta

Brian B. Looney

\begin{abstract}
$\underline{\text { Abstract }}$
We have developed two models to predict the subsurface pressure at a particular depth based on surface atmospheric pressure measurements and soil properties. The two models use analytical solutions to the one-dimensional, partial differential equation governing gas flow in porous media based on conservation of mass and energy, Darcy's law for fluid velocity, and the real gas law. The two models differ in the boundary condition formulation of gas pressure transmission in the subsurface. Both models use solutions adapted from Carslaw and Jaeger (1959). The derivations of the equations are provided in Appendix 1. We measured atmospheric pressure and subsurface pressure at more than 15 different locations in the subsurface at the $M$ area of the Savannah River Site (SRS) for approximately one year. A pressure monitoring network that synchronized data acquisition and storage was used to log subsurface pressure data at 15 minute intervals from 1" diameter piezometer tubes (screen length $=$ five feet) installed at several depths in the unsaturated zone. When the subsurface pressure was greater than the surface (atmospheric pressure) at a particular time, air flow out of the piezometers was observed. Similarly, when the subsurface pressure was less than the surface pressure, flow of air from the surface into the piezometers was observed. The models were successful in predicting the correct direction of flow (based on the sign of the differential pressure between surface and subsurface) over $90 \%$ of the time. In addition, the models were successful in predicting the subsurface pressure response to surface pressure with a mean error of less than $3 \mathrm{mBars}$ for all of the data evaluated. By controlling valves on vadose zone wells in response to surface pressure changes, these models can optimize the removal of volatile contaminants using barometric pumping without an extensive and costly monitoring network. The models were coded in $\mathrm{C}$ and have been compiled for use on DOS-based computers.
\end{abstract}

\section{Solution method}

The solutions to the governing equations for both models use a series of complementary error functions involving previous values of surface atmospheric pressure, and soil properties and other parameters. BAROSOLV assumes a Neumann condition boundary at the water table, i.e., no pressure is transmitted across that boundary. The code uses a superpositioning technique to incorporate this condition by adding a mirror image of the surface atmospheric pressure signal at a depth equal to twice the depth to the water table. ATM_SUBA assumes a finite value equal to the average atmospheric pressure as the depth approaches infinity. In this model the pressure signal is assumed to dissipate at large depths.

Both models estimate subsurface pressure at a particular time based on surface pressure data from previous times. Each successive subsurface pressure estimate will have a larger pool of measured data available to help in the prediction (i.e., at time 1, the model can use the initial surface pressure datum; at time 2, surface pressure data at times 0 and 1 are used and so on.). Both 
models can employ all previous surface pressure data points or a user-selected subset of the most recent pressure data to predict the subsurface pressure. For example, the user can choose to use only the 50 surface pressure data immediately before the desired subsurface pressure value. The accuracy of the prediction should improve with a larger set of historical data but the computer processing time increases with larger sets of historical data.

Figure 1 shows the surface pressure, measured subsurface pressure and predicted subsurface pressure through time for the data set ( $3 \mathrm{afeb} . t \mathrm{xt}$ ) included on the attached disk. The BAROSOLV model was used for these results. Approximately 300 historical surface pressure data points are used for each subsurface pressure point. It is apparent from this figure that the model takes some time to equilibrate (approximately 3000 minutes) and then tracks the measured data well. The model correctly predicted the sign of the pressure gradient (which indicates the direction of flow) more than $96 \%$ of the time. Figure 2 shows the absolute value of the difference in pressure between the actual and predicted results. This figure shows that the error in the predicted pressure was less than 2 millibar once the model had equilibrated. It is important to select the number of historical data points with care when using this model. Normally one would expect that the more historical data points used the more accurate the predictions, however this model solves the governing equation using the superpositioning of two driving forces to account for Neumann boundary condition at the water table. The solution incorporates two complementary error functions that are summed and then used as a multiplier of a series of pressure differences as described in Appendix 1. When the sum of the complementary error functions is greater than one, this value is truncated to one to avoid violating numerical and physical boundary conditions. Figure 3 shows the mean squared error and the \% flow correct of the model as a function of the number of historical data points used. From this figure, the optimum number of historical data points is between 200 and 300 . A smaller amount of historical data points ensures faster processing times (less than two minutes for 2700 points on an 80486 processor).

Figure 4 shows the surface pressure, measured subsurface pressure, and predicted subsurface pressure through time using the ATM_SUBA model on the included data set (3afeb.txt). Figure 5 shows that for this model, there is a point where more data does not significantly increase the accuracy of the prediction. Generally this point is reached using 400 to 1000 historical data points. By choosing a smaller subset of historical data to be used by the model, processing time is greatly reduced. Figures 1 through 6 indicate that the BAROSOLV model (water table as Neumann boundary) predicts subsurface pressure better than ATM_SUBA (semiinfinite boundary) for this data set but additional testing on other data sets should be performed.

These models can be used to determine the cumulative permeability by varying the input values to the model and evaluating its performance. Figures 7 and 8 show the performance (as indicated by $\%$ flow correct and mean squared error) of each of the models as a function of permeability. The optimum number of historical data points were used for each value of the permeability.

- The user can determine the optìmum model and configuration based on individual data quality objectives and field implementation. 
Input

The model requires user-supplied input values. The user can enter these values from individual prompts (Basic user mode) or by entering several values at once (Speedy user mode). The data needed for entry are :

1) Path and filename for input data file (unitless) [infile].

2) Time between measurements (seconds) [deltat].

3) Total measurements (unitless) [tmax].

4) Number of historical data points (unitless) [erf_cycles].

5) Depth to well (meters) [z].

6) Depth to groundwater (meters) [dist].

7) Intrinsic permeability (Darcy's) [kz].

8)..Volumetric moisture content (unitless) [Sw].

9) Porosity (unitless) [n].

10) Yearly average surface pressure (mBars) [Pavg].

If the user chooses to enter the data without individual prompts they can choose to enter several parameters at once. Parameters 2-5 are entered in one line separated by spaces, and parameters 6-10 are entered in one line separated by spaces.

The input data file, infile should contain two columns of data in ASCII format with no header information. The first column should contain atmospheric pressures at successive times in millibars. The second file should contain subsurface pressures as measured in the field, also in millibars. If the subsurface pressure data are not available, a dummy data set for this column must be included for the program to correctly read the data from the file. The columns should be separated by white space only (i.e., space, tab, etc.).

\section{Output}

The output file is named either barosolv.csv or atm_suba.csv corresponding to the model that is run. The model will overwrite the output file each time the model is run so previous runs should be re-named to be saved! Therefore use DOS command "ren barosolv.csv newfile.csv" to save the output data to newfile.csv.

The file will consist of data arranged in columns (rows correspond to the measurement times supplied in the input file) in the following order:

1) Number of time intervals from start (start is at $t=1$ ).

2) Atmospheric pressure in $\mathrm{mBars}$.

3) Measured subsurface pressure in mBars (directly from the input file).

4) Predicted subsurface pressure in mBars (from model).

5) Actual pressure difference in $\mathrm{mBars}$ between the surface and subsurface (positive value means air is blowing out of the well).

6) Predicted pressure difference in $\mathrm{mBars}$ between the surface and subsurface (positive value means air is blowing out of the well).

7) Total number of times that the model correctly predicts the flow direction. 
Below the columns of output, the following is printed: the total number of time intervals, the permeability factor $(\mathrm{Lz})$, the mean squared error, and the percentage of time the direction of flow was correctly predicted.

\section{Sensitivity}

A brief sensitivity analysis was performed on the input parameters that are most difficult to measure. The results of this analysis are shown in Table 1. From this table it is apparent that the intrinsic permeability, the volumetric moisture content of the soil ( $\mathrm{Sw}=1-\mathrm{Sg}$ ), and the porosity have the greatest effects.

\section{Example}

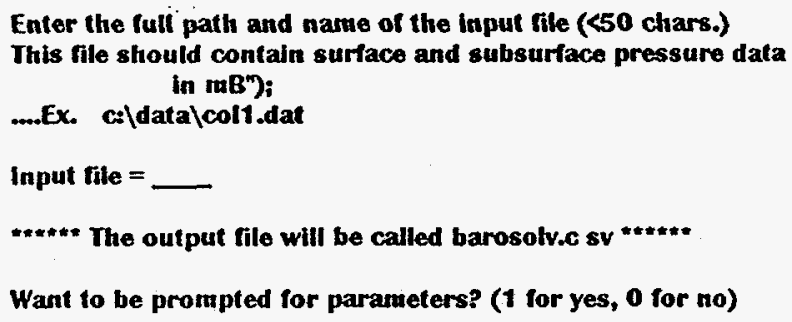

If the user wants to be prompted for parameters, the following appears on the monitor:

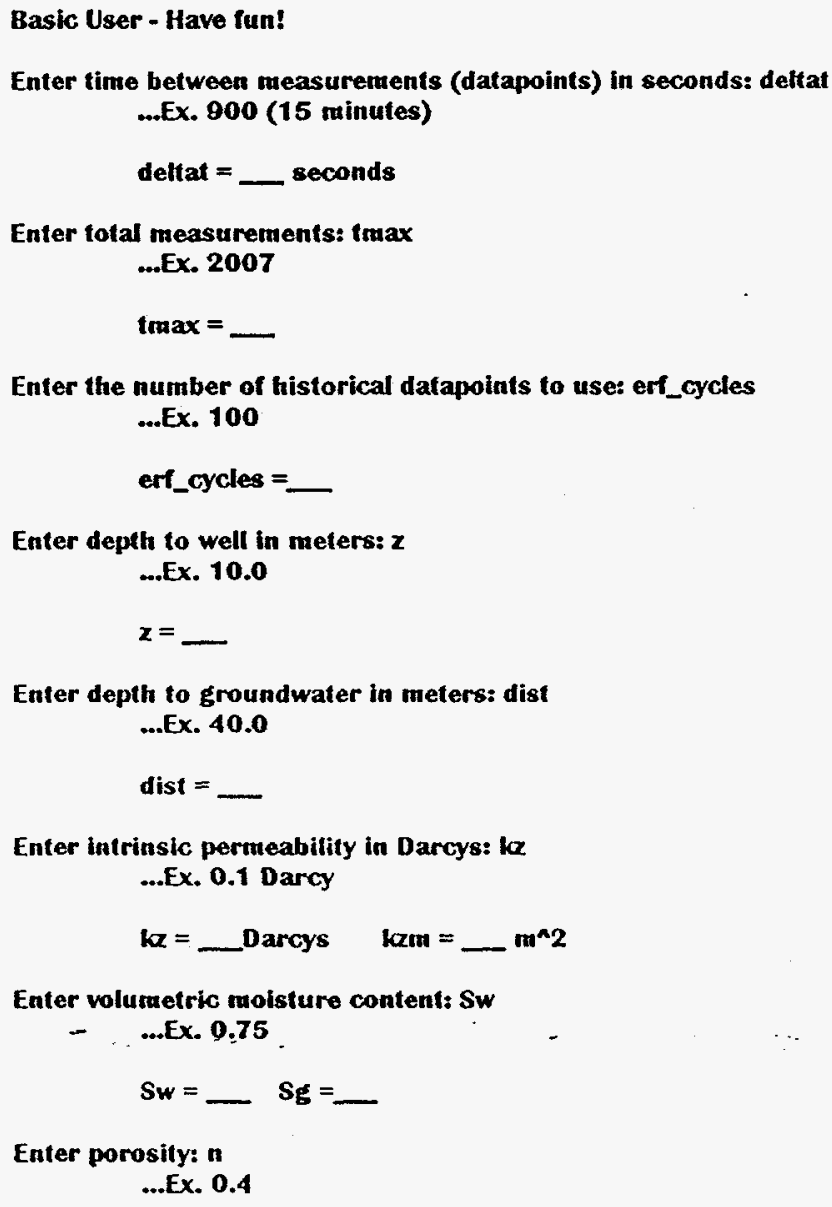




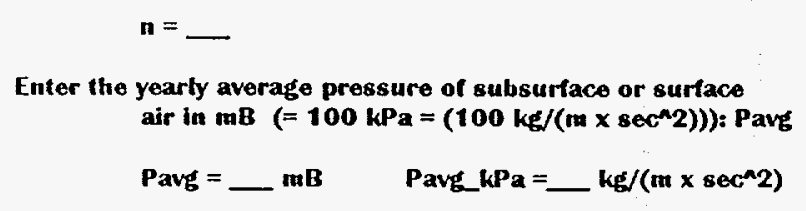

If the user does not want to be prompted for each parameter, they can enter parameters in two prompts. The following dialogue would appear on the monitor:

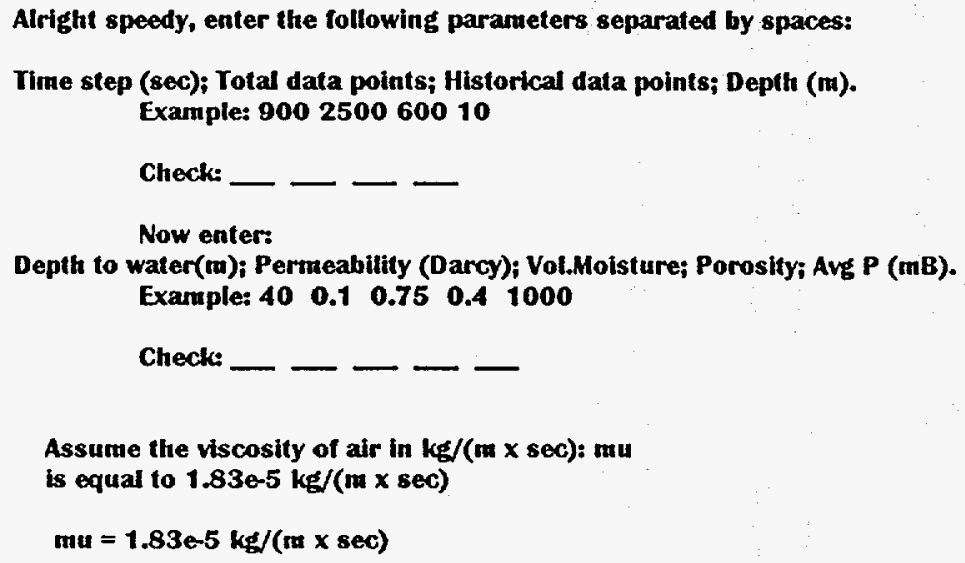

Models BAROSOLV and ATM_SUBA have identical input procedures.

\section{Files on Disk}

Two executable files have been included with this disk (barosolv.exe and atm_suba.exe). As described above, BAROSOLV uses superpositioning to solve the Neumann (no-flow) boundary condition in which the water table is the boundary. The water table acts as a pressure reflector for the pressure wave originating at the surface and transmitting down through the subsurface. ATM_SUBA is similar to BAROSOLV but assumes a semi-infinite boundary. As depth increases, the pressure in the subsurface becomes finite and equal to the average atmospheric pressure. In this model, the pressure wave originating at the surface is not reflected but instead dampens and dissipates as depth increases.

One data file has been included ( $3 \mathrm{afeb} . \mathrm{txt}$ ). This file is an ASCII file containing two columns of space-separated data. The first column contains atmospheric pressure data in millibars taken at SRS at constant intervals (every 15 minutes $=900$ seconds) over approximately 28 days consecutively. This corresponds to 2680 data points. The models use this data to predict the corresponding subsurface pressure. The second column contains subsurface pressure data taken at the same time intervals as the atmospheric pressure at SRS. The subsurface pressure data were measured from a one-inch diameter well with five feet of screen at a depth of approximately 30 meters. These data were used to validate the model results. The current versions of the models require two columns of data in the input file. This was necessary to validate the models, however, if validation is not required a dummy data set can be used in the second column. - If the dummy set is used the mean squared error and \% correct flow values will be meaningless. Subsequent versions of this code will not require two data columns in the input file. 
The last two files are model result files barosolv.csv and atm suba.csv. These are comma separated variable files that can be input directly into most spread sheets for easy plotting and further data treatment if desired. They were developed using the input file (3afeb.txt) supplied on this disk and the following values for soil properties and other parameters:
a) Time between measurements $=900$.
b) Total measurements $=2680$.
c) Number of historical data points $=293$ (for barosolv) or 2680 (for atm_suba).
d) Depth to well $=30$.
e) Depth to groundwater $=40$.
f) Intrinsic permeability $=0.12$ (for barosolv) or 1.0 for (atm_suba).
g) Volumetric moisture content $=0.75$.
h) Porosity $=0.4$
i) Yearly average pressure $=1000$.

The output is arranged in 7 columns (rows correspond to the times supplied in the input file) in the following order:

1) number of time intervals from start [t](start is at $t=1)$.

2) atmospheric pressure in mBars [Patm].

3) measured subsurface pressure in $\mathrm{mBars}[\mathrm{Psub}]$ (directly from the input file).

4) predicted subsurface pressure in mBars [Pout] (from model).

5) actual pressure difference in $\mathrm{mBars}$ between the surface and subsurface [press_diff_act] (positive value means air is blowing out of the well).

6) predicted pressure difference in $\mathrm{mBars}$ between the surface and subsurface [press_diff_theory] (positive value means air is blowing out of the well).

7) the total number of times that the model correctly predicts the flow direction [flow_error_total].

Below the columns of output, the following is printed: the total number of time intervals, the effective permeability factor $(\mathrm{Lz})$, the mean squared error, and the percentage of time the direction of flow was correctly predicted. The following summary values were obtained for the two example problems:

\section{barosolv.csv}

Number of data points $=2680$.

Effective Permeability factor $(\mathrm{Lz})=0.00647 \mathrm{~m}^{2} / \mathrm{sec}$.

Mean squared error $(\mathrm{MSE})=1.92 \mathrm{mB}^{2}$.

Percent Flow Correct $=96.19$.

Volumetric gas phase saturation $=0.25 \quad$ Porosity $=0.4$

$\rightarrow \quad$ Permeability $=0.12$ Darcy's Depth $=30$ meters. 
atm_suba.csv

Number of data points $=2680$.

Effective Permeability factor $(\mathrm{Lz})=0.0539 \mathrm{~m}^{2} / \mathrm{sec}$.

Mean squared error (MSE) $=2.16 \mathrm{mB}^{2}$.

Percent Flow Correct $=90.00 \%$.

Volumetric gas phase saturation $=0.25 \quad$ Porosity $=0.4$

Permeability $=1.0$ Darcy's Depth $=30$ meters.

\section{$\underline{\text { Reference }}$}

1. Carslaw, H. S. and J.C. Jaeger, Conduction of Heat in Solids, 2nd Ed., 1959, Oxford Science Publications, pp 305.

2. Falta, R. W., Notes and communications, Jan. - Sept. 1994. 


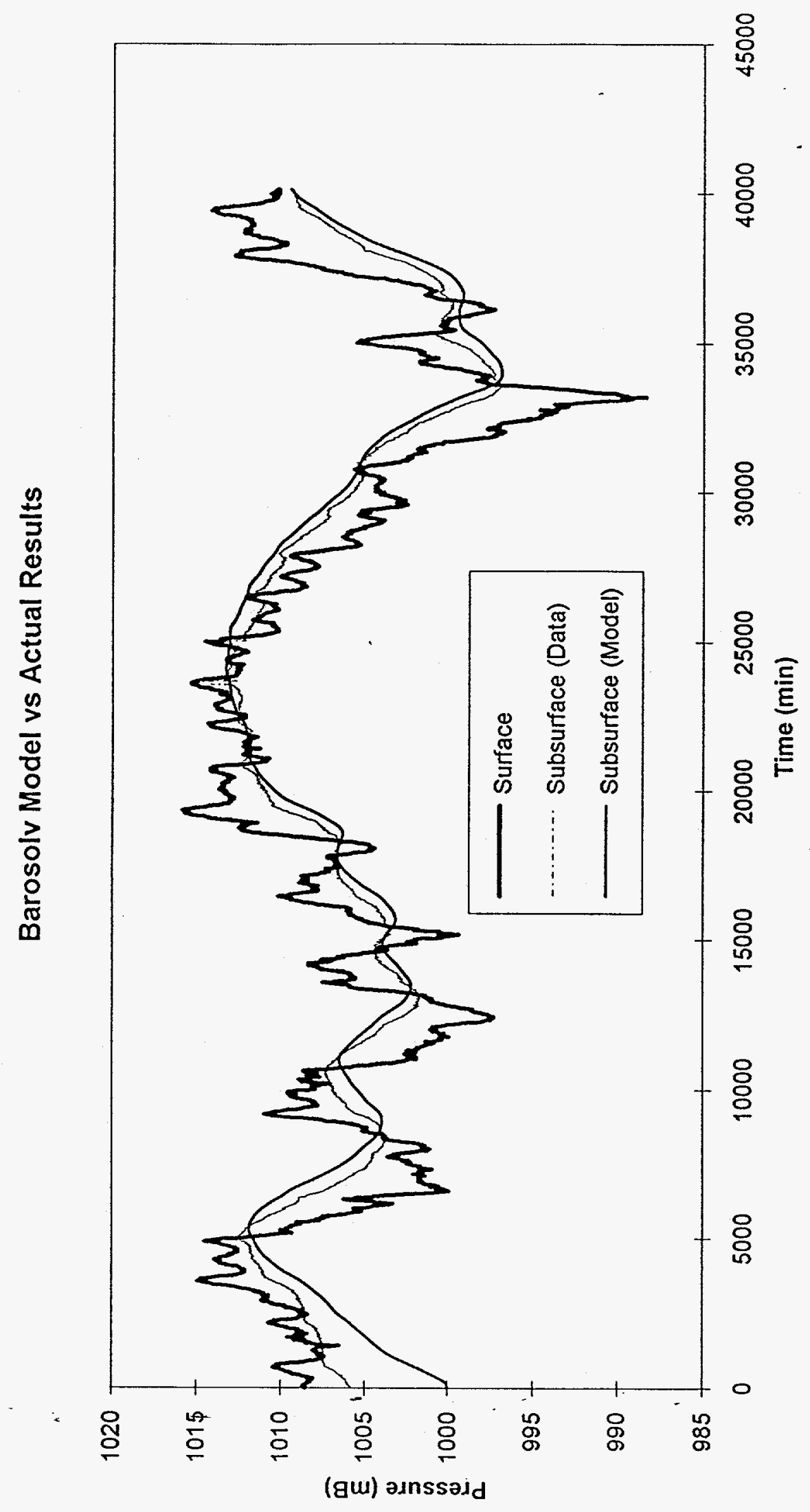




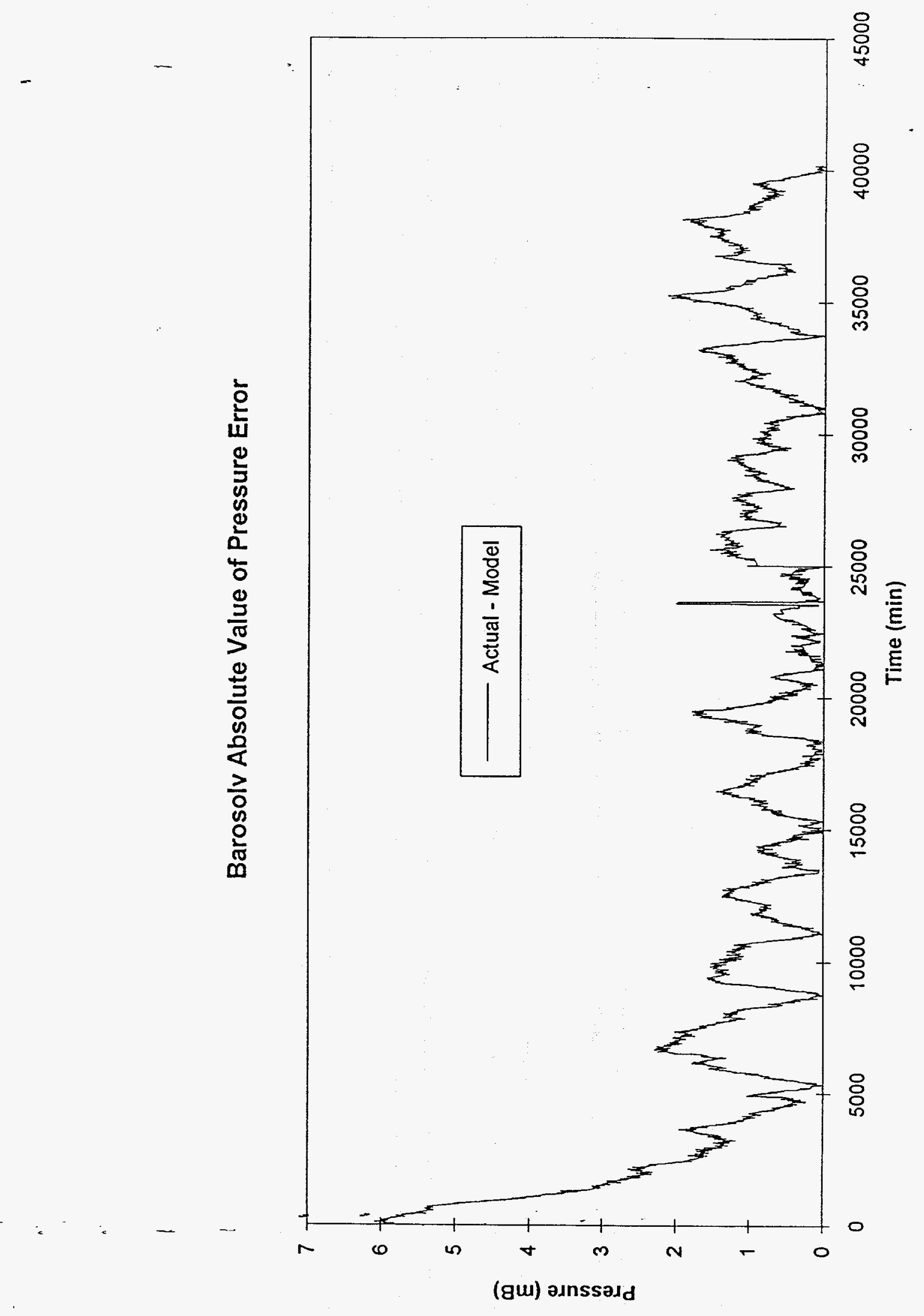


Barosolv performance vs Historical Data Points

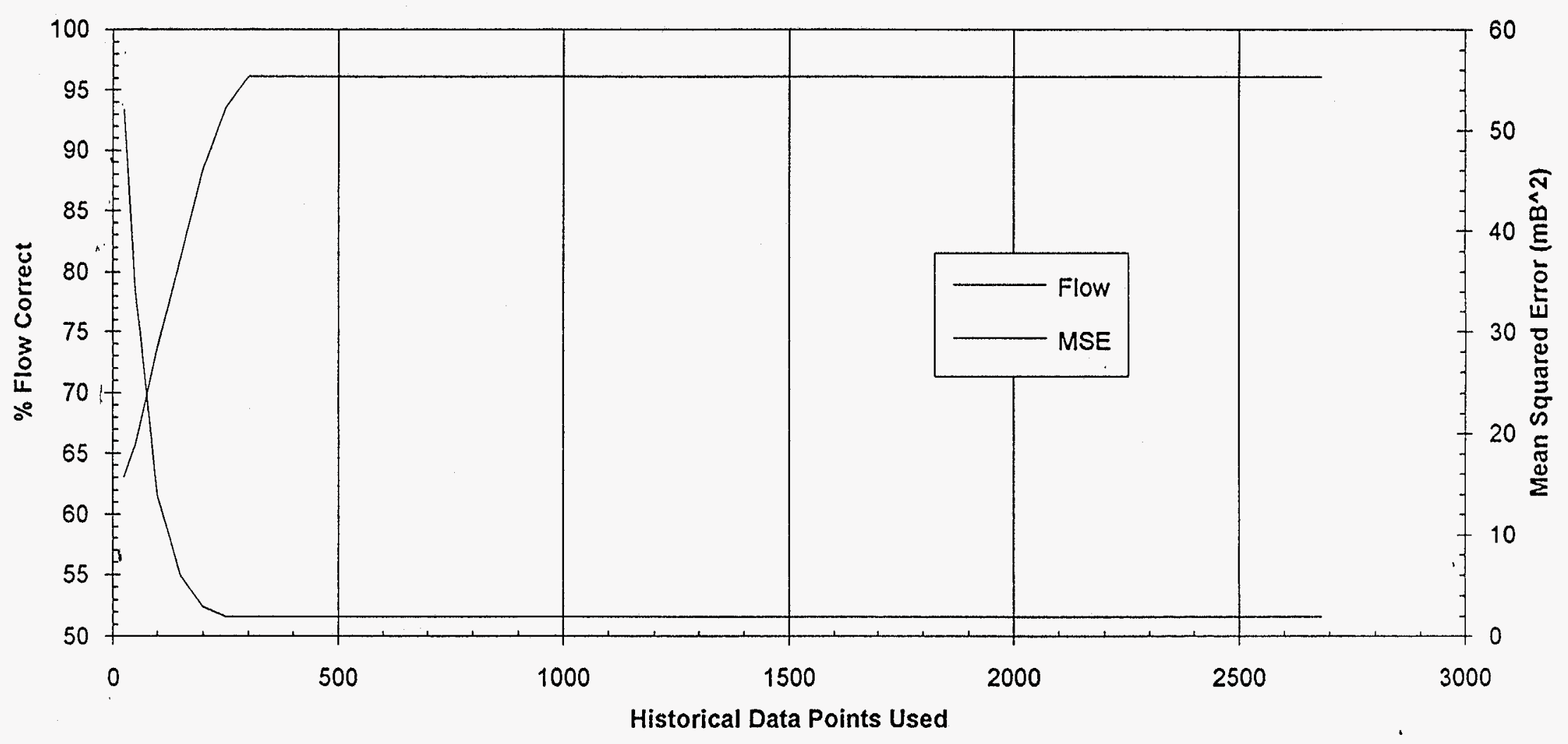

Figure 3 
Atm_suba Model vs Actual Results

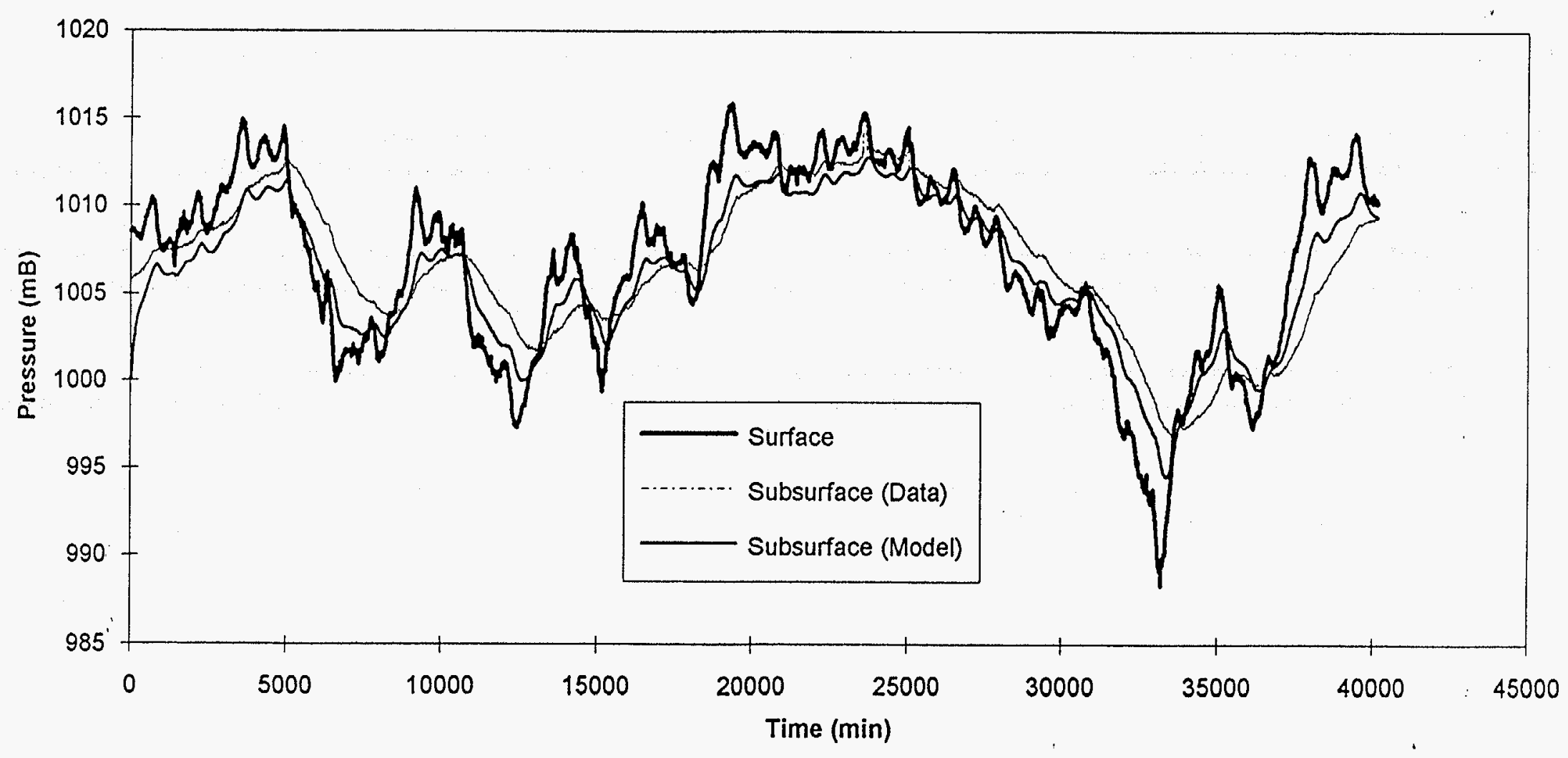

Figure 4 
Atm_suba Performance vs Historical Data Points

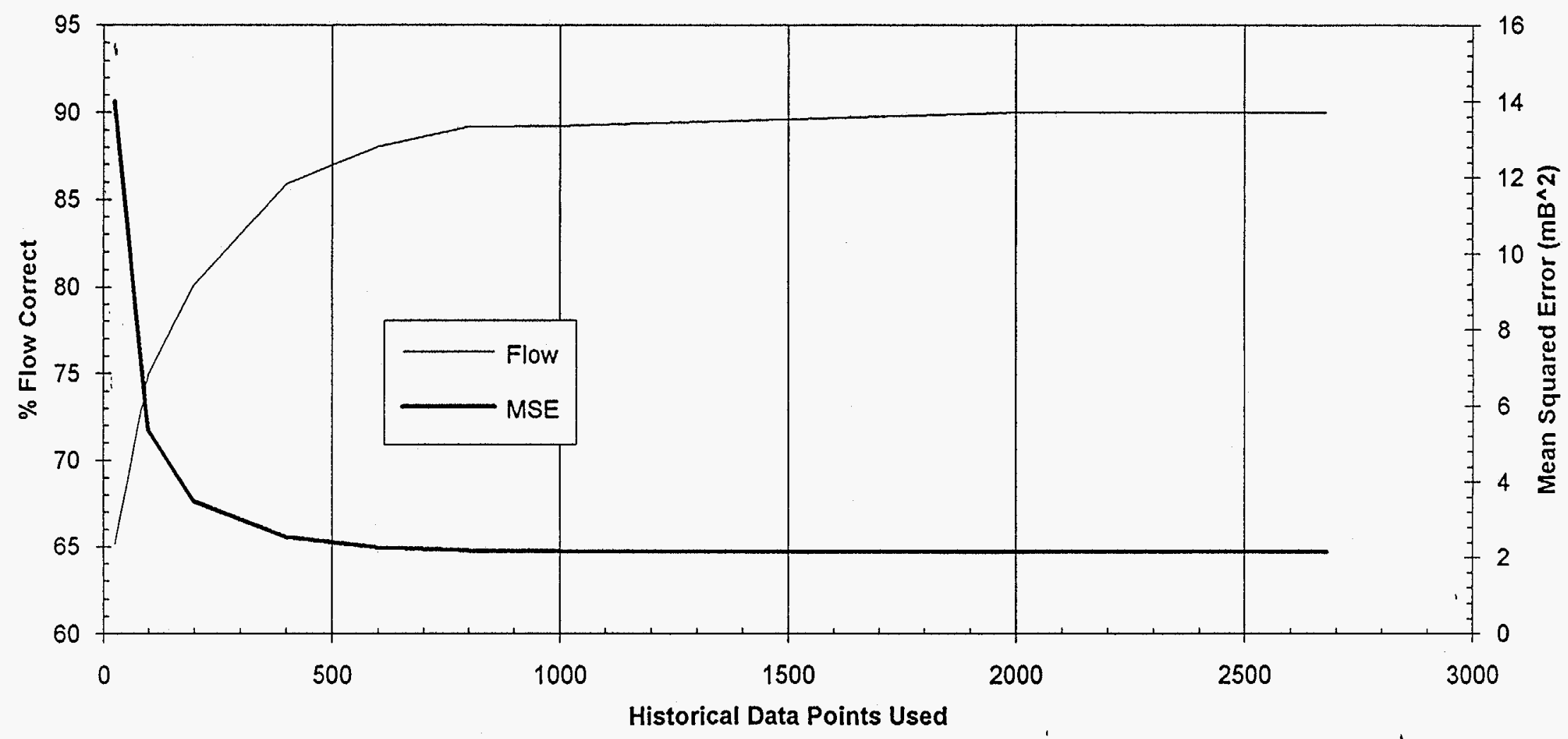




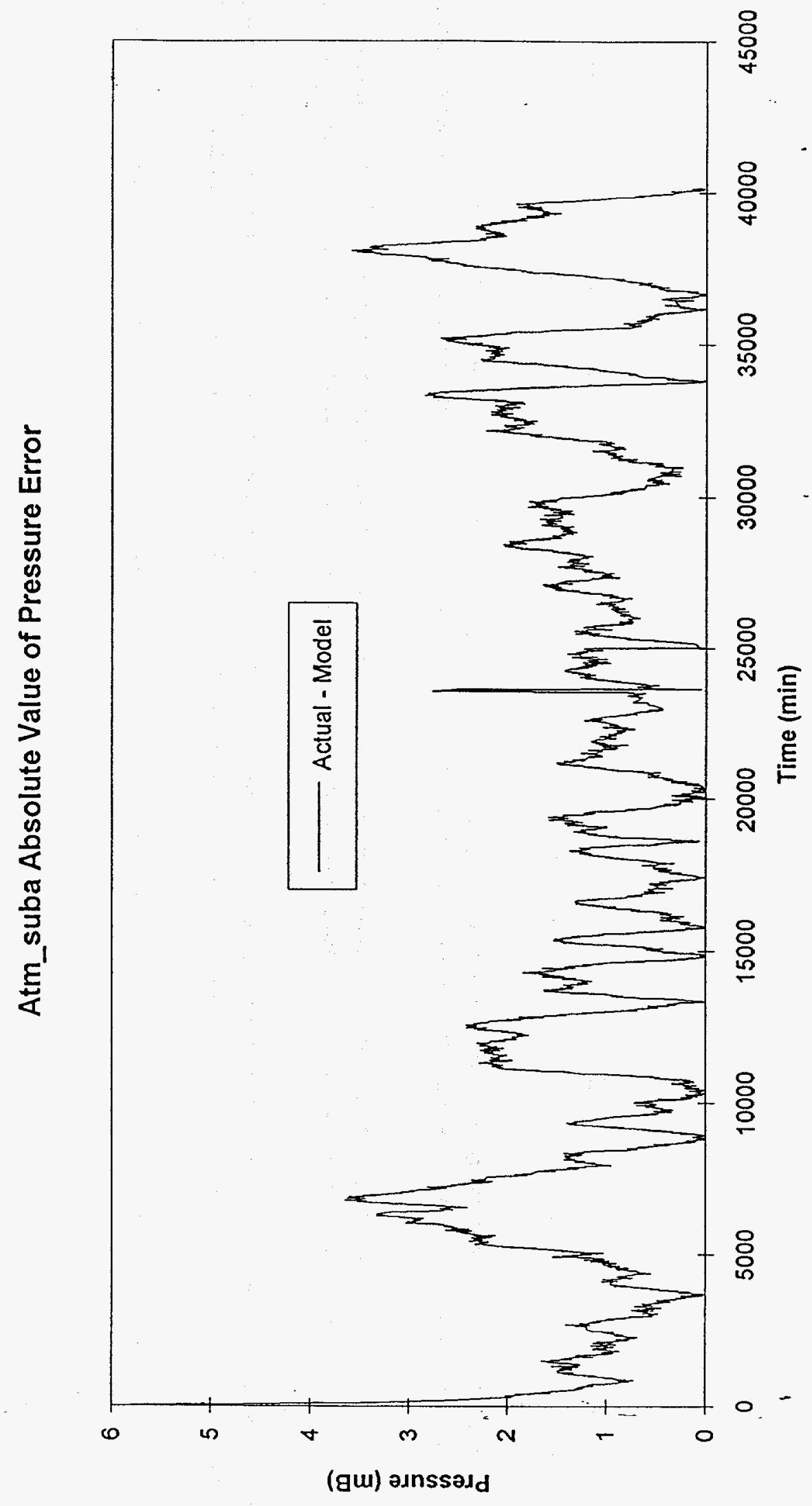


Optimum Permeability Using Barosolv

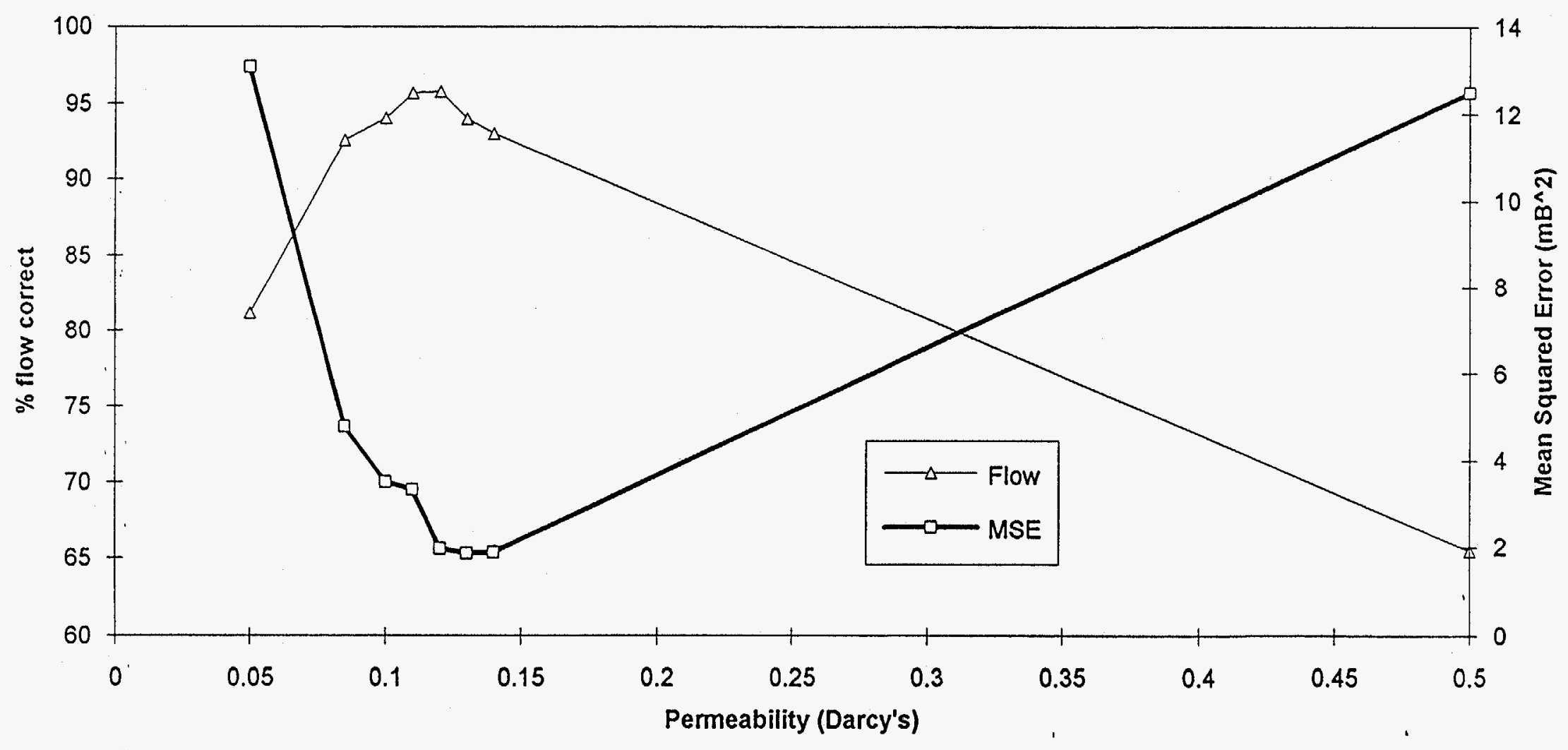

Figure 7 


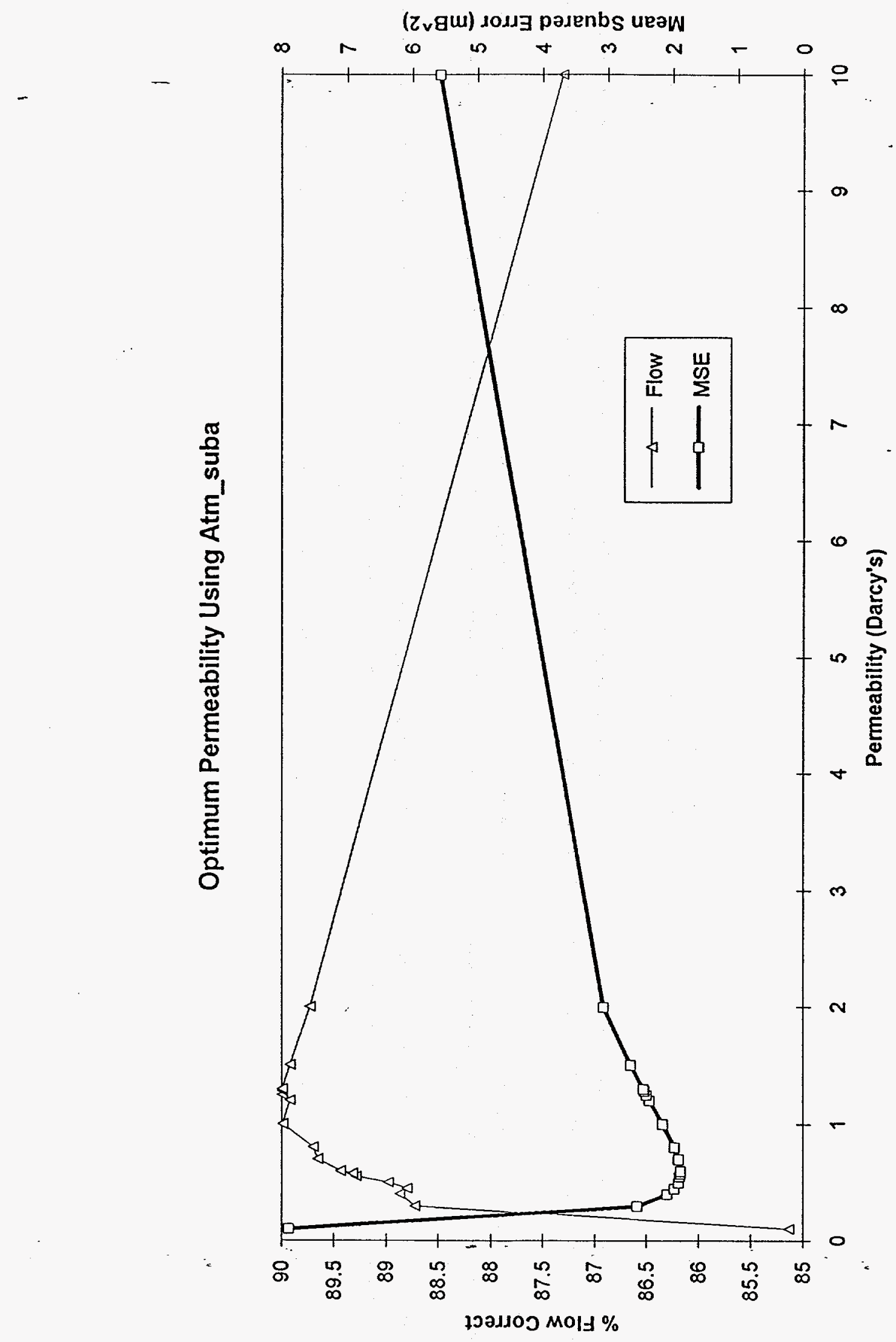

品 
TABLE 1

FALTASEN.XLS

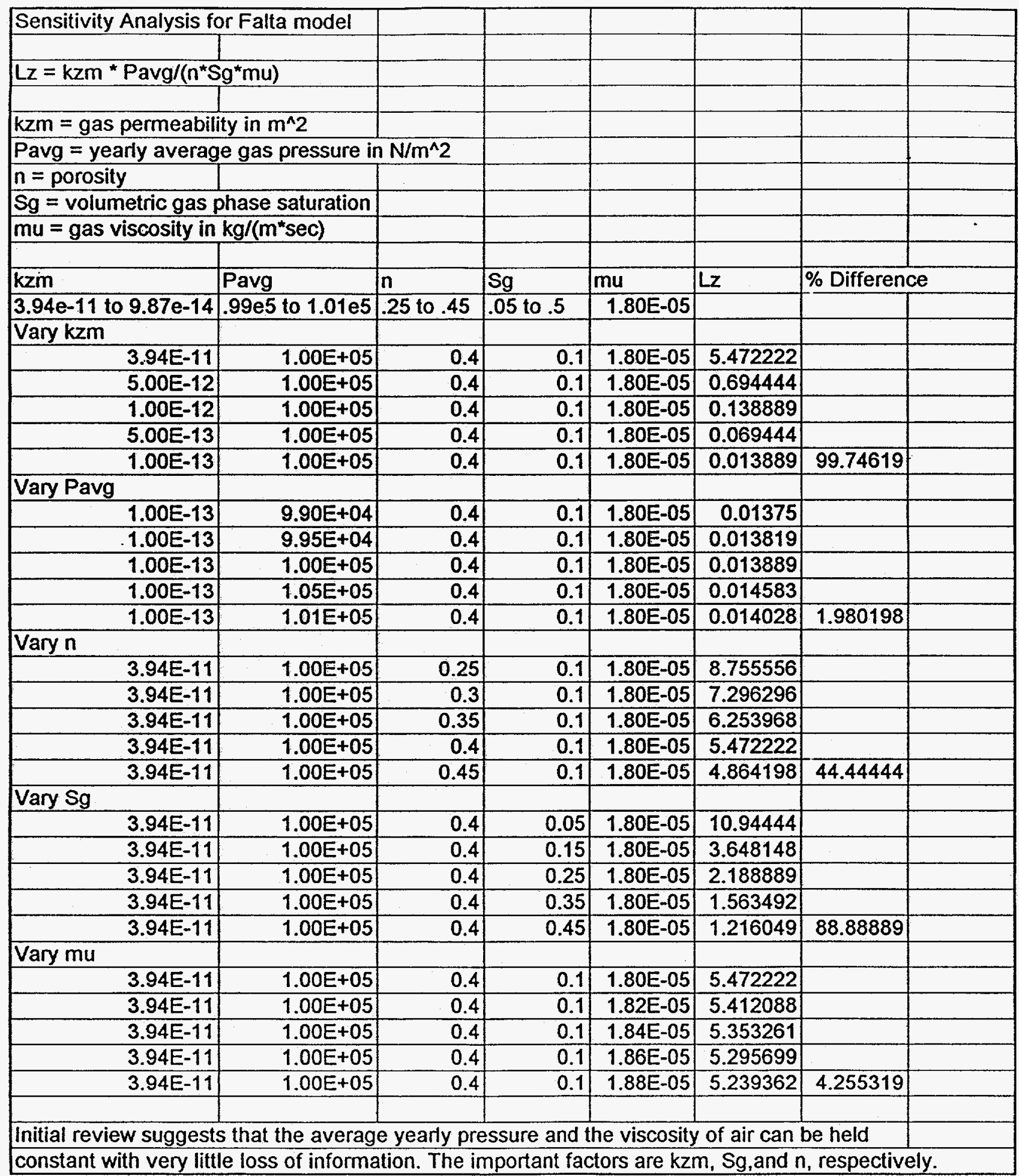


APPENDIX I

Barometric Pumping
cure Model

$S R 141002$

int Pressure. Model

$9 / 21 / 94$

From first principles of conservation of mass and energy For a finite volume:

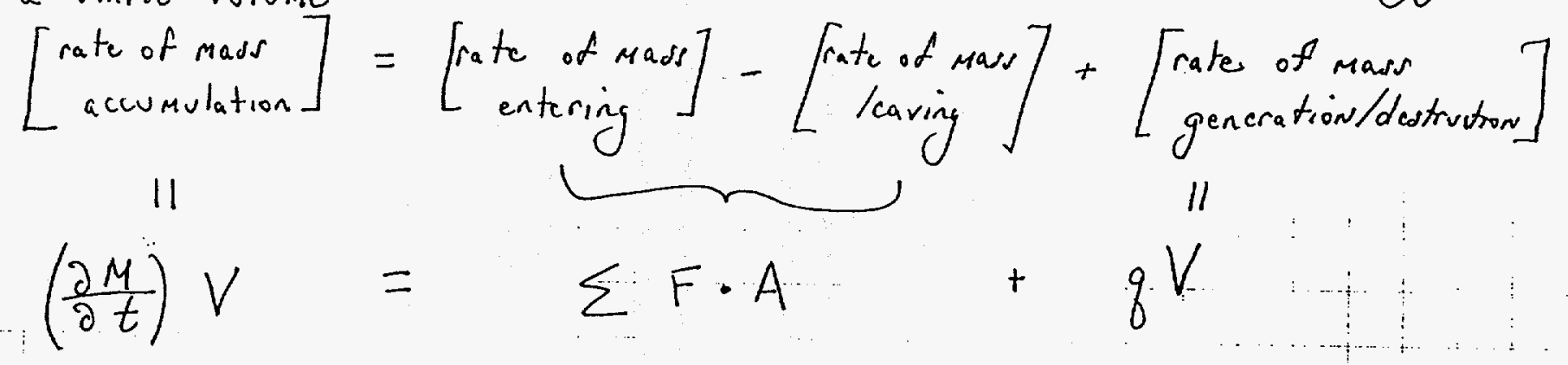

$M=$ amount of mass/unit volume

Divide both sides by volume

$V=$ volume of differential eleventh and use definition of derivative.

$F=$ mass $f / v x$

$$
\frac{\partial M}{\partial t}=\nabla \cdot \vec{F}+q
$$

$A=$ surface area

For gas flow:

$q=\frac{\text { rate of mass generation/dutruction }}{\text { unit volume }}$

$$
\frac{\partial M^{g}}{\partial t}=\nabla \cdot \vec{F} \dot{g}+q^{g}
$$

For subsurface media:

$$
\begin{aligned}
& M^{g}=\text { mass of gas/unit volume }=\varnothing \delta_{g} \rho_{g}=\theta_{g} \rho_{g} \\
& \phi=\text { porosity }(.2-.6) \quad[\text { novaits] } \\
& \delta_{g}=\text { volumetric gas place saturation }(0-.8) \text { [no units] }
\end{aligned}
$$

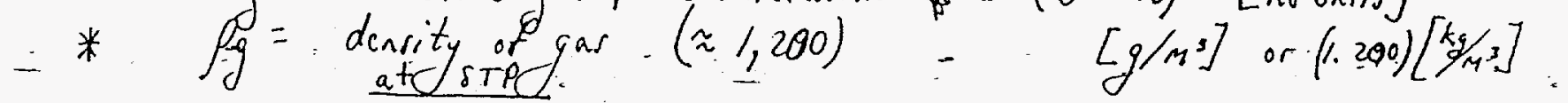

$$
\begin{aligned}
& \theta_{g}=\text { volumetric gar content }(=0-.5) \text { [no units] }
\end{aligned}
$$

To maintain generality: Need to express fo in terms af pressure. (compressibility of gas) 
2

Use the realgar law:

$$
\begin{aligned}
& P V_{m}=Z R T \\
& P=\text { pressure }(\approx 100,000)[P a]=\left[\frac{N}{\mathrm{~m}^{2}}\right]=\left[\frac{\mathrm{kg}}{\mathrm{Ms}^{2}}\right] \\
& V_{m}=\text { molar volume }[\mathrm{m} / \mathrm{mole}] \\
& Z=\text { compressibi\% ty factor [unites] }
\end{aligned}
$$

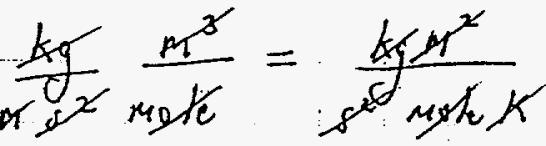

$$
\begin{aligned}
& R=\text { Universal gas constant } \\
& (=8.3 P i) \quad\left[\frac{\mathrm{N}^{2} \mathrm{~m}^{3}}{\mathrm{~m}^{2} \mathrm{~mole} K}\right]=\left[\frac{\mathrm{N} \cdot \mathrm{m}}{\mathrm{MO} / \mathrm{CK}}\right] \\
& =\left[\frac{\mathrm{kg} \mathrm{m}^{2}}{s^{2} \text { mole } K}\right] \\
& \text { since } \rho_{g}=\frac{M_{w t}}{V_{m}}=\mathrm{g} / \mathrm{m}^{3} \\
& T=a_{\text {solute temperature }(\approx 292)}[\mathrm{K}] \\
& \text { wt }=\text { molecv/ar weight }(\approx 28.9) .\left[\% / \mu_{0} / c\right] \\
& V_{M}=\frac{Z R T}{P} \\
& \text { so: } \rho_{g}=\frac{P M_{w t}}{Z R T} \text { where } Z(P, t)
\end{aligned}
$$
Over a small range of $P, T, Z \approx$ constant
and at $\approx$ atmospheric conditions,

$z \approx 1 \rightarrow$ ideal gas law

we assume $Z=\bar{z}=$ constant.

since $M^{g}=\theta_{g} \rho_{r}=\frac{\theta_{g} M_{w} t}{\bar{z} R T} P$

$$
\begin{aligned}
& {\left[\frac{\partial M^{g}}{\partial t}=\frac{\theta M_{\omega t}}{\bar{E} R T} \frac{\partial P}{\partial t}\right] \quad \text { Mason accumulation term }} \\
& F^{g}=\rho_{g} V \quad V=\text { Darcy velocity }
\end{aligned}
$$

then $-\nabla \cdot \dot{F}^{g}=-\nabla \cdot\left(\rho_{g} V\right)$ - 
3

Darcy's Law

$$
\begin{aligned}
& V=\frac{-\tilde{k}_{g}}{\mu}(\nabla P+\rho g \nabla z) \\
& k_{g}=k_{g} \cdot k
\end{aligned}
$$

$\tilde{k g}=$ gas permeability. tensor
$\left[\mathrm{m}^{2}\right]$

$\mu=g$ as viscosity

$$
(\approx: 1.81)
$$

[Kermis]

$k=$ intrinsic permeability of

Assume that the elevation head

* $(g g \nabla z) \rightarrow 0$ in comparison with media pressure head.

$$
\begin{aligned}
\therefore \quad V & =\frac{-\tilde{k}_{g}}{\mu} \nabla P \\
-\nabla \cdot F d & =\nabla \cdot\left\{\left(\frac{k_{g}}{\mu} \frac{P \mu_{\omega t}}{\bar{z} R T}\right)(\nabla P)\right\} \\
& =\frac{\mu_{w t}}{\mu \bar{z} R T} \nabla \cdot\left(\tilde{k_{g}} P \nabla P\right)
\end{aligned}
$$

Assume $n 0$ sources and sinks and the PDf is

$$
\begin{aligned}
& \frac{\partial M^{g}}{\partial t}=\nabla \cdot \overrightarrow{F^{g}} \\
& \Rightarrow\left[g_{g} \mu \frac{\partial P}{\partial t}=\nabla \cdot-\left(\tilde{k_{g}} P \nabla P\right)\right]
\end{aligned}
$$

Nonlinear because of $P \nabla P$ 


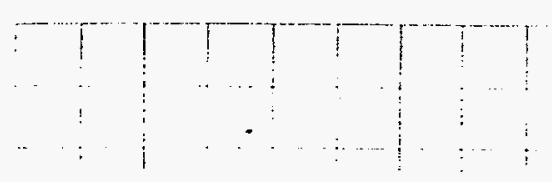

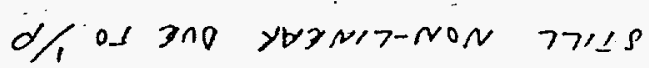

$$
\begin{aligned}
& {\left[\left({ }_{2} d \Delta^{b_{y}}\right) \cdot \Delta=\frac{7 b}{d e} \frac{d}{d b}\right]} \\
& \text { swose } 30 d \\
& \left.{ }_{2}\right) \frac{8 e}{e} \frac{d z}{1}=\frac{7 e}{d e} \quad \because \\
& 7 \frac{e}{d e} d z={ }_{2} d / e
\end{aligned}
$$

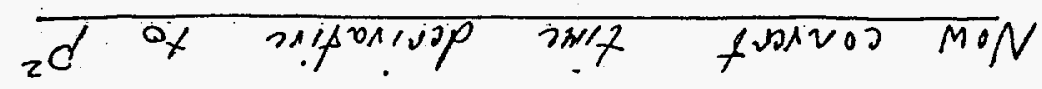

$$
\begin{aligned}
& \text { zd } 9 \text { \%'m soou!l } \\
& \left(d \Delta^{b_{y}}\right) \cdot \Delta 2 / 1=\left(d \Delta d^{b_{y}}\right) \cdot \Delta \\
& \text { snoisvorip }=\varepsilon \text { of bipuapy }
\end{aligned}
$$$$
(z e / d e d) z e / e=(z d) \frac{z z e}{2} z / 1 \text { os }
$$$$
\begin{aligned}
(z e d) z e / e z= & (z e / j e d z) z e / e=\left({ }_{2} d\right) \frac{z^{z e}}{z^{e}} \\
& (z / d e d) z e e^{z} y=\left(d \Delta d b_{y}\right) \cdot \Delta
\end{aligned}
$$

(z) voisvow'p suo v' spovipjoos vorsyers vi !' 30d swassy

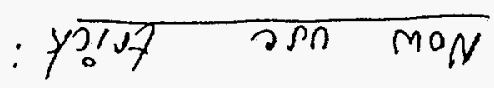

h : 
ANOTHER TRICK:

over a small range of $P( \pm 50 \%)$, can replace $\frac{1}{p}$ with $1 / \bar{p}$ and incur less than $2 \%$ error.

FINAL LINEAR POE

$$
\left[\frac{\theta_{g} \mu}{\bar{P}} \frac{\partial P^{2}}{\partial t}=\nabla \cdot\left(\tilde{k}_{g} \nabla P^{2}\right)\right]
$$

$\bar{p}=$ ambient average prow ore $\left(x, 100,000 \% \frac{\mathrm{kg}}{\mathrm{s} \mathrm{s}^{2}}\right]$

Note: For small variations in $P$, can lancarrze original equation:

$$
\theta_{g} \mu \frac{\partial P}{\partial t}=\nabla \cdot\left(\tilde{k_{g}} \rho \nabla P\right)
$$

by approximating $\tilde{k g} P$ term with $\tilde{k g} \bar{P}$

$$
\therefore \quad\left[\frac{g \mu}{\bar{P}} \frac{\partial P}{\partial t}=\nabla \cdot\left(\tilde{k_{g}} \nabla P\right)\right]
$$

For $1-d$ vertical flow of incompressible gas in

$$
\left(\frac{\phi \delta_{g} \mu}{\bar{P} k_{z}}\right) \frac{\partial P}{\partial t}=\not \partial \cdot \partial \frac{\partial^{2} P}{\partial z^{2}}
$$


Let $\lambda_{z}=\frac{\bar{P} K_{z}}{\not \delta_{g} \mu}$

so $\quad\left[\begin{array}{ll}\frac{1}{\lambda z} & \partial p / \partial t=\frac{\partial^{2} p}{\partial z^{2}}\end{array}\right]$

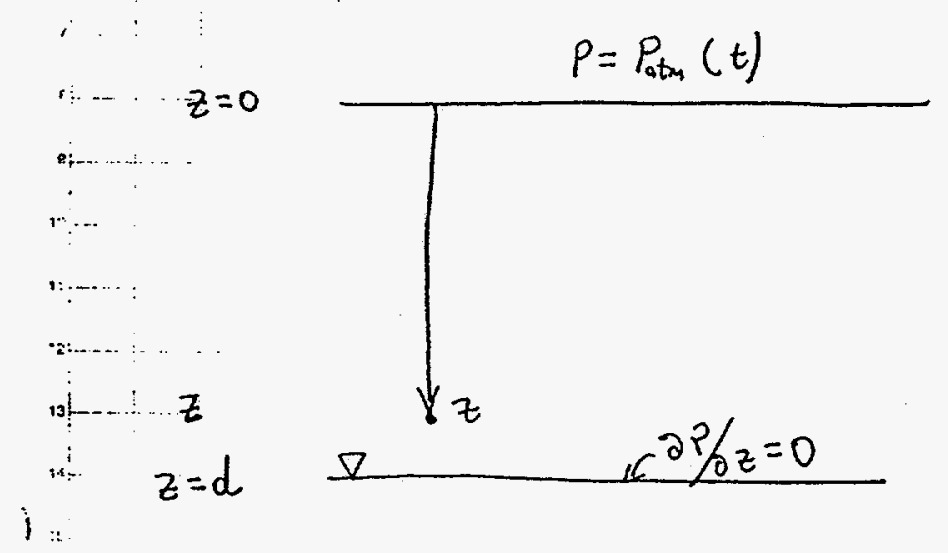

BouNDARY CONBITONS At

$$
Z=0, \quad P=P_{\text {atm }}(t)
$$

$z=d, \frac{\partial P}{\partial z}=0 \quad d=d$ coth to water

Initial condition tab lo. At $t=0, P=\bar{p}$

To get the effect of a 10 -flow boundary at $z=d$, can use superpositioning with

$$
P=P_{\text {attu }}
$$

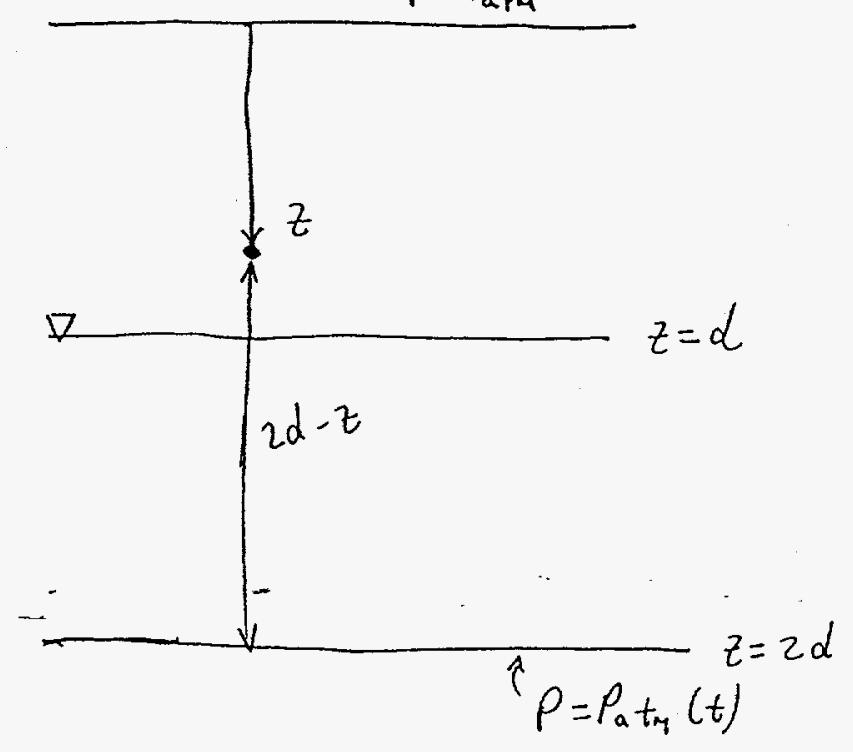




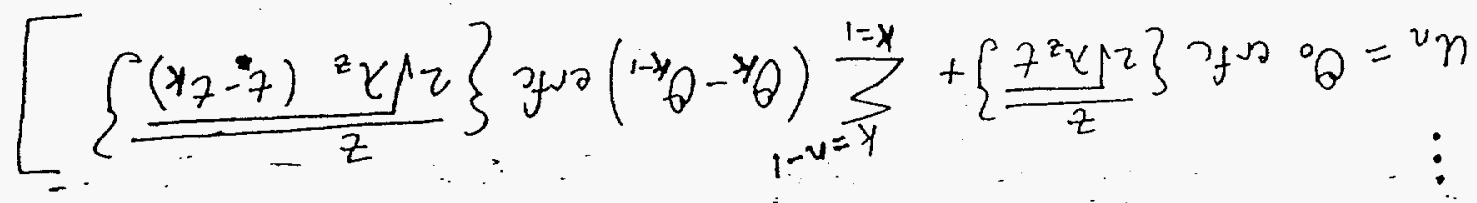

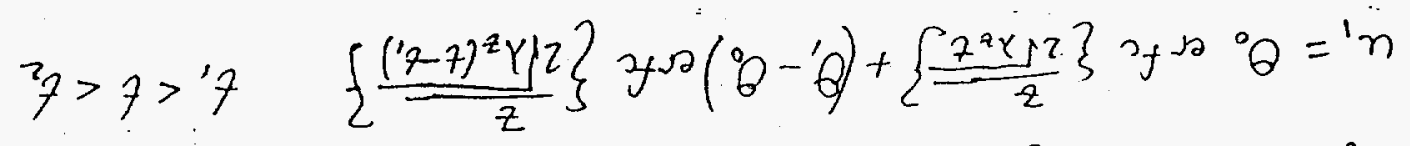

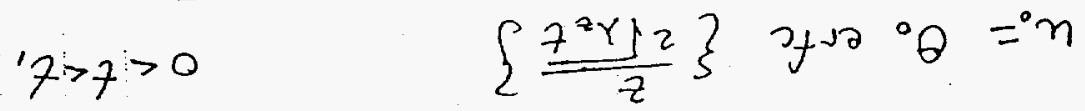

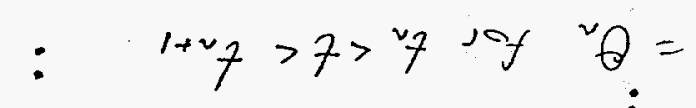

$$
\begin{aligned}
& \varepsilon>7>{ }^{2} z \text { sog }{ }^{2} \dot{\theta}= \\
& { }^{2} 7>7>17 \text { of }{ }^{\prime} \theta= \\
& 7>7>0 \text { if } 0=(7) 8 \text { ue noityos sys }
\end{aligned}
$$

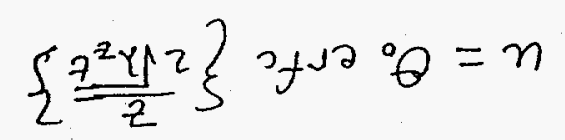

$: 0<7$ rof fouporos $=: 0=(77 \theta$ rof notyos ry 1

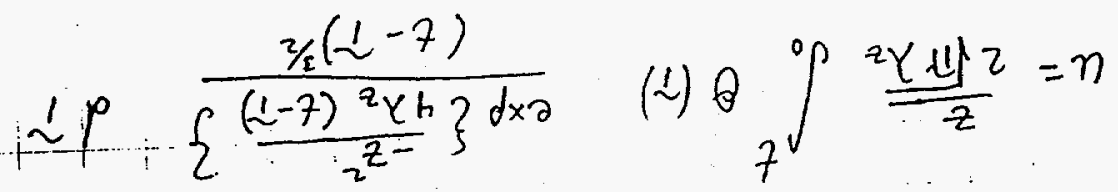

$$
\begin{aligned}
& 0=z \text { to } 1730 \text { hrout 1950 sog }
\end{aligned}
$$

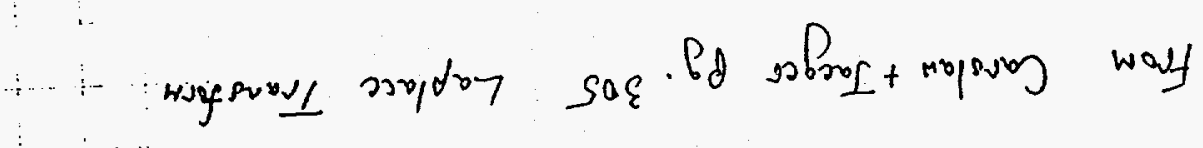

$$
\begin{aligned}
& d-(7) \text { win }=\overline{(7) \theta}=n \prime_{0=z} \\
& 0=n^{\prime} 0=7+\forall \\
& {\left[\frac{z e}{d z e}=\frac{78 / n e}{z e} \frac{z}{1}\right]} \\
& o s^{\prime} \frac{7 e}{d e}=\frac{7 e}{n e} \\
& \underline{d-d}=n \text { tr mon }
\end{aligned}
$$




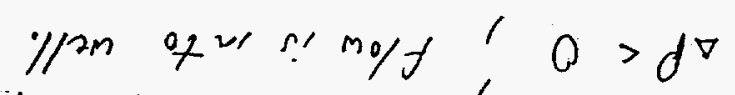

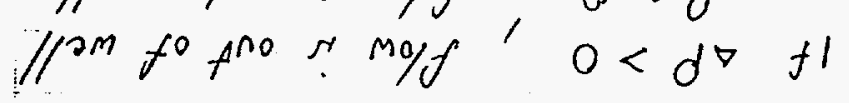

$$
v^{w+y}-v=v^{v}-v^{u}=d \nabla
$$

: v jorste! swet swos

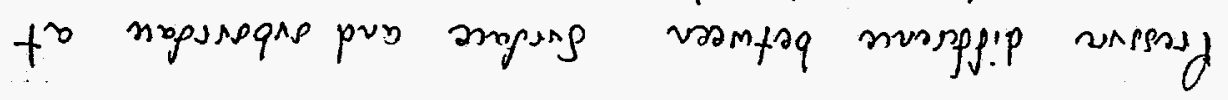

$$
\underline{d}-v^{w} w_{7} y=v_{0} \quad \underline{d}^{-v} d=v^{v}
$$

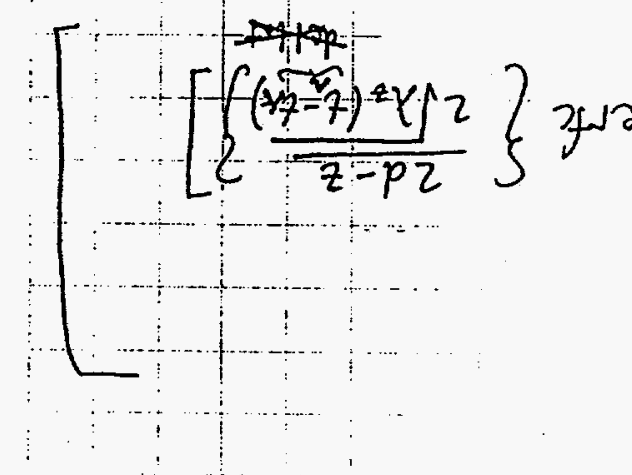

$$
\begin{aligned}
& \left.+\left\{\frac{\left(x z^{2}-7\right)^{z} x \rho z}{z}\right\} j \mu \partial\right]\left(1-x_{0}-x_{0}\right) \sum_{1-v=y}^{1=x}+
\end{aligned}
$$

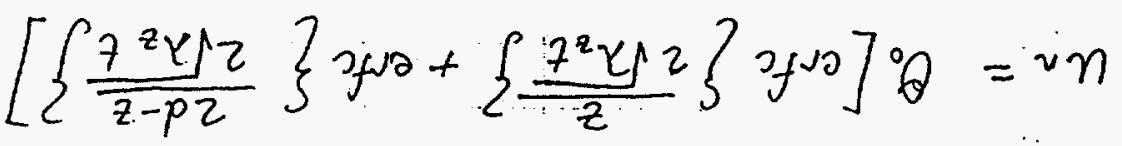

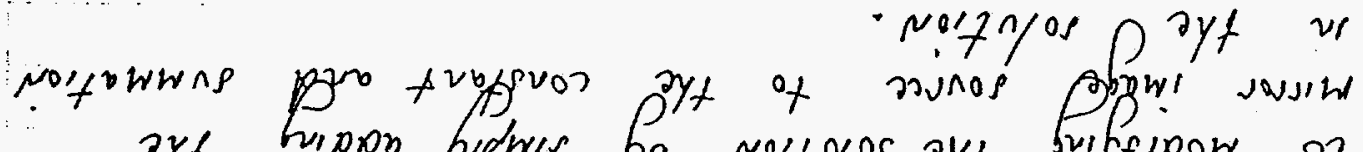
oye hippos hydwes hap roityos ayt buiffipow of

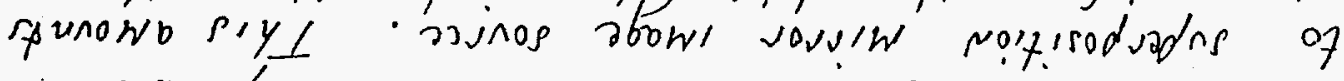

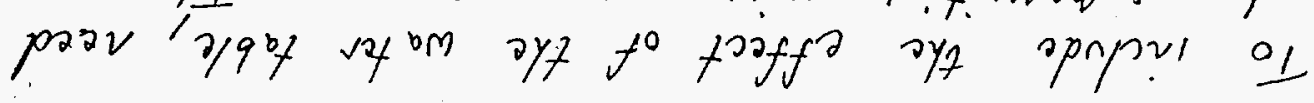

$8 \cdot m \cdots \cdots+1$,

Whitis 


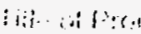

chimed

Programming considerations

UNITS

Generally use sI $(\mathrm{kg}, \mathrm{m}, s, e \mathrm{tc})$

$$
\begin{aligned}
& \text { Presovre }=P_{a}=\frac{k g}{m s^{2}} \quad \text { Notch. } \quad 100,000 \mathrm{~Pa}=1000 \mathrm{mBar} \\
& \text { Distance }=\text { meters }(z) \\
& \text { So multiply mar } x 100 \text { to get units right. } \\
& \text { time }=\operatorname{seconds}(t) \\
& \text { Permeability }=\operatorname{meter}^{2}\left(k_{z}\right) \Rightarrow \stackrel{\text { gravel }}{1 \times 10^{-9} \rightarrow 1 \times 10^{-16}} \\
& \text { Porosity }=\text { unites }(\phi) \Rightarrow 0.2-0.6 \\
& \text { ) } \\
& \text { Gas phase saturation }=\text { unites }(s g) \Rightarrow 0 \rightarrow 0.8 \\
& \text { - viscosity }=\mathrm{kg} / \mathrm{m}(\mu)=1.81 \times 10^{-5}
\end{aligned}
$$

From sensitivity analyse, $\bar{p}$ and $\mu$ are much less important $d$ than $k_{z}$, $\delta_{g}$, and $n$.

So an average value for $\lambda_{z}=\frac{\bar{P} k_{z}}{\bar{\phi} s g \mu}$

$$
=\frac{100,000}{1.81 \times 10^{-5}} \frac{1 \times 10^{-11}}{(.4)(.5)}=\left(5.525 \times 10^{9}\right)\left(5 \times 10^{-11}\right)=0.276
$$




\begin{tabular}{|c|c|c|c|c|c|c|c|}
\hline \multicolumn{7}{|c|}{ Sensitivity Analysis for Falta model } & \\
\hline & & & & & & & \\
\hline \multicolumn{8}{|c|}{$\mathrm{Lz}=\mathrm{kzm}{ }^{*}$ Pavg/(n*Sg*mu)} \\
\hline & & & & & & & \\
\hline \multicolumn{8}{|c|}{$\mathrm{kzm}=$ gas permeability in $\mathrm{m}^{\wedge} 2$} \\
\hline \multicolumn{8}{|c|}{ Pavg $=$ yearly average gas pressure in $N / m^{\wedge} 2$} \\
\hline \multicolumn{8}{|l|}{$n=$ porosity } \\
\hline \multicolumn{8}{|c|}{$\mathrm{Sg}=$ volumetric gas phase saturation } \\
\hline \multicolumn{8}{|c|}{$\mathrm{mu}=$ gas viscosity in $\mathrm{kg} /\left(\mathrm{m}^{*} \mathrm{sec}\right)$} \\
\hline & & & & & & & \\
\hline $\mathrm{kzm}$ & Pavg & $n$ & $\mathrm{Sg}$ & $\mathrm{mu}$ & Lz & \multicolumn{2}{|c|}{$\%$ Difference } \\
\hline $3.94 \mathrm{e}-11$ to $9.87 \mathrm{e}-14$ & $.99 \mathrm{e} 5$ to $1.01 \mathrm{e} 5$ & .25 to .45 & .05 to .5 & $1.80 E-05$ & & & \\
\hline \multicolumn{8}{|l|}{ Vary kzm } \\
\hline $3.94 \mathrm{E}-11$ & $1.00 E+05$ & 0.4 & 0.1 & $1.80 \mathrm{E}-05$ & 5.472222 & & \\
\hline $5.00 \mathrm{E}-12$ & $1.00 E+05$ & 0.4 & 0.1 & $1.80 \mathrm{E}-05$ & 0.694444 & & \\
\hline $1.00 \mathrm{E}-12$ & $1.00 E+05$ & 0.4 & 0.1 & 1.80E-05 & 0.138889 & & \\
\hline $5.00 \mathrm{E}-13$ & $1.00 E+05$ & 0.4 & 0.1 & 1.80E-05 & 0.069444 & & \\
\hline $1.00 E-13$ & $1.00 \mathrm{E}+05$ & 0.4 & 0.1 & $1.80 \mathrm{E}-05$ & 0.013889 & 99.74619 & $\because$ \\
\hline \multicolumn{8}{|l|}{ Vary Pavg } \\
\hline $1.00 \mathrm{E}-13$ & $9.90 E+04$ & 0.4 & 0.1 & $1.80 \mathrm{E}-05$ & 0.01375 & & \\
\hline $1.00 \mathrm{E}-13$ & $9.95 E+04$ & 0.4 & 0.1 & $1.80 \mathrm{E}-05$ & 0.013819 & & \\
\hline $1.00 \mathrm{E}-13$ & $1.00 E+05$ & 0.4 & 0.1 & $1.80 \mathrm{E}-05$ & 0.013889 & & \\
\hline $1.00 \mathrm{E}-13$ & $1.05 E+05$ & 0.4 & 0.1 & $1.80 \mathrm{E}-05$ & 0.014583 & & \\
\hline $1.00 \mathrm{E}-13$ & $1.01 E+05$ & 0.4 & 0.1 & $1.80 \mathrm{E}-05$ & 0.014028 & 1.980198 & \\
\hline \multicolumn{8}{|l|}{ Vary $n$} \\
\hline $3.94 E-11$ & $1.00 E+05$ & 0.25 & 0.1 & 1.80E-05 & 8.755556 & & \\
\hline $3.94 \mathrm{E}-11$ & $1.00 E+05$ & 0.3 & 0.1 & $1.80 \mathrm{E}-05$ & 7.296296 & & \\
\hline $3.94 E-11$ & $1.00 E+05$ & 0.35 & 0.1 & $1.80 \mathrm{E}-05$ & 6.253968 & & \\
\hline $3.94 E-11$ & $1.00 E+05$ & 0.4 & 0.1 & $1.80 \mathrm{E}-05$ & 5.472222 & & \\
\hline $3.94 E-11$ & $1.00 E+05$ & 0.45 & 0.1 & $1.80 \mathrm{E}-05$ & 4.864198 & 44.44444 & \\
\hline \multicolumn{8}{|l|}{ Vary $\mathrm{Sg}$} \\
\hline $3.94 \mathrm{E}-11$ & $1.00 E+05$ & 0.4 & 0.05 & 1.80 E-05 & 10.94444 & & \\
\hline $3.94 E-11$ & $1.00 E+05$ & 0.4 & 0.15 & $1.80 \mathrm{E}-05$ & 3.648148 & & \\
\hline $3.94 E-11$ & $1.00 \mathrm{E}+05$ & 0.4 & 0.25 & $1.80 \mathrm{E}-05$ & 2.188889 & & \\
\hline $3.94 E-11$ & $1.00 E+05$ & 0.4 & 0.35 & 1.80E-05 & 1.563492 & & \\
\hline $3.94 E-11$ & $1.00 \mathrm{E}+05$ & 0.4 & 0.45 & $1.80 \mathrm{E}-05$ & 1.216049 & 88.88889 & \\
\hline \multicolumn{8}{|l|}{ Vary mu } \\
\hline $3.94 E-11$ & $1.00 E+05$ & 0.4 & 0.1 & $1.80 E-05$ & 5.472222 & & \\
\hline $3.94 E-11$ & $1.00 \mathrm{E}+05$ & 0.4 & 0.1 & $1.82 E-05$ & 5.412088 & & \\
\hline $3.94 \mathrm{E}-11$ & $1.00 E+05$ & 0.4 & 0.1 & $1.84 \mathrm{E}-05$ & 5.353261 & & \\
\hline $3.94 E-11$ & $1.00 E+05$ & 0.4 & 0.1 & $1.86 \mathrm{E}-05$ & 5.295699 & & \\
\hline $3.94 E-11$ & $1.00 E+05$ & 0.4 & 0.1 & $1.88 \mathrm{E}-05$ & 5.239362 & 4.255319 & \\
\hline est & cerag & vearly pre & and & e viscosity & can & be held & \\
\hline
\end{tabular}




\section{APPENDIX C Valved Well Evaluation}

A significant finding during the SRS barometric pumping study was that contaminant removal efficiency using a valved well was greater than that for an open well or non-valved well. The removal efficiency decreased by more than a factor of two when surface air was allowed to flow into the well. The parameters measured during the study included flow using two mass flow meters (one for inflow and one for outflow), barometric pressure, and continuous concentration using the Bruel and Kjaer gas monitor.

Flow, pressure, and concentration profiles from piezometer CPTRAM-16 are shown in Figure C1. The valve was installed on the well to allow contaminanted air to blow out and prevent surface air from blowing in. Outflow (low surface pressure) concentrations using the control valve were fairly constant. However, when the valve was removed and air was allowed to flow into the contaminated formation during high pressure events, the contaminated soil gas near the well screen was diluted and the subsequent contaminant removal rates during outflow decreased. During outflow without the control valve, concentrations began low and increased as the formation was purged of the diluted soil gas. Outflow events never provided enough volume to completeley purge the formation (concentrations never reached the same level as when air was not allowed to flow into the well using the valve).

The average soil gas removal was $5,800 \mathrm{~V}$ day averaged from $3 / 10 / 94$ to $4 / 25 / 94$. The average removal rates with the control valve were $150 \mathrm{~g} /$ day PCE and $32 \mathrm{~g} /$ day TCE. When the control valve was removed and air was allowed to flow back into the formation, removal rates decreased by a factor of 2 to $78 \mathrm{~g} /$ day PCE and $18 \mathrm{~g} /$ day TCE. The average surface air inflow was 4,250 1/day averaged from 3/25/94 to 4/25/94. Removal rates were calculated by integrating the flow profile to determine the total outflow volume during each event. Average concentrations with the control valve were 3,760 ppmv PCE and 1,040 ppmv TCE and the removal rates with the control valve were calculated based on all outflow events during the testing period. The concentration profiles during the period without the control valve were fitted with a second degree polynomial with the independent variable equal to time. The mass removed was then calculated by integrating the flow and fitted concentration equations over 10 minute intervals. The total mass removed was divided by the time period when the valve was not installed on the well.

In additon to using the Baro-Ball control valve for passive vapor extraction, barometric pumping controlled with the Baro-Ball valve has several promising environmental applications including characterization and monitoring, bioventing and nutrient injection, and plume control. The Baro-Ball valve has been successfully used at SRS to purge vadose zone wells prior to soil gas sampling which provides a more accurate representation of the soil gas in the formation and saves considereble time and costs associated with purging the well with a pump. The natural flow from barometric pumping has also been used to fill soil gas sampling bags. The Baro-Ball valve can be inverted to only allow flow into the well which can be used for nutrient and oxygen (surface air) injection to stimulate bioremediation in the vadose zone. A network of peizometers with control valves allowing inflow or outflow can be used to control the migration of vapor plumes in the vadose zone. 


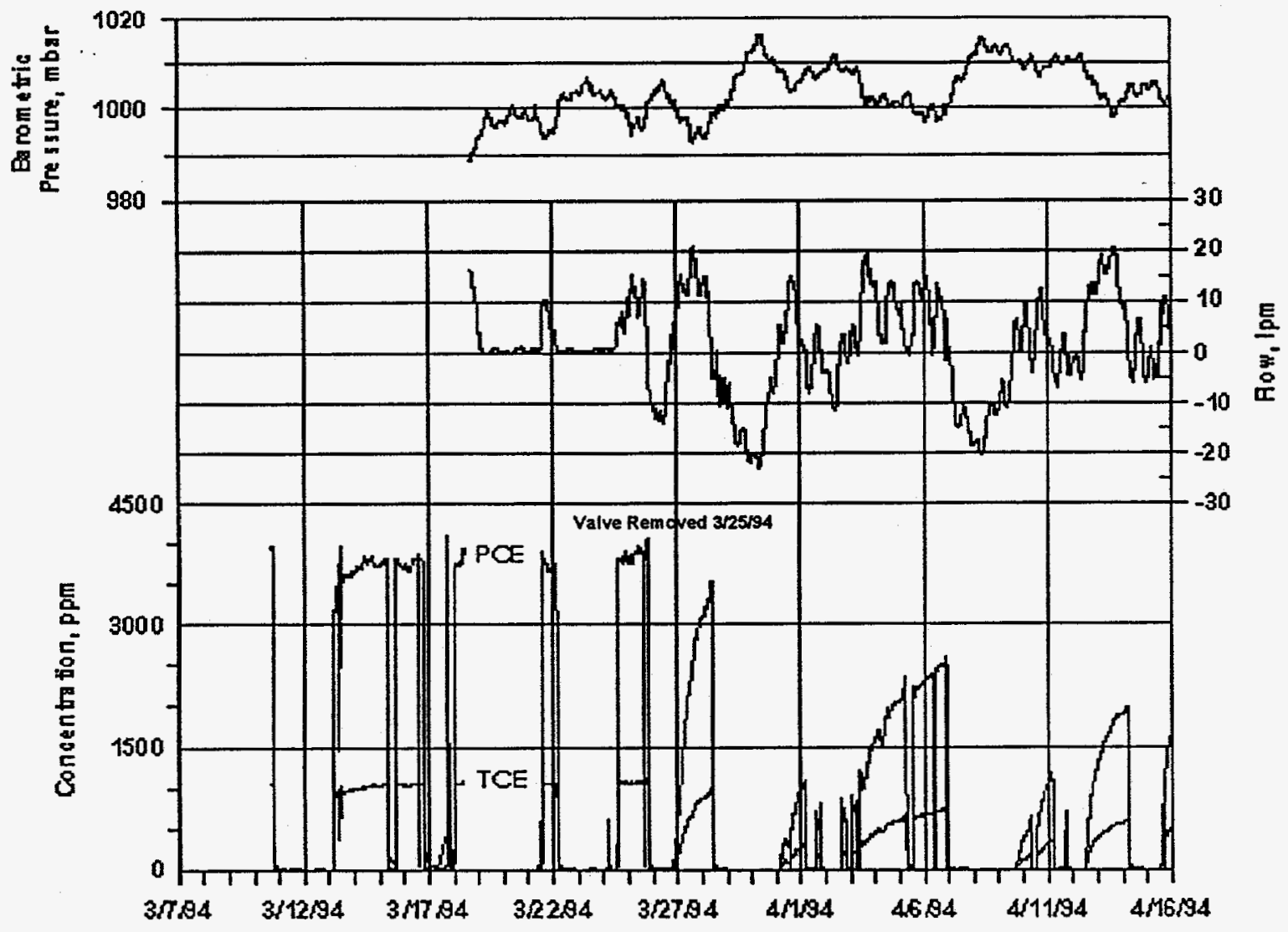

Figure $\mathrm{Cl}$ - CPTRAM concentration, pressure, and flow measurement with and without the Baro-Ball control valve. 